Structured

Management,

symptoms,yealth-

related Quality of Life

and Alcohol in

Patients with Atrial

Fibrillation

\title{
Neshro Barmano
}




\title{
Structured Management, Symptoms, Health-related Quality of Life and Alcohol in Patients with Atrial Fibrillation
}

\author{
Neshro Barmano
}

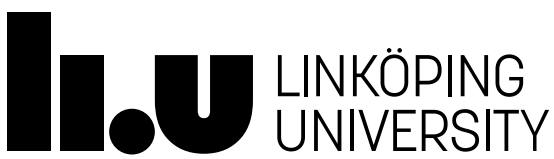

Department of Medical and Health Sciences Linköping University, Sweden Linköping 2019 
(C) Neshro Barmano, 2019

Cover/picture/Illustration/Design: A photo (taken by Neshro Barmano) of Tibelio Barmano's hands.

Published material has been reprinted with the permission of the copyright holder.

Printed in Sweden by LiU-Tryck, Linköping, Sweden, 2019

ISBN 978-91-7685-102-9

ISSN 0345-0082 
Till Alena, Tibelio, Leonora och Ilona

We know accurately only when we know little, with knowledge doubt increases.

(Johann Wolfgang von Goethe, 1749-1832) 


\section{CONTENTS}

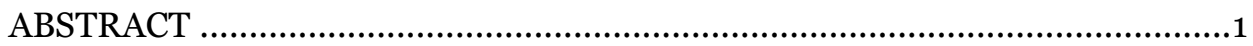

SVENSK POPULÄRVETENSKAPLIG SAMMANFATTNING............................. 3

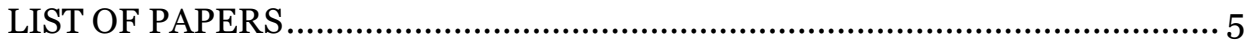

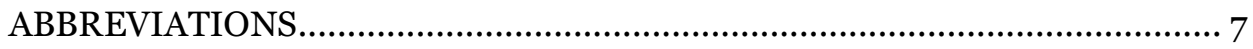

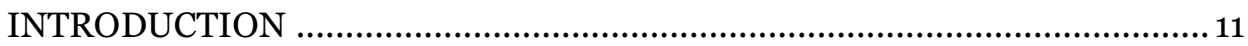

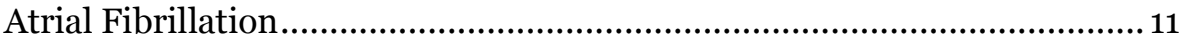

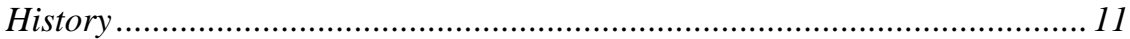

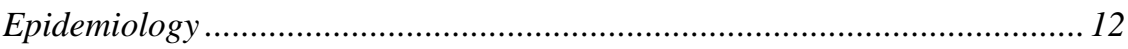

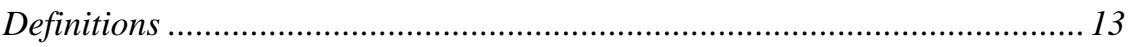

Pathophysiology............................................................................... 13

Clinical Presentation and Screening for Atrial Fibrillation........................... 14

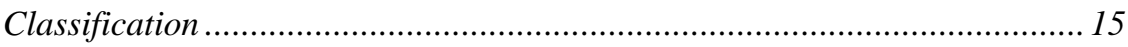

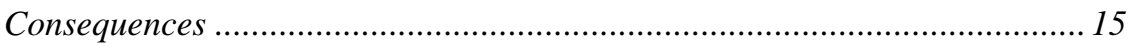

Management ….................................................................................... 15

Adherence to Guidelines …………………………............................... 19

Structured Care of Atrial Fibrillation.......................................................... 19

Symptoms and Health-related Quality of Life ...........................................20

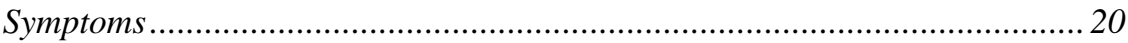

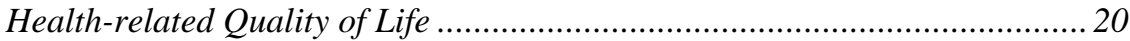

Symptoms and Health-related Quality of Life in Atrial Fibrillation ................ 21

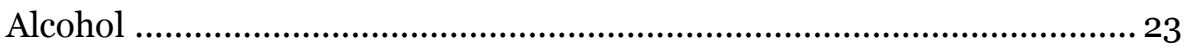

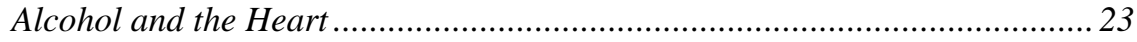

Alcohol Intake Recommendations............................................................ 24

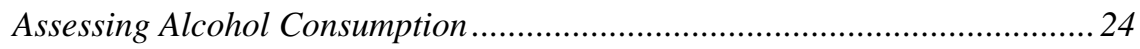

Ethyl Glucuronide in Hair....................................................................... 27

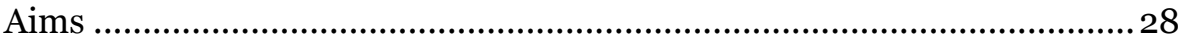


METHODS......................................................................................... 29

Ethical Considerations and Informed Consent........................................... 29

The SMaC-PAF Study - Paper I ............................................................... 29

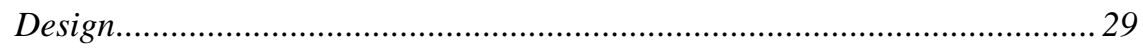

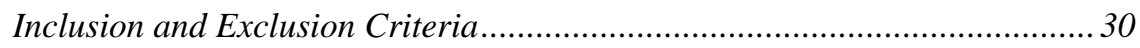

Structured Care of Patients with Atrial Fibrillation ...................................... 30

Patient-reported Outcome Measure Questionnaires......................................... 31

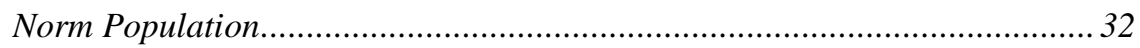

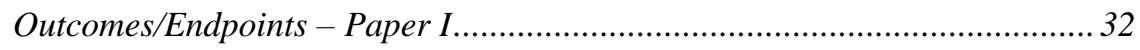

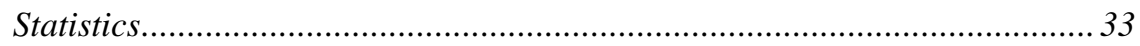

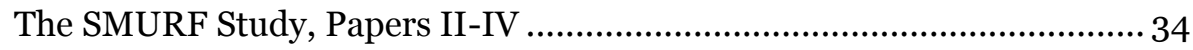

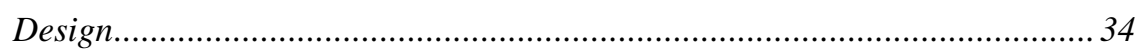

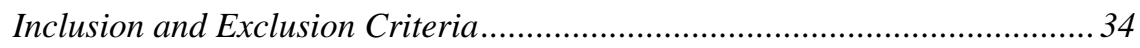

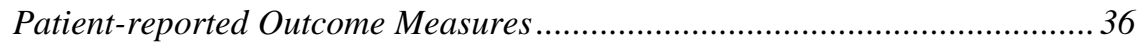

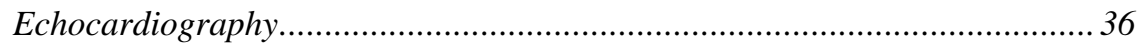

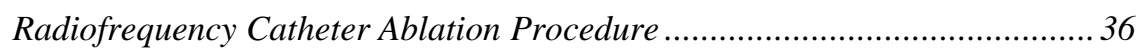

Cardiac Biomarkers and Other Blood Tests ................................................... 36

Pressure Measurements .......................................................................... 37

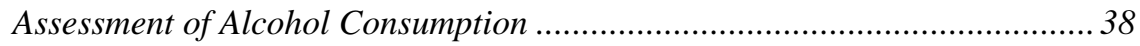

Recurrence of Atrial Fibrillation and Re-ablation.......................................... 38

Outcomes/Endpoints ……………........................................................... 38

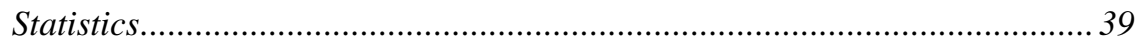

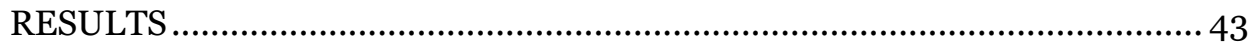

The SMaC-PAF Study - Paper I ............................................................... 43

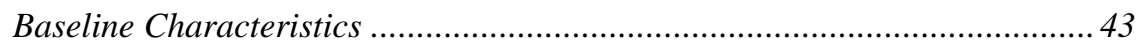

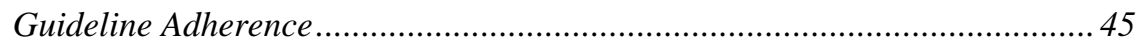

Patient-reported Outcome Measures ............................................................. 46

The SMURF Study - Papers II-IV ............................................................51

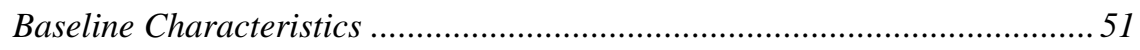

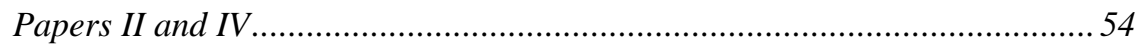

The Predictors of Arrhythmia-related Symptoms and Health-related

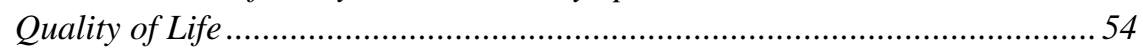


The Effect of Radiofrequency Catheter Ablation on Patient-reported Outcome Measures.

Paper III and the Association of Alcohol Consumption with Symptoms and Health-related Quality of Life ............................................................63

Alcohol Consumption ......................................................................... 63

Associations between Alcohol Consumption, Cardiac Biomarkers, Left Atrial Size, Re-ablation, Symptoms and Health-related Quality of Life.......... 63

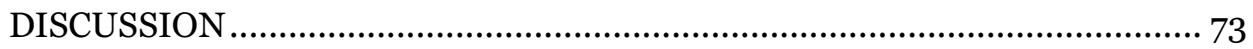

The SMaC-PAF Study - Paper I .................................................... 73

The Effect of Structured Management of Patients with Atrial Fibrillation on Guideline Adherence. 73

The Effect of Structured Management of Patients with Atrial Fibrillation on Patient-reported Outcome Measures ...................................................... 74

The SMURF study - Papers II-IV ................................................ 74

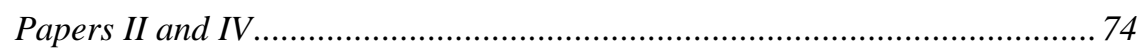

The Predictors of Symptoms and Health-related Quality of Life .................... 74

The Effect of Radiofrequency Catheter Ablation on Patient-reported Outcome Measures.

Paper III and the Association of Alcohol Consumption with Symptoms and Health-related Quality of Life.....

Associations between Alcohol Consumption, Cardiac Biomarkers, Left Atrial Size, Re-ablation, Symptoms and Health-related Quality of Life. 77

Methodological Considerations and Limitations................................. 79

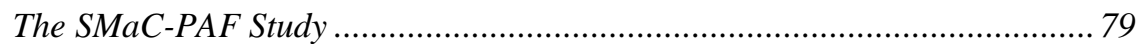

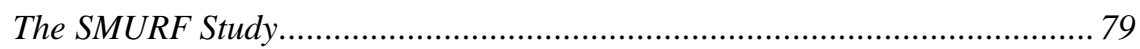

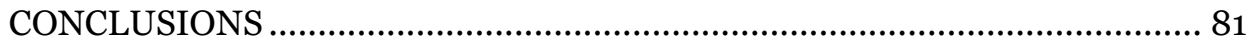

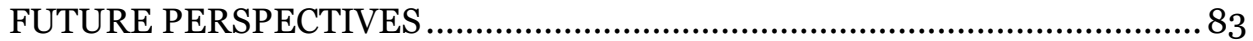

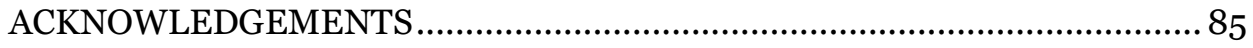

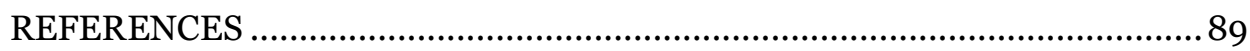




\section{ABSTRACT}

Atrial fibrillation (AF) is the most common cardiac arrhythmia, affecting at least $2.9 \%$ of the Swedish population. Although AF is associated with increased risk of ischaemic stroke, there have been many reports on the underuse of oral anticoagulants (OAC) and non-adherence to guidelines in other areas as well. AF is also associated with disabling symptoms and decreased health-related quality of life (HRQoL), but some patients are asymptomatic. The reasons for the great variation of symptoms remain unclear. Furthermore, although research on AF has increased, studies have mainly focused on treatment, while studies on risk factors, such as alcohol consumption, have only recently gained attention.

The aim of this thesis was to investigate whether structured care of patients with AF could improve guideline adherence and HRQoL compared to standard care, and to determine which factors affect symptoms and HRQoL prior to treatment with radiofrequency catheter ablation (RFA), as well as improvement after RFA. Furthermore, we aimed to examine the associations of alcohol consumption with cardiac biomarkers, the size of the left atrium (LA), and re-ablation.

This thesis is based on two studies. In the 'Structured Management and Coaching - Patients with Atrial Fibrillation' (SMaC-PAF) study, 176 patients were recruited to the intervention group, receiving a structured follow-up programme, and 146 patients were recruited to the control group, receiving standard care. The two groups were compared in regard to adherence to guidelines and patient-reported outcome measures (PROMs) assessing symptoms and HRQoL.

In the 'Symptom burden, Metabolic profile, Ultrasound findings, Rhythm, neurohormonal activation, haemodynamics and health-related quality of life in patients with atrial Fibrillation' (SMURF) study, 192 patients referred for their first RFA of AF were included. PROMs questionnaires were filled out, echocardiography was performed, and cardiac biomarkers were analysed. Alcohol consumption was assessed through interview and through analysis of ethyl glucuronide in hair (hEtG). AF recurrence and re-ablation within 12 months were examined.

In the first study, after one year, $94 \%(n=112)$ and $74 \%(n=87)$ of patients with indication for OAC in the intervention and the control groups, respectively, actually received treatment with $\mathrm{OAC}(\mathrm{p}<0.01)$. Both groups improved in anxiety and HRQoL scores over the year, but in the interven- 
tion group, arrhythmia-specific symptoms were less frequently experienced and the SF-36 scores were more similar to the norm population.

In the second study, the most important predictors of arrhythmiarelated symptoms and HRQoL prior to RFA were anxiety, depression and low-grade inflammation, while frequent $\mathrm{AF}$ attacks prior to RFA, freedom from AF recurrence after RFA, female gender, no enlarged LA, absence of diabetes, and the presence of heart failure were significant predictors of improvement in symptoms and HRQoL after RFA. Men with hEtG $\geq 7$ $\mathrm{pg} / \mathrm{mg}$ had higher levels of cardiac biomarkers, larger LA volumes and a higher re-ablation rate than men with $\mathrm{hEtG}<7 \mathrm{pg} / \mathrm{mg}$, while no such findings were present in women.

In conclusion, structured management was superior to standard care in patients with $\mathrm{AF}$, emphasising the importance of structured care, adjusted to local requirements, in order to improve the care and well-being of patients with AF. Although the reasons for the great variety of symptoms in patients with AF still are not yet fully understood, it seems that psychological factors and inflammation play a role, and that improvement in symptoms and HRQoL after RFA is influenced by gender, diabetes, heart failure, LA size and the frequency of attacks before, as well as freedom from AF after, RFA. Finally, alcohol consumption corresponding to $\mathrm{hEtG} \geq 7 \mathrm{pg} / \mathrm{mg}$ was associated with higher levels of cardiac biomarkers, larger LA size and a higher rate of re-ablation in men, implying that men with an hEtG-value $\geq 7 \mathrm{pg} / \mathrm{mg}$ have a higher risk for LA remodelling that could potentially lead to a deterioration of the AF situation. 


\section{SVENSK POPULÄRVETENSKAPLIG SAMMANFATTNING}

Ca 300 ooo svenskar beräknas lida av förmaksflimmer, en sjukdom som leder till att hjärtat slår oregelbundet och oftast för snabbt. Förmaksflimmer ökar risken för stroke, dvs. blodpropp i hjärnan, vilket kan förebyggas med proppförebyggande läkemedel, men som använts i alldeles för liten utsträckning. Utöver förebyggande av stroke, består behandlingen också av att hålla förmaksflimmerattacker borta, och på så sätt förbättra symtom. Det kan åstadkommas med hjälp av ablation, som innebär att en isoleringslinje mellan förmaken och lungvenerna åstadkommes med hjälp av värmeenergi. De senaste åren har forskning kring förmaksflimmer ökat markant, men orsaken till varför vissa har uttalade symtom medan andra inte känner något, kvarstår dock som något av ett mysterium. Forskningen har dessutom framförallt fokuserat på behandling snarare än på förebyggande åtgärder och riskfaktorer, så som alkoholkonsumtion.

Syftet med denna avhandling var att undersöka huruvida ett strukturerat omhändertagande av patienter med förmaksflimmer kan förbättra behandling samt livskvalitet, samt att undersöka vilka faktorer som påverkar symtom och livskvalitet vid behandling med ablation. Vidare var syftet att undersöka eventuella samband mellan alkoholintag och hjärtspecifika blodprover, vänster förmaksstorlek samt upprepad ablation. Alkoholintaget värderades genom analys av koncentrationen av det alkoholspecifika ämnet ethyl glucuronide i hår.

Sammanfattningsvis ledde det strukturerade omhändertagandet, jämfört med gängse rutin, till en klart förbättrad behandling enligt riktlinjer, färre sjukdomsspecifika symtom samt livskvalitet som i högre utsträckning nådde normalbefolkningens. Även om gåtan gällande den stora symtomvariationen ännu till fullo inte är löst, visar denna studie att psykologiska faktorer som ångest och depression, samt inflammation, verkar spela roll. Störst förbättring av symtom och livskvalitet efter ablation ses hos de med många förmaksflimmerattacker före ablation, frihet från flimmerattacker efter ablation, kvinnor, de utan förstorat vänster förmak, de utan diabetes, samt de med hjärtsvikt. Slutligen var ethyl glucuronide mer än 7 picogram per milligram hos män, en nivå tydandes på måttlig konsumtion av alkohol, associerat med högre nivåer av hjärtspecifika blodprover, större förmak och större andel upprepade ablationer, tydandes på att män med denna grad av alkoholkonsumtion har en större risk för förändringar i vänster förmak vilket kan förvärra sjukdomen. 
Structured Management, Symptoms, Health-related Quality of Life and Alcohol in Patients with Atrial Fibrillation 


\section{LIST OF PAPERS}

The thesis is based on the papers listed below, which will be referred to in the text by their Roman numbers.

I. Barmano N, Walfridsson U, Walfridsson H, Karlsson1 J-E. Structured Care of Patients with Atrial Fibrillation Improves Guideline Adherence.

Journal of Atrial Fibrillation. 2016 Dec;9(4):1498. doi:10.11529/jafib.1498.

II. Charitakis E, Barmano N, Walfridsson U, Walfridsson H.

Factors Predicting Arrhythmia-Related Symptoms and Health-

Related Quality of Life in Patients Referred for Radiofrequency Ablation of Atrial Fibrillation

JACC: Clinical Electrophysiology. 2017 May;3(5):494-502

doi: 10.1016/j.jacep.2016.12.004

III. Barmano N, Charitakis E, Kronstrand R, Walfridsson U, Karlsson JE, Walfridsson H, Nystrom FH.

The Association between Alcohol Consumption, Cardiac Biomarkers, Left Atrial Size and Re-ablation in Patients with Atrial Fibrillation Referred for Catheter Ablation.

PLoS ONE, 2019 Apr;14(4): e0215121.

https://doi.org/10.1371/journal.pone.0215121

IV. Barmano N, Charitakis E, Karlsson JE, Nystrom FH, Walfridsson $\mathrm{H}$, Walfridsson $\mathrm{U}$.

Predictors of Improvement in Arrhythmia-specific Symptoms and Health-related Quality of Life after Catheter Ablation of Atrial Fibrillation.

Clinical Cardiology. 2019 Feb;42(2) :247-255.

doi: 10.1002/clc.23134 
Structured Management, Symptoms, Health-related Quality of Life and Alcohol in Patients with Atrial Fibrillation 


\section{ABBREVIATIONS}

$1 \mathrm{Y}$

4M

5-HIAA

5-HTOL

$\beta$-HEX

$\mathrm{AAD}$

ACEi

$\mathrm{AF}$

ALT

ARB

ARREST-AF

AST

ASTA

B

BMI

BP

CABANA

CASTLE-AF

CDT

$\mathrm{CHA}_{2} \mathrm{DS}_{2}$-VASc

$\mathrm{CHADS}_{2}$

CI

CKD

CT
One year

Four months

5-hydroxyindole-3-acetic acid

5-hydroxytryptophol

$\beta$-hexosaminidase

Anti-arrhythmic drugs

Angiotensin converting enzyme inhibitor

Atrial fibrillation

Alanine aminotransferase

Angiotensin receptor blocker

Aggressive Risk Factor Reduction Study for Atrial Fibrillation and Implications for the Outcome of Ablation study

Aspartate aminotransferase

The Arrhythmia-Specific questionnaire in Tachycardia and Arrhythmia

Baseline

Body Mass Index

Bodily pain

Catheter Ablation versus Anti-arrhythmic Drug Therapy in Atrial Fibrillation study

Catheter Ablation versus Standard Conventional Therapy in Patients with Left Ventricular Dysfunction and Atrial Fibrillation

Carbohydrate-deficient transferrin

Congestive heart failure, Hypertension, Age $\geq 75$ (doubled), Diabetes, Stroke (doubled), Vascular disease, Age 65-74, Sex category (i.e. female gender)

Congestive heart failure, Hypertension, Age $\geq 75$,

Diabetes, Stroke (doubled)

Confidence interval

Chronic kidney disease

Computed tomography 


$\begin{array}{ll}\text { CV } & \text { Coefficient of variation } \\ \text { DC-cardioversion } & \text { Direct Current - cardioversion } \\ \text { ECG } & \text { Electrocardiogram } \\ \text { EF } & \text { Ejection fraction } \\ \text { EHRA } & \text { European Heart Rhythm Association } \\ \text { EQ-5D } & \text { EuroQol Health Questionnaire, five dimensions } \\ \text { EQ-VAS } & \text { EuroQol Health Questionnaire, Visual Analogue } \\ & \text { Scale } \\ \text { ER } & \text { Emergency room } \\ \text { ES } & \text { Effect size } \\ \text { EtG } & \text { Ethyl glucuronide } \\ \text { EtS } & \text { Ethyl sulphate } \\ \text { FAEEs } & \text { Fatty acid ethyl esters } \\ \text { FU } & \text { Follow-up } \\ \text { GFR } & \text { Glomerular filtration rate } \\ \text { GH } & \text { General health } \\ \text { GT } & \text { Glutamyl transferase } \\ \text { HADS } & \text { Hospital Anxiety and Depression Scale } \\ \text { HAS-BLED } & \text { Hypertension, Abnormal renal/liver function, } \\ & \text { Stroke, Bleeding history or predisposition, Labile } \\ \text { HDL } & \text { INR, Elderly (age>65), Drugs/alcohol } \\ \text { hEtG } & \text { High density lipoprotein } \\ \text { HRQoL } & \text { Ethyl glucuronide in hair } \\ \text { hsCRP } & \text { Health-related Quality of Life } \\ \text { LA } & \text { High-sensitive C-reactive protein } \\ \text { LAV } & \text { Left atrium } \\ \text { LAVI } & \text { Left atrial volume } \\ \text { LDL } & \text { Left atrial volume index } \\ \text { LV } & \text { Low density lipoprotein } \\ \text { MANTRA-PAF } & \text { Left ventricle } \\ \text { MCS } & \text { Medical Anti-arrhythmic Treatment or Radiofre- } \\ \text { MCV } & \text { Muency Ablation in Paroxysmal Atrial Fibrillation } \\ \text { MH } & \text { Mental component summary } \\ \text { MR-proADM } & \end{array}$


MR-proANP

NA

Ns

NT-proBNP

NYHA

OAC

PCS

PEths

$\mathrm{PF}$

PROMs

QoL

RA

RACE

RE

RFA

RP

RV

RVDP

RVSP

SD

SF

SF-12

SF-36

SMaC-PAF

SMURF

SoHT

SR

TEE

TG

TIA

TSA
Mid-regional fragment of pro atrial natriuretic peptide

Not applicable

Non-significant

N-terminal pro B-type natriuretic peptide

New York Heart Association

Oral anticoagulants

Physical component summary

Phosphatidylethanol species

Physical functioning

Patient-reported outcome measures

Quality of life

Right atrium

Rate Control Efficacy in Permanent AF study

Role-emotional

Radiofrequency catheter ablation

Role-physical

Right ventricle

Right ventricular diastolic pressure

Right ventricular systolic pressure

Standard deviation

Social functioning

The 12-Item Short Form Health Survey

The Medical Outcomes Study 36-Item Short-Form Health Survey

Structured Management and Coaching - Patients with Atrial Fibrillation study

Symptom burden, Metabolic profile, Ultrasound findings, Rhythm, neurohormonal activation, haemodynamics and health-related quality of life in patients with atrial Fibrillation study

Society of Hair Testing

Sinus rhythm

Transoesophageal echocardiography

Triglycerides

Transient ischaemic attack

Total serum sialic acid 
Structured Management, Symptoms, Health-related Quality of Life and Alcohol in Patients with Atrial Fibrillation

$\begin{array}{ll}\text { TTE } & \text { Transthoracic echocardiography } \\ \text { UK } & \text { United Kingdom } \\ \text { US } & \text { United States } \\ \text { VT } & \text { Vitality } \\ \text { WHO } & \text { World Health Organization }\end{array}$




\section{INTRODUCTION}

\section{Atrial Fibrillation}

\section{History}

The oldest description of atrial fibrillation (AF) might be the Assyrians' description of symptoms that probably included $\mathrm{AF}^{1}$, or perhaps the one found in "The Yellow Emperor's Classic of Medicine"2. Although it is said to have been written by the Chinese emperor Huangdi around $2600 \mathrm{BC}$, it is more likely to be a compilation of writings of several authors dating from about $300 \mathrm{BC}^{3}$. In the recorded history, William Harvey was probably the first to describe "fibrillation of the auricles" in animals in $1628^{2}$. Other notable physicians who described an irregular pulse that most likely was AF were Stokes and Wenckebach in the $19^{\text {th }}$ century 4

After the invention of the electrocardiograph in 1900, Lewis was the first to record an electrocardiogram (ECG) in a patient with $\mathrm{AF}^{2}$. The mechanisms remained controversial until 1970, when it was recognised that the irregular ventricular beating was a response to "randomly spaced atrial impulses of random strength reaching the atrioventricular node from random directions"2. Since then, there has been an exponential increase in publications concerning $\mathrm{AF}$, especially in the last two decades, which has led to remarkable improvements not only in understanding the mechanisms behind AF, but also the treatment of it 5 (Figure 1).

Figure 1. Annual number of search hits in PubMed using the term "atrial fibrillation", from 1945-2018.

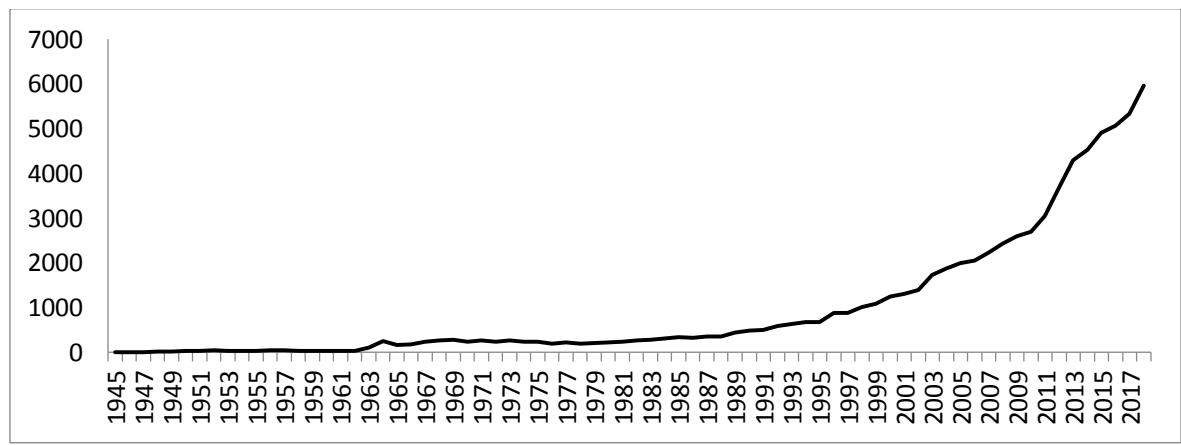

File obtained from PubMed (https://www.ncbi.nlm.nih.gov/pubmed/) on $18^{\text {th }}$ February 2019 . 


\section{Epidemiology}

$\mathrm{AF}$ is the most common cardiac arrhythmia in the world, affecting at least $2.9 \%$ of the Swedish population, not counting "silent AF" 6 . It has a significant impact on healthcare costs, accounting for $1 \%$ of the total healthcare costs in the United Kingdom (UK), and between 6-26 billion dollars in the US for 2008, mainly due to hospitalisations and stroke $\mathrm{e}^{7,8}$.

The prevalence increases with age and reaches $9-14 \%$ in the population above 80 years (Figure 2)6,9. Accordingly, the prevalence differs in different regions depending on the mean age in that region. The prevalence is higher in men, and more common in developed countries than in developing countries (Figure 3) ${ }^{7}$. Besides ethnic background, better surveillance could be a reason for the global variation?.

Figure 2. Prevalence of diagnosed atrial fibrillation in relation to age on $31 \mathrm{De}-$ cember 2010

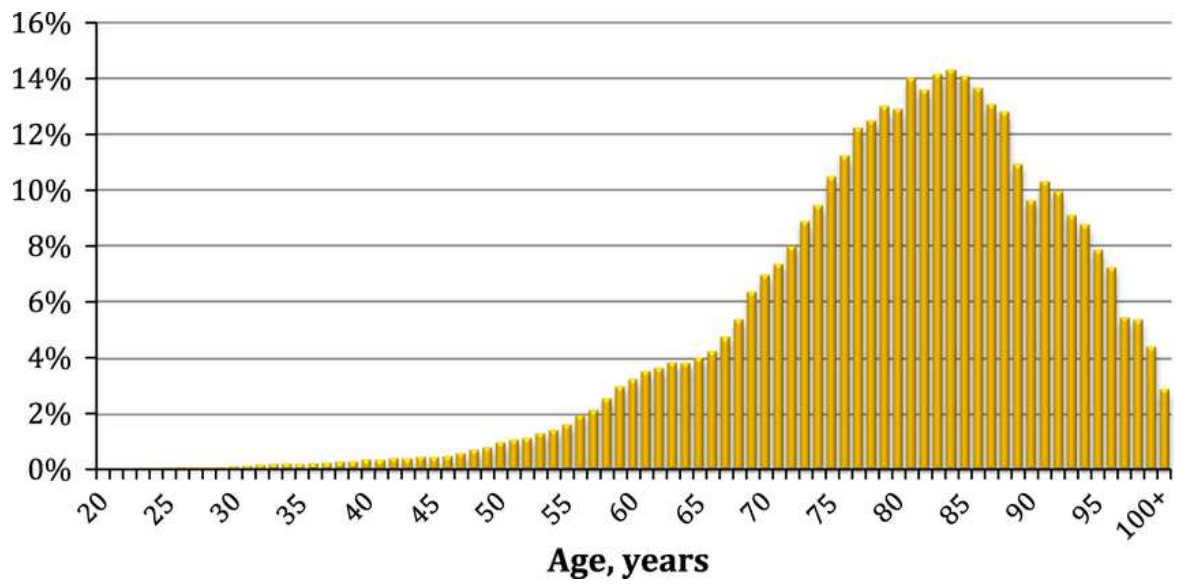

Reprinted from Friberg et al. JIM, 2013; 274(5): 461-468, with permission. 
Figure 3. World map showing the age-adjusted prevalence rates (per 100000 population) of atrial fibrillation in the 21 Global Burden of Disease regions.

Prevalence of atrial fibrilation and flutter (per 100,000) by region, 2010
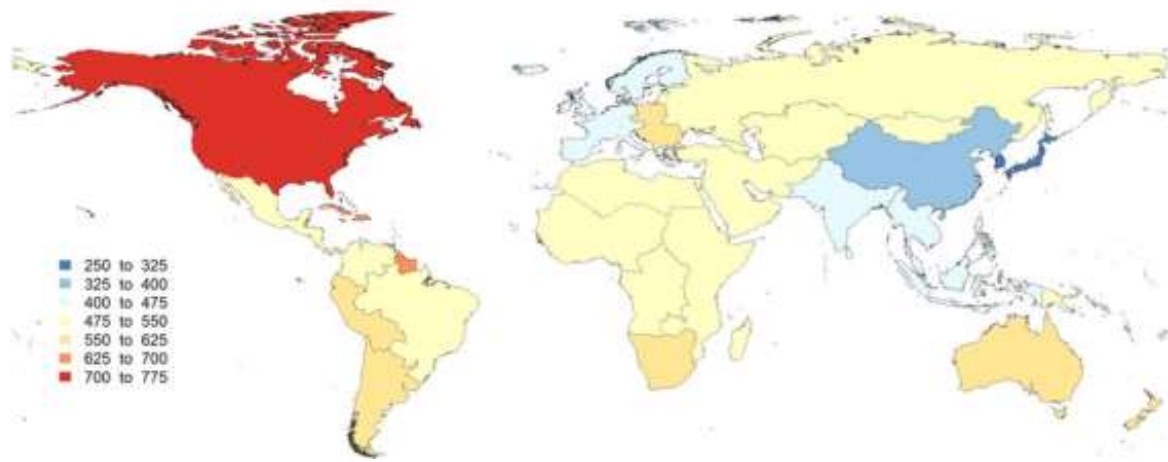

Reprinted from Chugh et al. Circulation, 2014;129:837-47, with permission.

\section{Definitions}

AF is characterised by disorganised atrial depolarisations leading to a rapid chaotic rhythm without effective atrial contraction ${ }^{10}$. The diagnosis of $\mathrm{AF}$, according to European and American guidelines, requires rhythm documentation through ECG, fulfilling the following typical characteristics of irregular RR intervals (when atrioventricular conduction is present) and absence of discernible distinct p-waves (and additionally irregular atrial activity in the American guidelines) $)^{8,11}$. An episode of at least 30 seconds is diagnostic by accepted convention ${ }^{8}$.

\section{Pathophysiology}

$\mathrm{AF}$ is a complex arrhythmia, requiring in general both a trigger to initiate the arrhythmia and a substrate/driver to maintain it ${ }^{10,12}$ As shown by Haisaguerre et al., cardiomyocytes with enhanced electrical activity located in the pulmonary vein sleeves are the most important source for ectopic beats initiating paroxysms of $\mathrm{AF}^{10,13}$. The more $\mathrm{AF}$ persists, the more non-pulmonary vein sources become important ${ }^{10}$.

$\mathrm{AF}$ can be maintained by a driver mechanism which may be rapid focal ectopic firing or by re-entry circuits (single or multiple) ${ }^{10,12}$. Re-entry requires a substrate (modified atrium) and a trigger (usually an ectopic beat) ${ }^{10}$. The excitation advances through the susceptible substrate with a circular of a spiral wave front (rotor) ${ }^{10}$. Should the arrhythmia sustain, it will lead to remodelling (electric, structural and neural/autonomic) of the atrium, which in turn further promotes the arrhythmia ${ }^{12}$. However, upon termination of the arrhythmia, the process is reversible (reverse remodelling $)^{12}$. 
Whereas electric remodelling can occur within hours, days or weeks, structural remodelling occurs on a longer time scale over months or years, and is associated with age and other underlying conditions ${ }^{10}$. Furthermore, the autonomic nervous system is also an important part of the remodelling process ${ }^{12}$.

Although much has been learned and understood concerning the mechanisms behind AF in the last few decades, much has still to be learned in order to improve preventive and therapeutic measures. For example, several genetic variants are known to predispose to $\mathrm{AF}$, and genetic information may be an important tool in the future in order to customise treatment to a single individual ${ }^{8}$.

\section{Clinical Presentation and Screening for Atrial Fi- brillation}

AF can present itself in different ways. For example, a patient can suffer from palpitations, chest pain, shortness of breath or dizziness. In some, an embolic complication may be the first symptom. In others, AF can be detected en passant.

Silent $\mathrm{AF}$ is common ${ }^{8,14}$, raising the issue of screening for $\mathrm{AF}$ in order to prevent stroke. Sequential stratified ECG monitoring in stroke survivors has been able to detect $\mathrm{AF}$ as an embolic cause in $24 \%^{15}$. The European guidelines recommend screening in patients that have suffered from a transient ischaemic attack (TIA) or stroke, in patients with cardiac devices (interrogation for atrial high rate episodes), and opportunistic screening in patients above 65 years of age ${ }^{8}$. Concerning systematic screening in the general population, AF meets the World Health Organization (WHO) criteria for screening of a disease. In the large STROKESTOP study, in which a general Swedish population aged 75-76 years were screened for AF through intermittent ECG recording using a hand-held ECG transtelephonic recorder for two weeks, $5.1 \%$ of the screened population were found to have untreated $\mathrm{AF}^{16}$. A five-year follow-up (FU) showed that the incidence of stroke declined to a greater extent compared to a control area in which screening was not performed ${ }^{17}$ and the screening method was found to be cost-effective ${ }^{18}$. Currently, according to the European guidelines, screening of patients $>75$ years or those at high stroke risk may be considered (Class IIb recommendation with a B level of evidence) ${ }^{8}$. 


\section{Classification}

In most patients, $\mathrm{AF}$ progresses from short infrequent episodes to longer and more frequent episodes and finally to a permanent condition ${ }^{8}$. In a few patients, AF will remain paroxysmal over several decades ${ }^{8}$. Based on the presentation and duration of AF episodes, AF can be classified into five types ${ }^{8}$ :

1. First diagnosed AF: AF that is diagnosed for the first time

2. Paroxysmal AF: AF that terminates spontaneously within seven days (most often within 48 hours) or is cardioverted within seven days

3. Persistent AF: AF that lasts longer than seven days

4. Long-standing persistent AF: Continuous AF lasting for more than one year when a decision is made to adopt rhythm control therapy

5. Permanent AF: AF that is accepted by the patient and the physician, without further attempts to restore sinus rhythm (SR)

\section{Consequences}

$\mathrm{AF}$ is independently associated with a doubled risk of all-cause mortality, increased risk of stroke and heart failure ${ }^{19}$. Cognitive impairment with white matter lesions and decreased health-related quality of life (HRQoL) are also common in patients with $\mathrm{AF}^{8}$. Furthermore, $10-40 \%$ of $\mathrm{AF}$ patients are hospitalised every year8.

\section{Management}

The management of AF aims to improve symptom burden and HRQoL, and to prevent adverse events. This is accomplished through four main treatment measures: risk factor modification, stroke prevention, rate control, and rhythm control ${ }^{20}$.

\section{Risk Factor Modification}

Established risk factors for the development of AF, of which some are modifiable and some are not, include age, gender, heart failure, previous myocardial infarction, hyperthyroidism, chronic obstructive pulmonary disease, chronic kidney disease, valvular heart disease, myocardial infarction, hypertension, diabetes mellitus, obesity, smoking, alcohol consumption and habitual vigorous exercise ${ }^{8,21}$. Although $\mathrm{AF}$ prevention in the form of assessment of modifiable risk factors is a cornerstone in the management of AF, research in this field has been scant. However, the field is an emerging research area, and studies have demonstrated improvement in $\mathrm{AF}$ burden and outcomes following radiofrequency catheter ablation 
(RFA) via weight management and cardiorespiratory fitness, which might also improve HRQoL"22. In the 'Aggressive Risk Factor Reduction Study for Atrial Fibrillation and Implications for the Outcome of Ablation' (ARREST-AF) study, treatment of several risk factors was included as elements of an aggressive cardiovascular risk factor management programme, leading to improved AF-related outcomes ${ }^{23}$.

\section{Stroke Prevention}

The Framingham study showed that $15 \%$ of all strokes, and $25 \%$ of all strokes after the age of 80 , were due to $\mathrm{AF}^{24}$. When stroke occurs in association with AF, mortality is higher and disability greater ${ }^{25}$. The risk of stroke in patients with paroxysmal or persistent $\mathrm{AF}$ is as great as for those with permanent $\mathrm{AF}$, and absence of symptoms does not reduce the risk of thromboembolism ${ }^{26-28}$. So far, anticoagulation is the only intervention that has proven to have an impact on mortality in patients with $\mathrm{AF}^{8}$. Although $\mathrm{AF}$ per se increases the risk of stroke, the risk is largely dependent on concomitant risk factors. Previous guidelines recommended the use of the $\mathrm{CHADS}_{2}$-score, while current guidelines recommend the use of the $\mathrm{CHA}_{2} \mathrm{DS}_{2}$-VASc-score for the decision-making on whether a patient should be treated with OAC or not (Table 1 and Table 2) ${ }^{8,11,29}$.

Table 1. The $\mathrm{CHA}_{2} \mathrm{DS}_{2}$-VASc-score

\begin{tabular}{ll}
\hline Risk factor & Score \\
\hline C - Congestive heart failure/LV dysfunction & 1 \\
H - Hypertension & 1 \\
$\mathbf{A}_{\mathbf{2}}$ - Age $\geq 75$ & 2 \\
D - Diabetes mellitus & 1 \\
$\mathbf{S}_{2}$ - Stroke/TIA/thrombo-embolism & 2 \\
V - Vascular disease & 1 \\
A - Age 65-74 & 1 \\
Sc - Sex category (i.e. female gender) & 1 \\
\hline Note 1: The CHA2 DS $_{2}$-VASc-score is a stroke risk classification scheme, using a points system ranging from zero to nine. Conges- \\
tive heart failure, hypertension, diabetes, vascular disease, age 65-75 years, and female gender give one point each, while age above \\
75 and previous stroke/TIA or other arterial embolism give two points. In the previous CHADS 2 -score, vascular disease, age-65-74, \\
and female gender were not included as risk factors, and only previous stroke/TIA gave two points, yielding a score ranging from \\
zero to six. \\
LV, left ventricle; TIA, transient ischaemic attack
\end{tabular}


Table 2. Stroke risk according to $\mathrm{CHA}_{2} \mathrm{DS}_{2}$-VASc-score

\begin{tabular}{ll}
\hline Total score & $\begin{array}{l}\text { Adjusted stroke rate (\%/year) ac- } \\
\text { cording to } \mathbf{C H A}_{\mathbf{2}} \mathbf{D S}_{\mathbf{2}} \text {-VASc-score }\end{array}$ \\
\hline $\mathrm{O}$ & 0 \\
1 & 1.3 \\
2 & 2.2 \\
3 & 3.2 \\
4 & 4.0 \\
5 & 6.7 \\
6 & 9.8 \\
7 & 9.6 \\
8 & 6.7 \\
9 & 15.2 \\
\hline Reprinted from Lip et al. Stroke, $2010 ; \mathbf{4 1}(12): 2731-8$, with permission.
\end{tabular}

In patients with a $\mathrm{CHA}_{2} \mathrm{DS}_{2}$-VASc-score of o, or female gender as a sole risk factor, it is reasonable to omit OAC, while OAC is recommended in men with a score $\geq 2$ and in women with a score $\geq 3^{8,11}$. A score of 1 in men and 2 in women indicates that OAC should be considered, considering individual characteristics and patient preferences ${ }^{8}$. Simultaneously, the bleeding risk has to be taken into consideration, in which the HAS-BLED (Hypertension, Abnormal renal/liver function, Stroke, Bleeding history or predisposition, Labile INR, Elderly (age $>65$ ), Drugs/alcohol) score can be used ${ }^{8}$. However, the risk factors overlap, and the HAS-BLED should not be used to withhold OAC, but rather to identify and correct treatable factors ${ }^{8}$.

\section{Rate Control}

Untreated AF often results in a high ventricular rate. Most AF patients therefore require medical treatment that reduces the ventricular rate, which improves symptoms and HRQoL, and reduces morbidity and the likelihood of developing tachycardia-induced cardiomyopathy ${ }^{11}$. An optimal target heart rate that applies to every patient with $\mathrm{AF}$ cannot be given, but should rather be individualised. In the 'Rate Control Efficacy in Permanent AF' (RACE) study, there was no difference in a composite of clinical events with a lenient heart rate target $<100$ b.p.m. compared to a strict heart rate target $<80$ b.p.m. ${ }^{30}$. However, some patients will remain symptomatic although the heart rate is controlled, requiring additional measures.

Pharmacological rate control can be achieved with beta-blockers, digoxin and calcium-channel blockers ${ }^{8}$. Should pharmacological treatment have no effect in the setting of an emergent unstable patient, urgent cardioversion should be considered ${ }^{8}$. If pharmacological treatment is insufficient to control rate and symptoms in the long term, and if rhythm control 
therapy is excluded as a treatment option, atrioventricular node ablation with implantation of a pacemaker can be an alternative ${ }^{8,11}$.

\section{Rhythm Control}

Rhythm control means that the aim is to restore and maintain SR. Restoration of SR can be achieved either through pharmacological cardioversion, or through electrical direct current (DC) cardioversion, which can be applied both in the acute setting and electively. Repetition of DCcardioversions as a means to control the rhythm is rarely effective in the long term and should only be an alternative for those with infrequent $\mathrm{AF}$ episodes. Instead, consideration of different options to maintain SR should be carried out early in the management of a patient with paroxysmal or persistent AF.

Maintaining SR can be achieved through medication with antiarrhythmic drugs (AAD), or via catheter ablation with isolation of the pulmonary veins, most commonly achieved with radiofrequency energy ${ }^{8,11,31}$. Treatment with AAD is a non-invasive rhythm control method, but the disadvantages with AADs are the safety issues, and their relatively low capacity to maintain $\mathrm{SR}^{32,33}$. RFA of AF is more effective than $\mathrm{AAD}$ in maintaining SR and in improving HRQoL ${ }^{34-39}$, and is in general recommended when $\mathrm{AAD}$ has failed, but can be recommended as a firstline therapy in selected patients ${ }^{8}$.

No study has so far shown advantages of rhythm control over rate control concerning mortality, bleeding or thromboembolic events in a general AF population ${ }^{40-44}$. Although the "Catheter Ablation versus Standard Conventional Therapy in Patients with Left Ventricular Dysfunction and Atrial Fibrillation' (CASTLE-AF) study showed beneficial results with RFA over AAD, this was a specific AF population 45. The recently published 'Catheter Ablation versus Anti-arrhythmic Drug Therapy in Atrial Fibrillation' (CABANA) trial did not show superiority of RFA over AAD in the intention-to-treat analysis of the primary end point (a composite of death, disabling stroke, serious bleeding, or cardiac arrest) ${ }^{46}$. However, in a secondary end point analysis concerning death or cardiovascular hospitalisation, and in the treatment received and per protocol analysis of the primary endpoint, $\mathrm{RFA}$ was superior to $\mathrm{AAD}^{46}$. The results are thus exploratory, demanding further studies in order to be clarified. One must therefore keep in mind that rhythm control therapy is still mainly aimed at improving symptoms and HRQoL. 


\section{Adherence to Guidelines}

In the first decade of this century, there were several studies showing a discrepancy between guideline recommendations and actual management of patients with AF in an everyday clinic, especially concerning stroke prevention $47-50$. Reasons for non-adherence were underestimation of stroke risk, exaggeration of bleeding risk, lack of knowledge of guidelines and trials, reluctance to change current antithrombotic therapy, high age, and patients unwilling to medicate with $\mathrm{OAC}^{27,49-52}$.

\section{Structured Care of Atrial Fibrillation}

In order to improve the care of patients with $\mathrm{AF}$, different approaches in dedicated structured care models have been tested in recent years ${ }^{53-57}$. At the time of planning of the studies that constitute this thesis, no such study had been conducted. The studies have shown positive results, with the greatest impact in a study by Hendriks et al., leading to a recommendation for an integrated approach with structured organization of care and $\mathrm{FU}$ in all patients with $\mathrm{AF}$ in the current European guidelines (Figure $4)^{8}$.

Figure 4. Fundamentals of structured care of atrial fibrillation patients.

\begin{tabular}{|c|c|c|c|}
\hline $\begin{array}{l}\text { Patient in- } \\
\text { volvement }\end{array}$ & $\begin{array}{c}\text { Multidisciplinary } \\
\text { teams }\end{array}$ & $\begin{array}{l}\text { Technology } \\
\text { tools }\end{array}$ & $\begin{array}{c}\text { Access to all } \\
\text { treatment } \\
\text { options for AF }\end{array}$ \\
\hline $\begin{array}{l}\text { - Central role in care } \\
\text { process } \\
\text { - Patient education } \\
\text { - Encouragement and } \\
\text { empowerment for self- } \\
\text { management } \\
\text { - Advice and education } \\
\text { on lifestyle and risk } \\
\text { factor management } \\
\text { - Shared decision- } \\
\text { Making }\end{array}$ & $\begin{array}{l}\text { - Physicians (general phy- } \\
\text { sicians, cardiology and } \\
\text { stroke AF specialists, sur- } \\
\text { geons) and allied health } \\
\text { professionals work in a } \\
\text { collaborative practice } \\
\text { model } \\
\text { - Efficient mix of commu- } \\
\text { nication skills, education, } \\
\text { and experience }\end{array}$ & $\begin{array}{l}\text { - Information on AF } \\
\text { - Clinical decision sup- } \\
\text { port } \\
\text { - Checklist and com- } \\
\text { munication tools } \\
\text { - Used by healthcare } \\
\text { professionals and pa- } \\
\text { tients } \\
\text { - Monitoring of therapy } \\
\text { adherence and effec- } \\
\text { tiveness } \\
\text { Navigation system } \\
\text { to support decision- } \\
\text { making in treat- } \\
\text { ment team }\end{array}$ & $\begin{array}{l}\text { - Structured support } \\
\text { for lifestyle changes } \\
\text { - Anticoagulation } \\
\text { - Rate control } \\
\text {-Anti- } \\
\text { arrhythmic drugs } \\
\text { - Catheter and surgical } \\
\text { interventions (abla- } \\
\text { tion, LA appendage } \\
\text { occluder, AF surgery } \\
\text { etc.) } \\
\text { Complex manage- } \\
\text { ment decisions } \\
\text { underpinned by an } \\
\text { AF Heart Team }\end{array}$ \\
\hline
\end{tabular}

Note: Fundamentals of structured care of patients with atrial fibrillation according to the European guidelines.

AF: Atrial fibrillation; LA: Left atrium

Reprinted from Kirchhof et al. Eur Heart J 2016; 37(38): 2893-962, with permission. 


\section{Symptoms and Health-related Quality of Life}

\section{Symptoms}

A symptom is defined as "the subjective evidence of disease or physical disturbance observed by a patient" 58 . In contrast to signs of a disease, which can be objectively assessed (such as heart murmurs, or fever), symptoms can only be known through the patient's communication ${ }^{8}$. Symptoms can be produced by the disease itself, by the treatments against the disease, or by comorbid medical conditions ${ }^{5}$. The primary objective of many treatments is to relieve symptoms, rather than cure the disease.

\section{Health-related Quality of Life}

The concept of quality of life (QoL) emerged in the late 1940s, when the WHO defined health as being not only the absence of disease, but also the presence of physical, mental and social well-being59-61. Although QoL does not have a universally accepted clear definition ${ }^{62}$, the WHO defines it as "an individual's perception of their position in life in the context of the culture and value systems in which they live and in relation to their goals, expectations, standards and concerns. It is a broad ranging concept that is affected in a complex way by the person's physical health, psychological state, personal beliefs, social relationships and their relationship to salient features of their environment" 63 .

An individual's QoL can be influenced by many factors and it can mean different things to different people. For example, socio-economic status is one factor that can influence QoL 64 , and QoL is one thing for a town planner and another for a patient. However, there is rarely an interest in QoL in such broad terms in medical trials, but rather in those aspects that are affected by a disease or a treatment ${ }^{62}$. To distinguish between the broader sense of the term QoL and QoL that is affected by health status or medical interventions, the term HRQoL is used ${ }^{62}$.

It is generally recognised that HRQoL has several dimensions, and that it can be measured subjectively, by asking the individual 59,62. Patientreported outcome measures (PROMs) is another term to describe instruments that measure different aspects of HRQoL by asking the patient. Questionnaires can consist of a different number of questions (or items), that may focus on a single dimension, or several dimensions. Thus, some questionnaires are multi-dimensional, while some focus on one or few dimensions, such as anxiety and depression for example. Furthermore, some questionnaires are intended for general use, irrespective of the illness or condition, or even apply to healthy people ${ }^{59,62}$. These generic in- 
struments can be used to compare the HRQoL of patients from different conditions, and in the general population. Their disadvantage is that they often lack the ability to illustrate aspects of HRQoL that are specific to a certain condition, which has led to the development of disease-specific instruments.

There are several reasons to measure HRQoL in medical studies. To name a few, HRQoL can be the most important endpoint in studies on treatments that do not affect survival, in health-economic evaluations, or when comparing study treatments that have the same efficacy and safety, but possibly a substantial different effect on HRQoL ${ }^{62}$.

\section{Symptoms and Health-related Quality of Life in Atrial Fibrillation}

Assessing symptoms and measuring HRQoL is especially useful in chronic conditions such as AF, which is not immediately life-threatening but can have a great impact on $\mathrm{HRQOL}^{60}$. Except for stroke prevention, different treatment modalities in AF, such as rate and rhythm control, mainly aim at improving symptoms and HRQoL. Thus, assessing symptoms and measuring HRQoL is an important part of AF treatment.

Data show that patients with AF have significantly poorer HRQoL than the general population and worse or similar HRQoL than patients with structural heart disease and coronary artery disease ${ }^{60}$. Women with AF often report significantly worse HRQoL and a greater symptom burden than men 59,65-67. HRQoL does not seem to be correlated to traditional objective measures of illness severity, such as frequency and duration of the arrhythmia, cardiac dysfunction or New York Heart Association (NYHA) $\operatorname{class}^{68}$.

Anxiety and depression are common in patients with AF69. Thrall et al. showed that approximately one third of patients with AF have elevated levels of anxiety and depression ${ }^{69}$. Anxiety and depression are also known predictors of HRQoL ${ }^{69}$, and are associated with $\mathrm{AF}$ recurrence after $\mathrm{RFA}^{70}$. Although several possible mechanisms behind this relationship have been suggested, such as correlation with systemic inflammation and elevated sympathetic tone ${ }^{70}$, the actual mechanism remains unclear. Both anxiety and depression have been shown to be improved after RFA70,71.

The European guidelines recommend health care professionals to use the European Heart Rhythm Association (EHRA) symptom scale in order to assess symptom severity (Figure 5), to guide symptom-oriented treatment decisions, and for longitudinal patient profiling ${ }^{8}$. 
Figure 5. The European Heart Rhythm Association symptom scale.

\begin{tabular}{|c|c|c|}
\hline Modified EHRA score & Symptoms & Description \\
\hline 1 & None & AF does not cause any symptoms \\
\hline $2 \mathrm{a}$ & Mild & $\begin{array}{l}\text { Normal daily activity not affected } \\
\text { by symptoms related to AF }\end{array}$ \\
\hline $2 \mathrm{~b}$ & Moderate & $\begin{array}{l}\text { Normal daily activity not affected } \\
\text { by symptoms related to AF, but } \\
\text { patient troubled by symptoms }\end{array}$ \\
\hline 3 & Severe & $\begin{array}{l}\text { Normal daily activity affected by } \\
\text { symptoms related to AF }\end{array}$ \\
\hline 4 & Disabling & $\begin{array}{l}\text { Normal daily activity discontin- } \\
\text { ued }\end{array}$ \\
\hline
\end{tabular}

AF: atrial fibrillation; EHRA: European Heart Rhythm Association

Reprinted from Kirchhof et al. Eur Heart J 2016; 37(38): 2893-962, with permission

At least 34 HRQoL instruments have been used in AF studies59. The most commonly used and validated instruments in AF studies are The Medical Outcomes Study 36-Item Short Form Health Survey (SF-36), the 12-Item Short Form Health Survey (SF-12) and The EuroQol Health Questionnaire, five dimensions (EQ-5D)59. However, these are generic instruments reflecting general health, which is influenced by comorbidities commonly present in patients with AF. Recommendations urge the use of disease-specific instruments, which allow the detection of diseasespecific changes between patients and over time, especially when measuring changes in symptom burden ${ }^{31}$. Several arrhythmia- and AF-specific instruments have been developed ${ }^{31,59}$, although they are constrained by a lack of cross-validation ${ }^{8}$. 


\section{Alcohol}

Since the beginning of recorded history, alcohol has been a part of human culture $^{72}$. Alcohol contributes substantially to the global burden of disease, accounting for approximately $4 \%$ of total mortality, mainly caused by injury, liver cirrhosis, cancer and cardiovascular disease ${ }^{72}$. However, the association between cardiovascular disease and alcohol is a matter of debate.

\section{Alcohol and the Heart}

Although there is no doubt that heavy drinking has a negative effect on the cardiovascular system, there are data supporting a beneficial effect of light to moderate drinking on cardiovascular disease, especially ischaemic heart disease ${ }^{72-74}$. Explanatory mechanisms that have been suggested are activation of the fibrinolytic system, the effect on platelet aggregation, an antioxidant effect, an improved lipid profile, an improved endothelial function, and an improvement of diabetes and hypertension 74,75 . The cardio protective effect of alcohol consumption seems to be $J$-shaped, with a sharp initial decline and a slow turn upwards, indicating cardio protection already at very low doses ${ }^{7}$. However, the shape of the curve differs depending on which population is examined. Furthermore, the nadir of the curve, in which a maximum cardio protective effect is seen, is at a dose that from a clinical and public health perspective is associated with many other disease outcomes ${ }^{76}$.

The effect of excessive alcohol intake on the myocardium is a process that progresses gradually, ultimately leading to a state known as alcohol cardiomyopathy, characterised by a non-ischaemic dilated cardiomyopathy with, in latter stages, heart failure ${ }^{77}$. Alcohol consumption is also linked to arrhythmias. In 1978 the term "holiday heart syndrome" was described, indicating an acute cardiac rhythm disturbance, most frequently AF, after binge drinking, in healthy people 75 . The exact mechanisms are not clear, but some mechanisms have been suggested, such as cardiac conduction interference facilitating re-entry, shortening of the atrial refractory period, increased sympathetic, but also parasympathetic, activity, a rise in plasma free fatty acids and acetaldehyde arrhythmogenic effects through an increase in systemic and intramyocardial catecholamines75. Also chronic alcohol intake has been associated with increased risk of AF. Data from the Framingham study showed that heavy alcohol consumption, i.e. $>36 \mathrm{~g} /$ day, significantly increased the risk of $\mathrm{AF}^{78}$. More contemporary data show an increased risk even at moderate intake (1-2 standard drinks a day, each standard drink containing 10-12 g alcohol), at least in men ${ }^{79}$. Some studies suggest a dose-dependent relationship, in which each increase of one standard drink per day, increases the risk of AF by 
$8 \%^{80,81}$. However, in a more recent meta-analysis, low levels of alcohol intake (less than 6-7 standard drinks per week) were not associated with increased risk of $\mathrm{AF}^{79}$.

\section{Alcohol Intake Recommendations}

Due to the heterogeneity concerning the J-shaped alcohol curve depending on the population being examined, a potential cardio protective association cannot be generally assumed, even at low levels of intake, making it hard to advocate alcohol consumption for health reasons ${ }^{76}$. Governments, though far from all, instead have recommendations that define a threshold of alcohol intake, above which risk consumption is defined. While the WHO defines risky drinking as more than two standard drinks (in some countries called units) a day, each standard drink containing 10 $\mathrm{g}$ of pure ethanol, in both men and women ${ }^{82}$, the definitions of a standard drink and the definitions of risk consumption differ greatly among those countries that have adopted drinking recommendations. The definitions of standard drinks range from 8-20 g, and the definitions of risky drinking range from 10-42 $\mathrm{g} /$ day for women and 10-56 g/day for men ${ }^{82}$. For example, in the UK, the recommendations are not to exceed 14 units (1 unit equal to $8 \mathrm{~g}$ of alcohol) per week for both genders. In Sweden, a standard drink equals $12 \mathrm{~g}$ of alcohol, and the recommendations are below 14 and 9 drinks/week for men and women, respectively ${ }^{83}$.

\section{Assessing Alcohol Consumption}

One method of assessing alcohol consumption is to ask the patient. Although self-report is considered to be the gold-standard, it can be unreliable and prone to underreporting, especially in legal contexts ${ }^{84,85}$. Therefore, an objective tool that retrospectively gives reliable information about the long-term alcohol consumption would be desirable. However, a perfect such tool does not exist. Still, alcohol biomarkers are currently used and can have important applications in medicine and public safety ${ }^{84}$.

Although acute alcohol consumption can easily be detected through the measurement of the blood or breath levels of ethanol itself, it does not give any information about long-term alcohol consumption, which is often of interest ${ }^{84}$. There are several biomarkers of long-term alcohol consumption, none being perfect in the sense of sensitivity and specificity, and with variable results in different populations (Table 3$)^{84,86}$. In contrast to elevated concentrations of the widely and traditionally used biomarkers (mean corpuscular volume, alanine aminotransferase, aspartate aminotransferase, $\gamma$-glutamyl transferase, carbohydrate-deficient transferrin), which can be due to many different conditions, elevated concentrations of ethyl glucuronide (EtG) are apparent only in the presence of 
alcohol, since the formation of EtG (as well as ethyl sulphate (EtS), phosphatidylethanol species (PEths) and fatty acid ethyl esters (FAEEs)) is dependent on the presence of ethanol ${ }^{84,87}$. 
Structured Management, Symptoms, Health-related Quality of Life and Alcohol in Patients with Atrial Fibrillation

Table 3. Biomarkers of alcohol consumption

\begin{tabular}{llllll}
\hline $\begin{array}{l}\text { Alcohol bi- } \\
\text { omarker }\end{array}$ & Source & $\begin{array}{l}\text { Sensitivity } \\
(\%)\end{array}$ & $\begin{array}{l}\text { Specificity } \\
(\%)\end{array}$ & Time frame & Confounders \\
\hline MCV & Blood & $30-75$ & $60-90$ & $2-4$ months & $\begin{array}{l}\text { Liver diseases, } \\
\text { vitamin B12 or } \\
\text { folic acid defi- } \\
\text { ciency, haema- } \\
\text { tological dis- } \\
\text { eases, reticulo- } \\
\text { cytosis or hypo- } \\
\text { thyroidism }\end{array}$ \\
EtG & & & & $\begin{array}{l}\text { None } \\
\end{array}$ \\
& $\begin{array}{l}\text { Blood } \\
\text { Urine } \\
\text { Hair } \\
\text { Nails }\end{array}$ & $70-90$ (hair) & $80-95$ (hair) & $\begin{array}{l}8 \text { h (blood) } \\
80 \text { h (urine) }\end{array}$ & \\
& & & &
\end{tabular}

\begin{tabular}{|c|c|c|c|c|c|}
\hline TSA & Blood & $48-82$ & $18-96$ & NA & $\begin{array}{l}\text { Cancer, cardio- } \\
\text { vascular dis- } \\
\text { ease }\end{array}$ \\
\hline 5-HTOL/5-HIAA & Urine & 100 & NA & $5^{-15} \mathrm{~h}$ & \\
\hline PEths & Blood & $94.5^{-100}$ & 100 & 4 days & None \\
\hline CDT & Blood & $60-70$ & $80-95$ & 1.5-2 weeks & $\begin{array}{l}\text { Anorexia ner- } \\
\text { vosa, pregnan- } \\
\text { cy, iron defi- } \\
\text { ciency, chronic } \\
\text { illnesses and } \\
\text { menopausal } \\
\text { status }\end{array}$ \\
\hline GGT & Blood & $40-60$ & $80-90$ & 14-26 days & $\begin{array}{l}\text { Liver damage, } \\
\text { cardiovascular } \\
\text { disease, diabe- } \\
\text { tes }\end{array}$ \\
\hline ALT/AST & Blood & $\begin{array}{l}18-58 \text { (ALT) } \\
15-69 \text { (AST) }\end{array}$ & 50-95 (AST) & NA & Liver damage \\
\hline$\beta$-HEX & $\begin{array}{l}\text { Blood } \\
\text { Urine }\end{array}$ & $\begin{array}{l}\text { 69-94 (blood) } \\
81-85 \text { (urine) }\end{array}$ & $\begin{array}{l}\text { 91-98 (blood) } \\
84-96 \text { (urine) }\end{array}$ & $\begin{array}{l}6.5 \text { days } \\
\text { (blood) }\end{array}$ & $\begin{array}{l}\text { Hypertension, } \\
\text { diabetes, cir- } \\
\text { rhosis, myo- } \\
\text { cardial infarc- } \\
\text { tion, in preg- } \\
\text { nancy and after } \\
\text { oral contracep- } \\
\text { tive use }\end{array}$ \\
\hline $\begin{array}{l}\text { Acetaldehyde } \\
\text { adducts }\end{array}$ & Blood & $65-73$ & $88-94$ & Up to 3 weeks & NA \\
\hline $\begin{array}{l}\text { Sialylation of } \\
\text { Apo J }\end{array}$ & Blood & $90-92$ & $\sim 100$ & Up to 8 weeks & NA \\
\hline $\begin{array}{l}\text { Fatty acid ethyl } \\
\text { esters }\end{array}$ & $\begin{array}{l}\text { Blood } \\
\text { Hair }\end{array}$ & NA & NA & $\begin{array}{l}100 \mathrm{~h} \text { (blood) } \\
2 \text { months } \\
\text { (hair) }\end{array}$ & NA \\
\hline Cytokines & Blood & NA & NA & NA & NA \\
\hline CDT + GT & Blood & $60-90$ & $80-95$ & NA & $\begin{array}{l}\text { See CDT and } \\
\text { GGT }\end{array}$ \\
\hline CDT + MCV & Blood & $60-95$ & $80-95$ & NA & $\begin{array}{l}\text { See CDT and } \\
\text { MCV }\end{array}$ \\
\hline
\end{tabular}

Note: Bio fluid sources, sensitivity and specificity values are listed for established alcohol biomarkers. Confounding factors for each biomarker are listed, as well as their diagnostic time frames (time period during which the marker is indicative of alcohol intake).

5-HIAA: 5 -hydroxyindole-3-acetic acid; 5-HTOL: 5-hydroxytryptophol; $\beta$-HEX: $\beta$-hexosaminidase; ALT: Alanine aminotransferase; AST: Aspartate aminotransferase; CDT: Carbohydrate-deficient transferrin; EtG: Ethyl glucuronide; GT:Glutamyl transferase; MCV: Mean corpuscular volume; NA: Not applicable; PEths:Phosphatidylethanol species; TSA: Total serum sialic acid.

Reprinted from Torrente et al. Expert Rev Proteomics 2012; 9(4): 425-36, with permission. 


\section{Ethyl Glucuronide in Hair}

Hair testing is especially useful when aiming for a retrospective assessment of consumption of drugs after they have been eliminated from the body, and is possible because compounds are incorporated into hair ${ }^{87}$. Hair testing is a well-established technique with applications in both clinical and forensic toxicology, and the Society of Hair Testing (SoHT) provides practice guidelines that include recommended sample collection and storage procedures, sample preparation, pre-treatment, analysis and the use of cut-offs ${ }^{88}$.

Ingested ethanol is mainly eliminated from the body through oxidative metabolism but a small proportion $(<0.1 \%)$ is eliminated through non-oxidative metabolism, i.e. conjugation reactions, resulting in $\mathrm{EtG}$, EtS, PEths and FAEEs ${ }^{87}$. These metabolites can be detected in the blood or urine, but with a relatively narrow diagnostic time frame ${ }^{89}$. In contrast, hair analysis has a wide diagnostic time frame, yielding information about the consumption over months to years, depending on the hair length being analysed ${ }^{89}$. While detection of ethanol itself is not possible in hair, due to its volatile nature ${ }^{87}$, EtG is a stable marker that can be detected in hair and analysed. The average hair growth is $1 \mathrm{~cm} / \mathrm{month}$, and the SoHT recommends analysis of o- 3 up to o- $6 \mathrm{~cm}$ proximal scalp hair, preferably from the vertex posterior part of the scalp ${ }^{88}$. Consequently, the EtG concentration in a $3 \mathrm{~cm}$ length of hair corresponds to the alcohol consumption during the previous three months.

Although studies have shown a relationship between the administered dose of ethanol and the hEtG concentration, there is a high degree of biological variability in the dose-concentration relationship ${ }^{90,91}$. For this reason, cut-off values are used as signs of excessive/chronic alcohol consumption and repeated alcohol consumption. Although different values have been suggested, the SoHT consensus states that hEtG concentrations $\geq 30 \mathrm{pg} \mathrm{EtG} / \mathrm{mg}$ strongly suggest excessive/chronic alcohol consumption, defined as consumption of more than $60 \mathrm{~g}$ of pure ethanol per day, while $\mathrm{hEtG}$ concentrations $\geq 7 \mathrm{pg} / \mathrm{mg}$ (but below $30 \mathrm{pg} / \mathrm{mg}$ ) strongly suggest repeated alcohol consumption (contradicting self-reported abstinence) ${ }^{92}$. The cut-off value of $30 \mathrm{pg} / \mathrm{mg}$ has been proven to have a high sensitivity and specificity ${ }^{91}$. 


\section{Aims}

The aims of this thesis were:

- to investigate whether structured care compared to standard care of a general AF-population could improve guideline adherence and HRQoL as well as decrease symptoms, anxiety and depression (Paper I).

- to explore predictors of arrhythmia-specific symptoms and HRQoL prior to RFA (Paper II), as well as the predictors of their improvement after RFA (Paper IV), and to evaluate the effect of RFA on symptoms, HRQoL, anxiety and depression, in patients with AF (Paper IV).

- to examine the associations of objectively measured and selfreported alcohol consumption with cardiac biomarkers, the size of the left atrium (LA), and re-ablation, and to describe long-term alcohol consumption, evaluated with an objective marker, in a population with AF referred for RFA (Paper III). Furthermore, the association of alcohol consumption with symptoms and HRQoL was not included in any of the papers, but was one of the initial aims of this thesis and is thus presented in this thesis. 


\section{METHODS}

The thesis is based on data from the two studies 'Structured Management and Coaching - Patients with Atrial Fibrillation' (SMaC-PAF) which forms the basis for Paper I, and 'Symptom burden, Metabolic profile, Ultrasound findings, Rhythm, neurohormonal activation, haemodynamics and health-related quality of life in patients with atrial Fibrillation' (SMURF), which forms the basis for Papers II-IV.

\section{Ethical Considerations and Informed Consent}

Concerning the SMaC-PAF study, one might argue that it is unethical to provide more structured care to only half of the study population. However, all patients received at least standard care, and before the study was undertaken it was not known whether the structured care would be better than standard care.

Concerning the SMURF study, the RFA procedure in the study was more time-consuming than a normal RFA. Furthermore, additional blood tests were taken and the amount of hair taken was a tuft of the same size as a pen's thickness. Overall, the benefits of carrying out the study and thus answering the study questions were judged to exceed any discomfort that study patients might feel.

In both studies participation was completely voluntary and the patients had the right to discontinue the study at any time, without the need for any explanation. The Regional Ethical Review Board in Linköping, Sweden, approved both studies (Dnr M145-09 and Dnr 2011/40-31). All patients gave their written consent and the studies complied with the Declaration of Helsinki93.

\section{The SMaC-PAF Study - Paper I}

\section{Design}

The study had a non-randomised prospective design. The intervention took place at the Ryhov county hospital in Jönköping, Sweden, while patients in the control group were enrolled at three county hospitals in the same area (Kalmar, Eksjö and Norrköping, Sweden). All patients were asked to fill out questionnaires at inclusion and after one year, and their medical records were examined one year after inclusion. There was no study-related contact with patients in the control group, while patients in the intervention group were followed at the $\mathrm{AF}$ clinic as described below. 
The first patient was included in December 2009 and the last FU was made in April 2014.

\section{Inclusion and Exclusion Criteria}

Inclusion criteria were:

- Patient visiting the emergency room (ER) due to AF

- Age $\geq 18$ years

Exclusion criteria were:

- unwillingness to participate

- unstable coronary artery disease

- sepsis or other severe infection

- AF early after thoracic surgery

- acute pulmonary embolism

- hyperthyroidism

- malignant disease with expected survival less than one year

- dementia or insufficient knowledge of the Swedish language making it difficult to independently fill out the questionnaires.

Eligible patients were informed about the study at the ER or at the cardiac ward. Written informed consent was obtained prior to enrolment. Enrolled patients at the intervention centre were then scheduled for an outpatient visit at the AF outpatient clinic (see below) within two weeks. Patients enrolled at the hospitals serving as control centres were only asked to fill out the questionnaires and then received "standard care".

\section{Structured Care of Patients with Atrial Fibrillation}

\section{Education and Preparations}

Prior to the study onset, physicians at the emergency care unit in the intervention centre were educated concerning current guidelines. A pocket sized laminated algorithm was presented, containing recommendations for treatment with OAC and with suggestions for outpatient management.

\section{Atrial Fibrillation Outpatient Clinic}

The AF outpatient clinic was active one day weekly and manned by two cardiologists and two nurses. All patients included in the study were followed at the AF outpatient clinic one or two weeks after discharge and then at three and additionally at 12 months FU. Data were entered in the Swedish National quality AF registry (Auricula) at the first and last visits. 
The nurses' perspective was to increase the patients' knowledge about AF through information and education. They also provided lifestyle advice focusing on overweight/obesity, alcohol, coffee, stress and psychological distress. An information booklet from the Swedish Heart and Lung Foundation was handed out containing general information about AF including basic anatomy, physiology, symptoms and treatment.

The physicians used a checklist to ensure that treatment was given according to guidelines. If OAC was not prescribed when indicated, an explanation was mandatory.

Increased availability was also ensured in the structured AF outpatient clinic. Patients could reach a nurse every weekday morning. The AF outpatient clinic was also equipped with a trans-telephonic thumb ECG, which was handed out to some patients, for example when investigating whether the patients' symptoms were due to AF or not.

\section{Patient-reported Outcome Measure Questionnaires}

\section{The Medical Outcomes Study 36-Item Short Form Health Sur- vey}

SF-36 is a generic questionnaire designed to measure an individual's physical and mental health. It comprises 35 items grouped into eight scales and one question concerning changes in health outside the scales. The eight scales are physical functioning (PF), role-physical (RP), bodily pain (BP), general health (GH), vitality (VT), social functioning (SF), roleemotional (RE), and mental health (MH) ${ }^{94}$. For each of the eight scales, scores were coded, summed, and transformed to a scale from o (worst possible health) to 100 (best possible health) ${ }^{94}$. The eight scales are summarised in physical and mental component summaries (PCS and MCS, respectively), standardised to a norm with a mean of 50 and a standard deviation (SD) of $10^{95}$. SF-36 has been widely used in research, including studies of patients with arrhythmias59,60.

\section{The EuroQol Health Questionnaire, Five Dimensions and Eu- roQol Health Questionnaire, Visual Analogue Scale}

The EQ-5D/EuroQol Health Questionnaire-Visual Analogue Scale (EQVAS) questionnaire was used to characterise health state. The EQ-5D questionnaire assesses five dimensions: mobility, self-care, activity, pain/discomfort, and mood, each with three levels of severity. The UK EQ-5D index tariff was used to obtain a weighted index, with a range from -0.59 to 1.0, where 1.0 represents full health ${ }^{96}$. The EQ-VAS records the respondents' self-rated health status on a vertically graduated (o-100) visual analogue scale with 100 (best imaginable health state) at the top 
and o (worst imaginable health state) at the bottom. EQ-5D/EQ-VAS has been extensively validated and has often been used in AF studies 59 .

\section{The Hospital Anxiety and Depression Scale}

The domain-specific questionnaire Hospital Anxiety and Depression Scale (HADS) consists of 14 items constituting two subscales, where seven items assess anxiety and seven assess depression. Responses are scored from o to 3 with higher scores denoting more psychological distress. The score for each subscale ranges from $o$ to 21. The scores are categorised as normal (o-7), possible (8-10), and probable ( $\geq 11)$ anxiety and depression, respectively ${ }^{97,98}$. HADS has previously been used in patients with AF99.

\section{The Arrhythmia-Specific Questionnaire in Tachycardia and Arrhythmia}

The Arrhythmia-Specific questionnaire in Tachycardia and Arrhythmia (ASTA) is a disease-specific, validated, questionnaire divided into three separate parts: Part I evaluates the patient's latest episode of arrhythmia and current medication ${ }^{100,101}$. Part II assesses symptom burden, and includes a nine-item symptom scale with a four-point response scale (ASTA symptom scale) ${ }^{101}$. Outside of the symptom scale there are questions concerning the frequency and duration of arrhythmia episodes and experience of near syncope, syncope and palpitations in connection with arrhythmia. Part III assesses HRQoL with a 13-item scale, with the same four-point response scale (ASTA HRQoL scale) as for the symptom scale $^{100}$. Values range from $\mathrm{o}$ to 100 and higher scores reflect higher symptom burden and a worse effect on HRQoL, due to the arrhythmia ${ }^{100,101}$. In an earlier version of ASTA, which was used in the SMaC-PAF study, there were no scale score calculations, and Part II consisted of 10 items, but has since then been reduced to nine items during the validation process ${ }^{100}$.

\section{Norm Population}

In 2006, a survey of the population in south-eastern Sweden was conducted, including assessment of HRQoL measured with, among others, SF- $36^{102}$. In total, 7238 individuals responded to the survey, and the individuals aged 65-74 years were used for comparison.

\section{Outcomes/Endpoints - Paper I}

The primary outcomes were the effect of structured care on:

1) adherence to guidelines, evaluated by five criteria: 
a) appropriate prescription of OAC according to the $\mathrm{CHADS}_{2}$ and $\mathrm{CHA}_{2} \mathrm{DS}_{2}-\mathrm{VASc}$ criteria (Table 1 and Table 2)

b) echocardiogram performed

c) thyroid laboratory tests performed

d) no $\mathrm{AAD}$ prescribed to patients with permanent $\mathrm{AF}$

e) no class 1c-AAD prescribed in the presence of structural heart disease

2) symptoms, anxiety, depression and HRQoL, as assessed by the PROMs questionnaires described above.

At study onset, the recommendations in the guidelines were based on the $\mathrm{CHADS}_{2}$ classification scheme and suggested the use of OAC when $\mathrm{CHADS}_{2} \geq 2$ in patients without contraindications. During the study, new guidelines were published recommending the use of the $\mathrm{CHA}_{2} \mathrm{DS}_{2}-\mathrm{VASc}$ classification scheme and treatment with OAC for scores $\geq 1$.

\section{Statistics}

In order to detect a five-point difference in the scales in SF-36 between the groups, using an alpha of 0.05 and a power of $0.80,200$ patients in each group were required.

Normally distributed variables are presented as means $\pm \mathrm{SD}$, whereas categorical variables are presented as percentages and numbers. Differences between the two groups for normally distributed variables were tested with the independent $\mathrm{t}$-test, and the paired $\mathrm{t}$-test for differences over time within the groups. For non-normally distributed variables the Mann-Whitney U test was used for testing differences between the two groups, and Wilcoxon's signed rank test, or McNemar's test for dichotomous variables, within groups over time. For categorical variables the Chi-square test or Fischer's exact test were used between groups, and for proportions the z-test with continuity correction was used. All calculations were made with SPSS statistical software version 20.0 (Armonk, NY: IBM Corp). P-values <0.05 were considered as statistically significant. 


\section{The SMURF Study, Papers II-IV}

\section{Design}

The SMURF study was conducted between January 2012 and April 2014. Patients referred to the University Hospital in Linköping, Sweden, for RFA due to AF, were considered for participation. The SMURF study consisted of an observational and an interventional part. In this thesis, only the observational part of the study was used, which was a single centre cohort study (Figure 6). The study was registered at www.clinicaltrials.gov (NCTo1553045).

After screening, potentially eligible patients received written information about the study and the PROMs questionnaires. Prior to the RFA, oral information was given and informed consent was signed. The questionnaires were collected. A full baseline evaluation including medical history, physical examination and 12-lead ECG was performed. Transoesophageal and transthoracic echocardiography (TEE and TTE), and a CT scan of the heart were performed according to clinical routine. Patients were then catheterised according to clinical routine and blood samples for the analysis of high-sensitive C-reactive protein (hsCRP), Nterminal pro B-type natriuretic peptide (NT-proBNP), the mid-regional fragment of pro atrial natriuretic peptide (MR-proANP) and the midregional portion of pro-adrenomedullin (MR-proADM) were taken from the femoral vein. Intracardiac pressures were recorded in the right atrium (RA), LA and right ventricle (RV). Blood samples were repeated the day after the RFA and FU was made after four and 12 months (Figure 6).

\section{Inclusion and Exclusion Criteria}

Consecutive patients were asked about study participation if they met the inclusion criteria and did not have any of the exclusion criteria.

The inclusion criteria were:

- Age $\geq 18$ years with paroxysmal or persistent AF

- Patients referred for first time RFA

- Patients with sufficient knowledge of the Swedish language to fill out the study questionnaires independently.

Exclusion criteria were:

- Patients who had previously undergone catheter or surgical AF ablation

- Patients with previous or planned heart surgery

- Patients with left ventricular ejection fraction (EF) $<35 \%$ 


\section{- Patients with acute coronary syndrome during the past three months.}

Figure 6. Enrolment and follow-up chart of the SMURF-study.

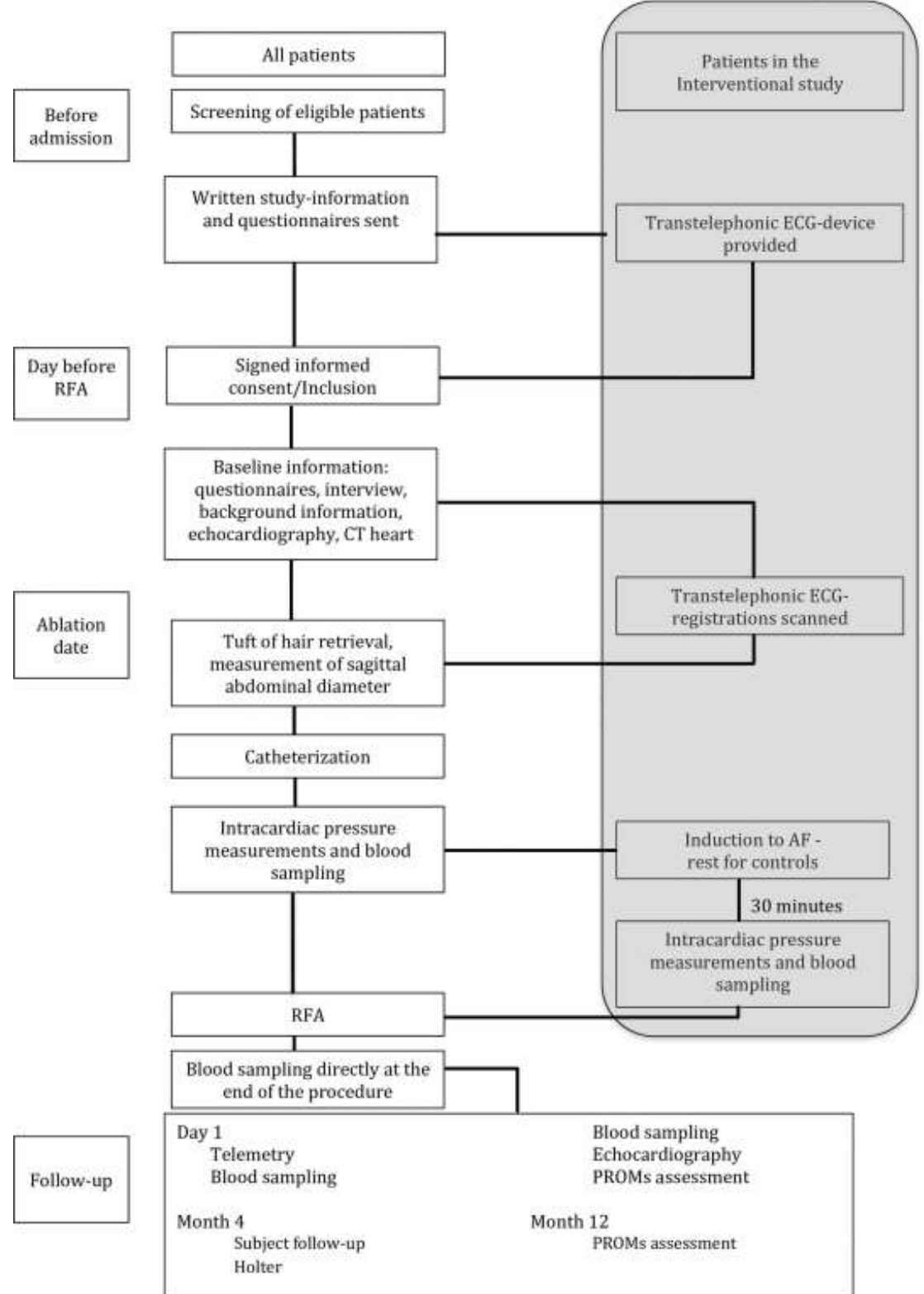

Note: The right column with grey background depicts the flow for patients included in the interventional part of the study, and was not included in this thesis.

AF: atrial fibrillation; CT: Computed tomography; ECG: Electrocardiogram; PROMs: Patient-reported outcome measures; RFA radiofrequency catheter ablation 


\section{Patient-reported Outcome Measures}

PROMs were assessed with SF-36, HADS and ASTA at baseline, at the four-month FU and 12-month FU.

\section{Echocardiography}

All patients underwent TEE and TTE prior to RFA. GE Vivid 7 or GE Vivid E9 system (GE Healthcare, Horten, Norway) were utilised with a $3.5-\mathrm{MHz}$ transducer for TTE and a 7-MHz transducer for TEE. The measurements and evaluation were performed according to the guidelines of the European Society of Echocardiography.

Left ventricular EF was calculated using the biplane Simpson's method. Left atrial volume (LAV) was measured using the biplane area-length method and was corrected for body surface area to obtain the LAV index (LAVI).

\section{Radiofrequency Catheter Ablation Procedure}

All procedures were performed under conscious sedation using propofol and remifentanil. Two trans-septal sheaths were inserted through the right femoral vein into the LA and perfused using heparinised saline with irrigation rate $2 \mathrm{ml} / \mathrm{h}$. Heparin was administered to maintain an activated clotting time of $>350 \mathrm{~s}$ throughout the procedure. RFA was performed under the guidance of a computer-based mapping system, CARTO (Biosense Webster, Diamond Bar, California, USA). Mapping and ablation were performed using an open-irrigated catheter (ThermoCool, Biosense Webster, Diamond Bar, California, USA). A 7-F, 20-pole circumferential diagnostic catheter was used for the assessment of pulmonary vein activation and isolation (Lasso, Biosense Webster, Diamond Bar, California, USA). Radiofrequency energy was delivered in a power-controlled mode with a maximum energy setting of $35 \mathrm{~W}$ at an irrigation rate of 17-30 $\mathrm{mL} / \mathrm{min}$, and the maximum energy setting in the posterior wall was $25 \mathrm{~W}$. The endpoint of the procedure was electrical disconnection of all pulmonary veins by antral ablation verified during SR by entry and exit block of all pulmonary veins. In patients with persistent $\mathrm{AF}$, additional ablation in order to create LA lines was at the discretion of the operator and verified by pacing manoeuvres. Patients with AF were routinely converted to SR on completion of the RFA procedure.

\section{Cardiac Biomarkers and Other Blood Tests}

Blood samples were collected in plastic vials containing ethylenediaminetetraacetic acid and analyses were performed at the Department of 
Clinical Chemistry at Linköping University hospital. The vials were centrifuged at $3100 \mathrm{~g}$ for $20 \mathrm{~min}$ and then frozen at $-70^{\circ} \mathrm{C}$. No sample was thawed more than twice.

The concentrations of NT-proBNP were measured on the Elecsys 2010 platform (Roche Diagnostics, Mannheim, Germany). The total coefficient of variation (CV) for NT-proBNP was $4.6 \%$ at $426.5 \mathrm{pg} / \mathrm{mL}$ $(\mathrm{n}=487)$ and $3.2 \%$ at $2308 \mathrm{pg} / \mathrm{mL}(\mathrm{n}=485)$. Plasma concentrations of MR-proANP were measured on a kryptor platform (Brahms AG, Hennigsdorf, Germany). The intra assay CV for MR-proANP according to the manufacturer was $\leq 5 \%$ for concentrations between 10 and $20 \mathrm{pmol} / \mathrm{L}$, $<3.5 \%$ for concentrations between 20 and $1000 \mathrm{pmol} / \mathrm{L}$, and $<3.5 \%$ for concentrations over $1000 \mathrm{pmol} / \mathrm{L}$.

The hsCRP analysis was performed using the wide range C-Reactive Protein immunoturbidimetric assay on the ADVIA 1650 system (Siemens Healthcare Gmbh, Erlangen, Germany). The total CV was $5.35 \%$ at 0.9 $\mathrm{mg} / \mathrm{l}$ and $1.17 \%$ at $12.3 \mathrm{mg} / \mathrm{l}$.

Liver enzymes, lipid profile and serum creatinine were measured and analysed according to clinical routine. The glomerular filtration rate (GFR) was estimated through the Cockroft-Gault formula: GFR $=((140-$ Age)*weight*k)/serum creatinine, where $\mathrm{k}$ is 1.23 for men and 1.04 for women (weight measured in kilograms and the unit for serum creatinine $\mu \mathrm{mol} / \mathrm{l})$.

\section{Pressure Measurements}

The sagittal thoracic diameter was measured in the fourth intercostal space and the reference pressure (zero level) was placed in the middle of this diameter. The mean pressures were measured in the RA and LA, and the systolic and end-diastolic pressures in the right ventricle after transseptal puncture by using the multipurpose high flow 5 French catheter (MR A1, Cordis ${ }^{\circledR}$, Miami, Fl., USA) during quiet breathing. The pressures were recorded for at least $15 \mathrm{~s}$ and stored for offline analysis (EPWorkMate; St. Jude Medical, Saint Paul, MN, USA). 


\section{Assessment of Alcohol Consumption}

\section{Self-reported Alcohol Consumption}

Patients were interviewed about their weekly alcohol consumption, and the reported amount of alcohol was translated into units. In this study, one unit corresponded to eight grams of alcohol, ingested in the form of beer, wine or spirits. High consumption was defined as more than 14 and nine units/week in men and women, respectively, and low consumption as consumption below this level.

\section{Ethyl Glucuronide in Hair}

Hair samples were collected as close as possible to the scalp and the proximal $3 \mathrm{~cm}$ were used for estimation of hEtG. The hair was placed in marked envelopes and sent to the National Board of Forensic Medicine, where it was cut into smaller segments and prepared, handled and analysed according to routine ${ }^{90}$. The total CV for hEtG was $16 \%$ at $7 \mathrm{pg} / \mathrm{mg}$, $8.3 \%$ at $33 \mathrm{pg} / \mathrm{mg}$, and $6.2 \%$ at $267 \mathrm{pg} / \mathrm{mg}$ hair.

\section{Recurrence of Atrial Fibrillation and Re-ablation}

$\mathrm{AF}$ recurrence after RFA and re-ablation was analysed up to 12 months after the initial RFA, through examination of medical records, the Swedish national registry for catheter ablation, and the $24 \mathrm{~h} \mathrm{ECG} \mathrm{monitoring}$ at the four-month FU. AF recurrence was defined as a documented episode of $\mathrm{AF}$ or atrial flutter lasting more than 30 seconds, and/or the need for re-ablation.

\section{Outcomes/Endpoints}

The primary endpoints of the studies were:

\section{Paper II}

- to examine possible predictors of arrhythmia-specific symptoms and HRQoL, as well as general HRQoL, prior to RFA of AF.

\section{Paper III and the Association of Alcohol Consumption with Symptoms and Health-related Quality of Life}

1) to examine associations of both objectively measured and selfreported alcohol consumption with cardiac biomarkers, LA size, reablation, symptoms and HRQoL 
2) to describe long-term alcohol consumption, measured objectively, in a population with AF referred for RFA

\section{Paper IV}

1) to explore possible predictors of improvement in arrhythmiaspecific symptoms and HRQoL after RFA of AF

2) to analyse the effect of RFA on symptoms, HRQoL, anxiety and depression in a population undergoing RFA for their first time

\section{Statistics}

When calculating the sample size for the SMURF study, the main objective was to determine the effect of restoration of SR and initiation of $\mathrm{AF}$ on NT-proBNP and MR-proANP (the interventional part of the SMURF study and thus not part of this thesis). The patients included in the study by Wozakowska-Kaplon et al. ${ }^{103}$ and possible dropouts were taken into account, after which the conclusion was drawn that 200 patients would be sufficient to meet all the aims of the SMURF study.

Normally distributed continuous variables are generally expressed as means \pm SD and non-normally distributed variables as medians with $25^{\text {th }}$ to $75^{\text {th }}$ percentiles within brackets. Categorical data are presented as counts with percentages within brackets. The analyses were performed using the SPSS 24.0 (IBM, Armonk, New York). All reported p-values were two-sided and a p-value $<0.05$ was considered statistically significant.

\section{Paper II}

Multiple linear regression analysis was performed to determine possible predictors of arrhythmia-related symptoms and HRQoL. The baseline ASTA symptom scale score was used as a dependent variable to assess arrhythmia-related symptoms, while baseline ASTA HRQoL scale score, PCS and MCS were used as dependent variables to assess the patients' HRQoL. The independent predictors used in the analyses were NTproBNP, MR-proADM, low-grade inflammation (hsCRP $>3 \mathrm{mg} / \mathrm{L}$ vs. $\leq 3$ $\mathrm{mg} / \mathrm{L}$ ), the RV systolic and diastolic pressures, LA dilatation (body surface area indexed LAV $\left.>35 \mathrm{ml} / \mathrm{m}^{2} \mathrm{vs} . \leq 35 \mathrm{ml} / \mathrm{m}^{2}\right)$, heart failure $(\mathrm{EF}<45 \%$ vs. $\geq 45 \%$ ), obesity (body mass index (BMI) $>30 \mathrm{~kg} / \mathrm{m}^{2} \mathrm{vs.} \leq 30 \mathrm{~kg} / \mathrm{m}^{2}$ ), anxiety and depression (assessed by the HADS questionnaire), $\mathrm{CHA}_{2} \mathrm{DS}_{2-}$ VASc score ( $\geq 2$ points vs. $<2$ points), age, frequency of AF episodes ( $>10$ episodes vs. $\leq 10$ episodes of AF in the last month before RFA) and AF episode duration (longest AF episode duration of $\geq 1$ hour vs. $<1$ hour). The models were fit by an enter method, in which all variables were entered 
into the original model and then variables with p-values over 0.05 were removed.

\section{Paper III and the Association of Alcohol Consumption with Symptoms and Health-related Quality of Life}

Independent two-group analysis was performed with the independent $\mathrm{t}$ test for normally distributed variables and the Mann-Whitney U test for non-normally distributed variables. Wilcoxon's signed rank test was used for dependent two-group analyses. The Chi-square test was used for categorical variables. Spearman's correlation coefficient was used to assess the correlation between self-reported alcohol consumption and hEtG.

Multiple linear regression analysis was performed in order to correct for gender when evaluating the relationship between analysable hEtG and high density lipoprotein (HDL), and $\mathrm{CHA}_{2} \mathrm{DS}_{2} \mathrm{VASc}$ score. The dependent variable was $\mathrm{HDL}$ and $\mathrm{CHA}_{2} \mathrm{DS}_{2} \mathrm{VASc}$ score, respectively, with analysable hEtG (yes/no) as an independent variable and gender (male/female) as a covariate. Multiple linear regression analysis was also performed in order to evaluate the predictive role of gender and sagittal abdominal diameter on HDL. The dependent variable was HDL and the independent variables were sagittal abdominal diameter, gender and the use of statins.

Possible differences in cardiac biomarkers, echocardiographic measurements and number of re-ablations between the two groups based on the hEtG cut-off level of $7 \mathrm{pg} / \mathrm{mg}$, and also based on self-report, i.e. high vs. low consumption, were evaluated. Analyses were also stratified according to gender, due to the fact that cosmetic hair treatment can affect the hEtG analysis, and adjusted for age, systolic blood pressure, BMI, heart failure (yes/no) and actual heart rhythm (SR/AF), through multiple linear regression analysis. In this analysis, logarithmic transformation was used for NT-proBNP and MR-proANP in order to achieve normal distribution.

Binary logistic regression analysis was performed, with adjustment for the above mentioned co-variates, except for heart rhythm being replaced by AF type (paroxysmal/persistent), in order to analyse the association between alcohol consumption and re-ablation.

\section{Paper IV}

In order to analyse possible predictors of improvement in arrhythmiaspecific symptoms and HRQoL, the difference between the scores at the one-year FU and baseline were calculated for the ASTA symptom scale and the ASTA HRQoL scale, and used as the dependent variable in a simple linear regression analysis. The independent predictors used were: age, gender, BMI, hypertension (yes/no), heart failure (yes/no), diabetes 
(yes/no), AF type (paroxysmal or persistent), $\mathrm{CHA}_{2} \mathrm{DS}_{2}-\mathrm{VASc}$ score, $\mathrm{AF}$ episode duration (longest AF episode duration of $\geq 1$ hour vs. $<1$ hour in the last three months before RFA), frequency of AF episodes ( $>10$ episodes vs. $\leq 10$ episodes of AF in the last month before RFA), hsCRP, EF, $\mathrm{LAV}, \mathrm{AF}$ recurrence (yes/no), and finally, possible and probable anxiety and depression as assessed with HADS. All variables that turned out to be significant were used in a multiple linear regression analysis, conducted in a stepwise backward elimination fashion.

Analysis of the changes in all of the questionnaires summary scores, and in each item in ASTA, throughout the three measure points was performed using Friedman's test. In order to analyse between which time points there was a significant change, Wilcoxon's signed rank test was used between two measurement points. The magnitude of the change between baseline and one-year FU was assessed with effect size (ES), which was calculated and interpreted according to standard criteria where $<0.20$ denotes trivial, 0.20-0.49 small, 0.50-0.79 moderate and $\geq 0.80$ large ES ${ }^{104}$. 
Structured Management, Symptoms, Health-related Quality of Life and Alcohol in Patients with Atrial Fibrillation 


\section{RESULTS}

\section{The SMaC-PAF Study - Paper I}

\section{Baseline Characteristics}

The intervention group consisted of 199 patients and the control group of 162 patients, while 176 (88\%) and 146 (90\%) patients, respectively, were available for analysis (Figure 7). The two groups differed at baseline concerning educational degree, number of patients with $\mathrm{CHADS}_{2} \mathrm{op}$, and the number of patients having their first episode of AF (Table 4).

Figure 7. Study inclusion flow chart.

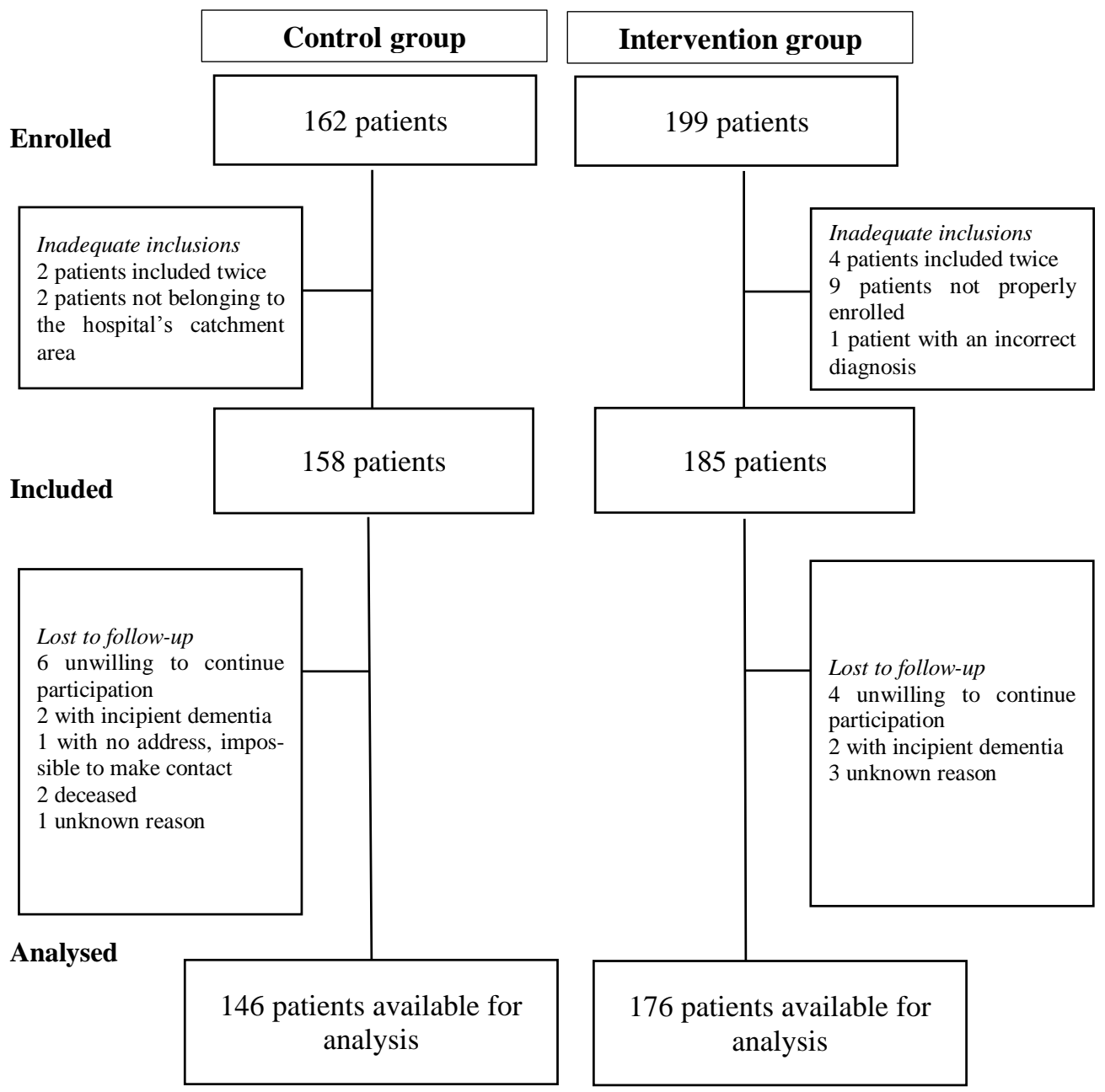


Table 4. Baseline characteristics in the SMaC-PAF study.

\begin{tabular}{|c|c|c|c|}
\hline Characteristics & $\begin{array}{l}\text { Intervention group } \\
(n=176)\end{array}$ & $\begin{array}{l}\text { Control group } \\
(n=146)\end{array}$ & p-value \\
\hline Age years, mean \pm SD & $66 \pm 10$ & $68 \pm 11$ & 0.06 \\
\hline Male gender, no. (\%) & $112(64)$ & $84(58)$ & 0.26 \\
\hline Type of AF, no. (\%) & & & 0.12 \\
\hline First episode & $42(24)$ & $50(35)$ & $<0.05$ \\
\hline Paroxysmal & $62(35)$ & $49(34)$ & $n s$. \\
\hline Persistent & $57(32)$ & $38(26)$ & $n s$. \\
\hline Permanent & $15(9)$ & $7(5)$ & $n s$. \\
\hline \multicolumn{4}{|l|}{ Comorbidity, no. (\%) } \\
\hline Hypertension & $81(46)$ & 79 (54) & 0.13 \\
\hline Diabetes & $13(7)$ & $20(14)$ & 0.06 \\
\hline Ischaemic heart disease & $21(12)$ & $24(17)$ & 0.34 \\
\hline Congestive heart failure & $23(13)$ & $14(10)$ & 0.28 \\
\hline $\begin{array}{l}\text { Chronic pulmonary dis- } \\
\text { ease }\end{array}$ & $10(6)$ & $5(3)$ & 0.42 \\
\hline Previous Stroke/TIA & $11(6)$ & $15(10)$ & 0.15 \\
\hline $\mathrm{CHADS}_{2}$-score no. (\%) & $\mathrm{n}=176$ & $\mathrm{n}=143$ & 0.09 \\
\hline o & $70(40)$ & $40(28)$ & $<0.05$ \\
\hline 1 & $57(32)$ & $57(40)$ & $n s$. \\
\hline$\geq 2$ & $49(28)$ & $46(32)$ & $n s$. \\
\hline $\begin{array}{l}\mathrm{CHA}_{2} \mathrm{DS}_{2} \text {-VASc-score no. } \\
(\%)\end{array}$ & & & 0.16 \\
\hline o & $30(17)$ & $15(11)$ & $n s$. \\
\hline 1 & $40(23)$ & $29(20)$ & $n s$. \\
\hline$\geq 2$ & $106(60)$ & 99 (69) & $n s$. \\
\hline \multicolumn{4}{|l|}{ OAC when indicated, no. (\%) } \\
\hline $\mathrm{CHADS}_{2} \geq 2$ & $24(65)$ & $17(63)$ & $n s$. \\
\hline $\mathrm{CHA}_{2} \mathrm{DS}_{2}-\mathrm{VASc} \geq 2$ & $44(60)$ & $34(60)$ & $n s$. \\
\hline $\mathrm{CHADS}_{2} \geq 1$ & $42(58)$ & $35(55)$ & $n s$. \\
\hline $\mathrm{CHA}_{2} \mathrm{DS}_{2}-\mathrm{VASc} \geq 1$ & $51(61)$ & $42(55)$ & $n s$. \\
\hline Cohabitation, no. (\%) & $\mathrm{n}=176$ & $\mathrm{n}=123$ & 0.90 \\
\hline Living alone & 39 (22) & $28(23)$ & $n s$. \\
\hline $\begin{array}{l}\text { Living with partner and/or } \\
\text { child }\end{array}$ & $137(78)$ & $95(77)$ & $n s$. \\
\hline Educational level no. (\%) & $\mathrm{n}=171$ & $\mathrm{n}=124$ & 0.02 \\
\hline Primary school & 66 (39) & $68(55)$ & $<0.05$ \\
\hline High school & $56(33)$ & $31(25)$ & $n s$. \\
\hline University & $49(29)$ & $25(20)$ & $n s$. \\
\hline Occupation no. (\%) & $\mathrm{n}=176$ & $\mathrm{n}=120$ & 0.32 \\
\hline Employed & $58(33)$ & $33(28)$ & $n s$. \\
\hline Unemployed/retirement & $118(67)$ & $87(73)$ & $n s$. \\
\hline
\end{tabular}

Cursive letters in the last column indicate significant $(\mathrm{p}<0.05)$ or non-significant (ns.) p-values for that specific category within the variable, by calculating the $\mathrm{z}$ score with continuity correction, while normal letters indicate the p-value for the complete variable, analysed with Chi2-test

AF: atrial fibrillation; OAC: Oral anticoagulants; SD: standard deviation; $\mathrm{CHADS}_{2}$ : congestive heart failure, hypertension, age $\geq 75$, diabetes, stroke/TIA; $\mathrm{CHA}_{2} \mathrm{DS}_{2}$-VASc: congestive heart failure, hypertension, age $\geq 75$, diabetes, stroke/TIA, vascular disease, age 65-74 years, sex category (i.e. female gender); TIA: transient ischaemic attack 


\section{Guideline Adherence}

At baseline, there was no difference in treatment with OAC according to guidelines between the intervention group and the control group, 24 (65 \%) vs. 17 (63\%, p = o.88) using $\mathrm{CHADS}_{2}$, and 51 (61\%) vs. $42(55 \%, \mathrm{p}=$ o.43) using $\mathrm{CHA}_{2} \mathrm{DS}_{2}$-VASc.

After one year, the number of patients treated according to guidelines in terms of adherence to all five criteria investigated, was significantly better in the intervention group, 152 (93\%) vs. 105 (74\%, p <0.01). The difference in adherence to guidelines was greater using the $\mathrm{CHA}_{2} \mathrm{DS}_{2}$ VASc-score, in favour of the intervention group, 148 (91\%) vs. $89(63 \%, p$ $<$ o.01). This was mainly due to an improvement in OAC treatment (Figure 8).

Figure 8. The proportion of patients treated with oral anticoagulation when indicated, at baseline and at the one-year follow-up.
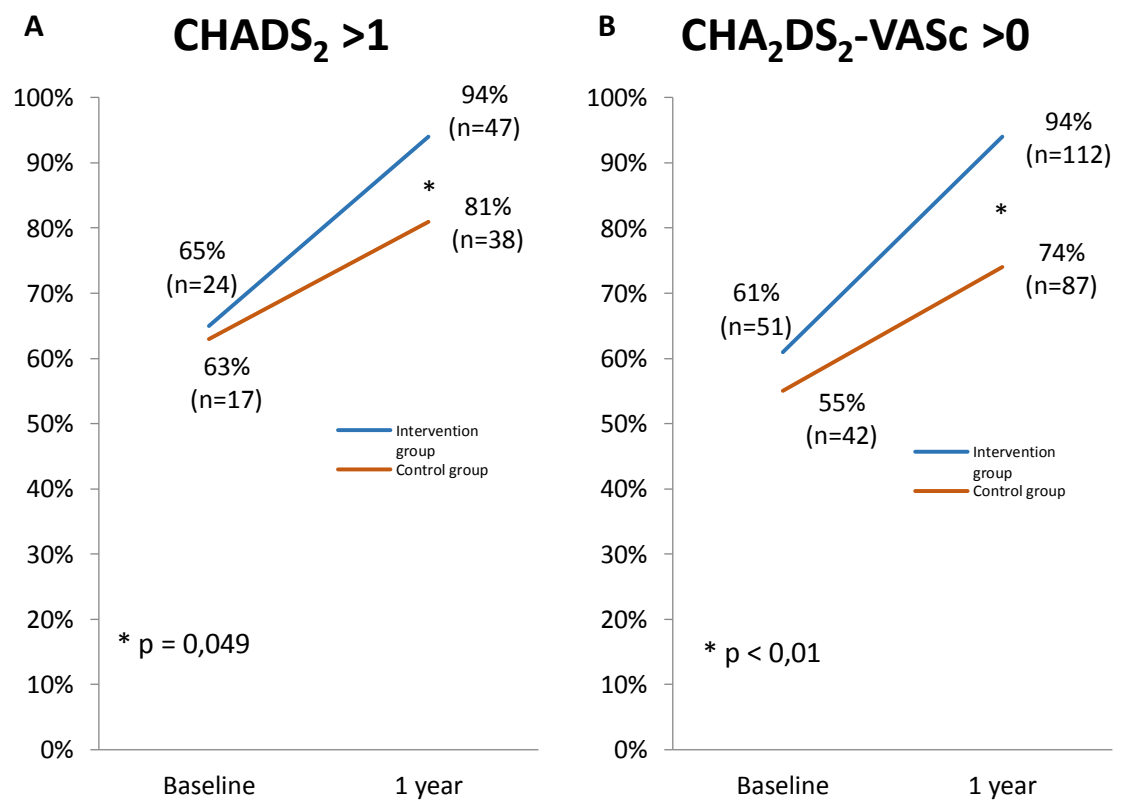

$\mathrm{CHADS}_{2}$ : congestive heart failure, hypertension, age $\geq 75$, diabetes, stroke/TIA; $\mathrm{CHA}_{2} \mathrm{DS}_{2}-\mathrm{VASc}$ : congestive heart failure, hypertension, age $\geq 75$, diabetes, stroke/TIA, vascular disease, age 65-74 years, sex category (i.e. female gender)

There was also a significant difference in whether thyroid function was tested or not, 175 (99\%) vs. 126 (86\%, p <0.01). However, there were no differences in investigations with echocardiogram, 164 (93\%) vs. 133 (92\%, $\mathrm{p}=0.62)$, in whether patients were treated with AAD despite permanent AF (none in both groups), or in whether a class Ic-AAD drug was 
used despite the presence of structural heart disease (two patients in each group).

During the FU, stroke, TIA or peripheral embolus occurred in five patients (3\%) in the intervention group and three patients (2\%) in the control group. Two patients in the intervention group suffered from intracerebral bleeding, while one patient in the intervention group and one patient in the control group suffered from gastrointestinal bleeding.

The number of patients with $\mathrm{CHA}_{2} \mathrm{DS}_{2}$-VASc o p after one year was 21 $(12 \%)$ in the intervention group and $11(8 \%)$ in the control group. However, seven (33\%) and five ( $46 \%$ ) of those patients were treated with $\mathrm{OAC}$ (n.s.) and the reasons were recent or planned ablation or DCcardioversion, patients' own desire to continue, being close to 65 years of age and in one patient a second echocardiography was planned since the left ventricular function was hard to evaluate due to arrhythmia in the first echocardiography.

\section{Patient-reported Outcome Measures}

The number of enrolled patients that did not return the questionnaires at FU was seven (4\%) in the intervention group and 48 (33\%) in the control group. There were also a number of missing answers within the returned questionnaires. Hence, the number of patients excluded from some of the PROMs analyses was larger than $4 \%$ in the intervention group and $33 \%$ in the control group.

\section{Symptoms, Anxiety and Depression}

Compared to the intervention group, patients in the control group reported more dizziness, cold sweats, weakness/fatigue, and tiredness at baseline, and after one year more weakness/fatigue, as assessed with ASTA (Figure 9). Over the year, significantly fewer patients were feeling pressure in the chest in the intervention group while no significant change was seen in the control group (Figure 9). 


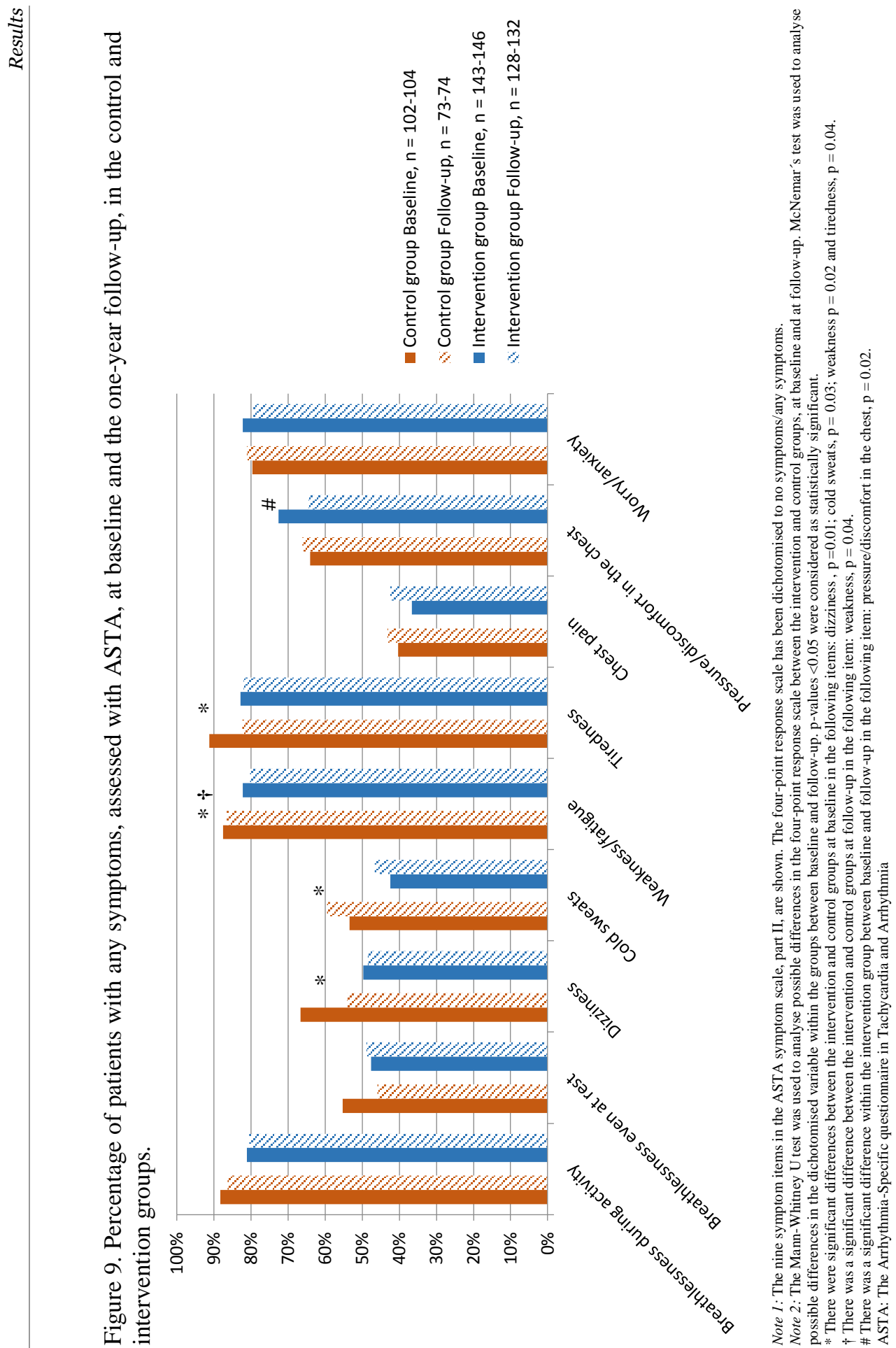


The degree of anxiety as assessed with HADS was normal at baseline, i.e. $\leq 7$, in 120 (75\%) patients in the intervention group and in $96(79 \%)$ patients in the control group. The degree of depression was normal in 128 (81\%) and 106 (86 \%) patients, in the intervention group and control group, respectively. There were no significant differences between the groups.

The degree of anxiety was reduced over the year in both groups, while depression did not change significantly (Table 5). The scoring did not differ between the groups at the one-year FU (Table 5).

\section{Health-related Quality of Life}

At baseline, patients in the control group reported a higher degree of inability to work, study or carry out daily activities $(\mathrm{p}=0.01)$, avoiding spending time with acquaintances $(\mathrm{p}=0.03)$ and family/relatives $(\mathrm{p}=0.03)$, compared to the intervention group, as assessed with ASTA. There were baseline differences between the groups also in SF-36, in which patients in the intervention group scored higher in four scales (PF, RP, SF and RE, Table 5). Over the year, there was a significant improvement in both groups in RP, VT, SF, MH, EQ-VAS and additionally RE in the control group (Table 5). There were no significant differences between the groups at the one-year FU in either subscale of SF-36 or EQ-5D/EQ-VAS (Table 5). However, in ASTA, more patients in the control group reported inability to work, study or carry out daily activities at the one-year FU, as compared to the intervention group $(\mathrm{p}=0.01)$.

\section{Comparisons with the Norm Population}

When comparing the two patient groups at baseline with a norm population, the patients in the intervention group scored significantly worse $(\mathrm{p}<0.05)$ in six out of eight scales (RP, GH, VT, SF, RE, MH) while the patients in the control group scored worse in seven of the scales (PF, RP, GH, VT, SF, RE, MH, Figure 10).

After one year, the patients in the intervention group improved in two scales ( $\mathrm{SF}$ and $\mathrm{MH}$ ) and scored similarly to the norm population and even better than the norm population in the BP scale. The patients in the control group still scored worse in seven out of eight scales, i.e. in all except $\mathrm{BP}$, equal to the situation at baseline. 


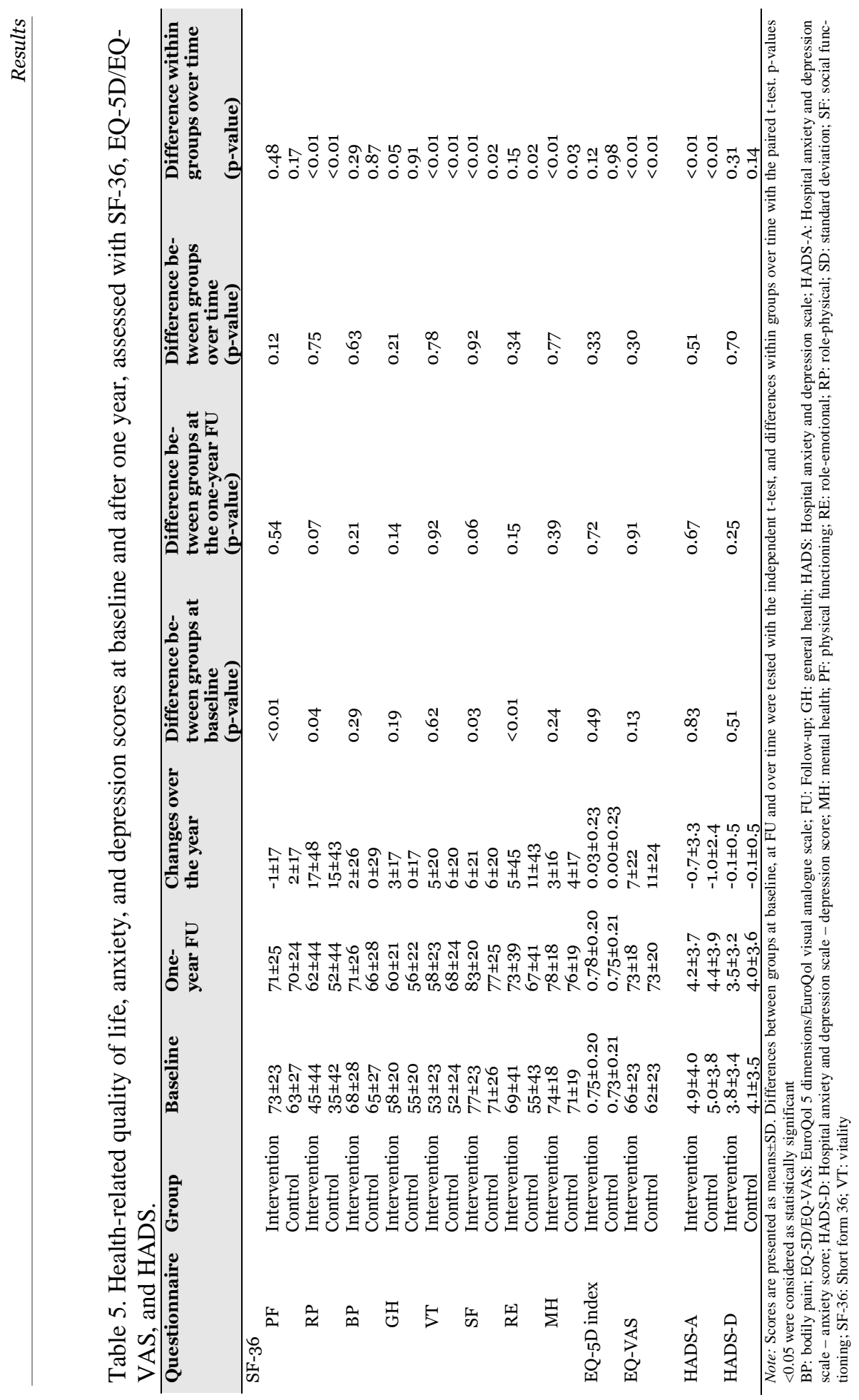




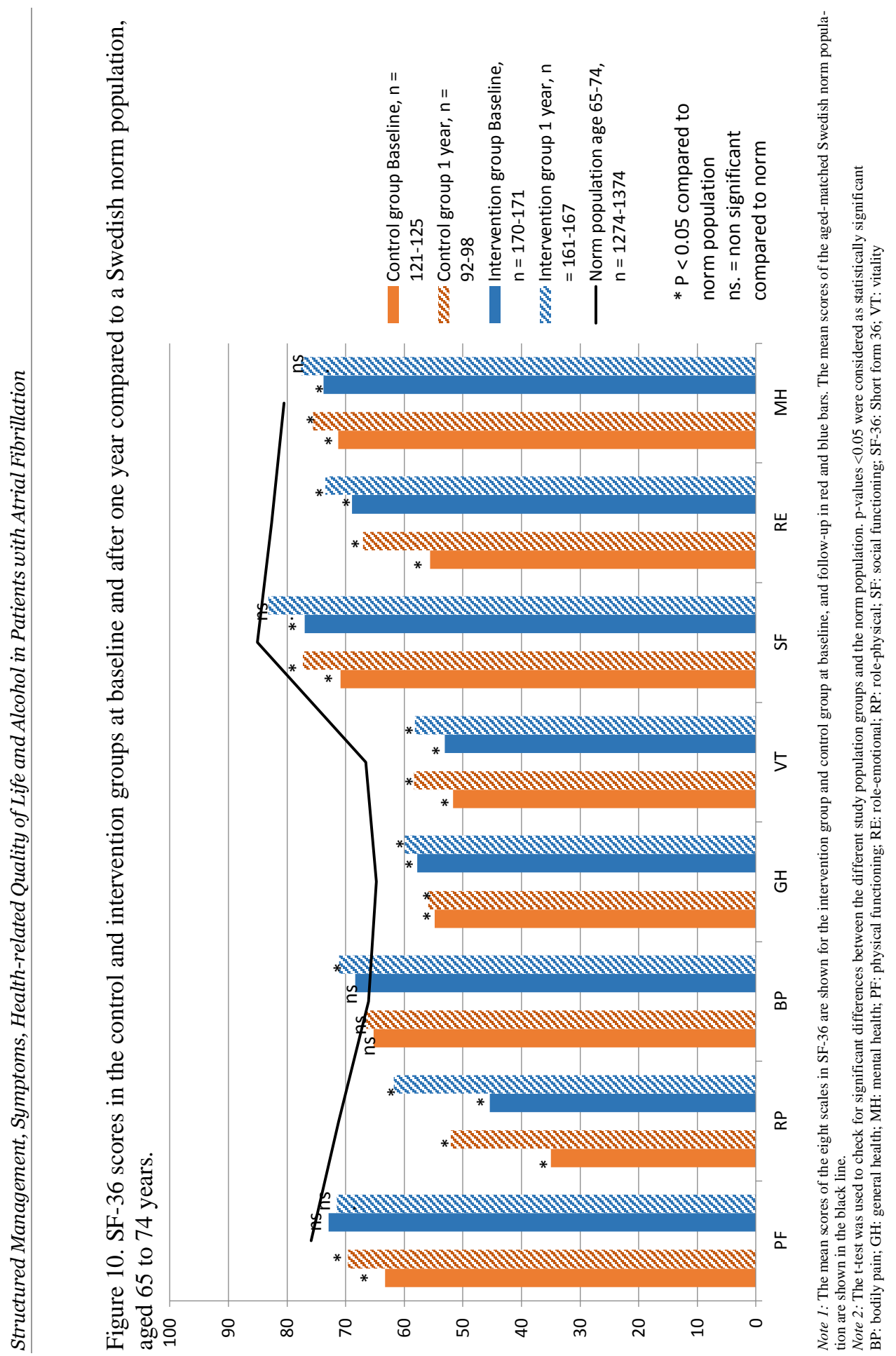




\section{The SMURF Study - Papers II-IV}

\section{Baseline Characteristics}

In total, 338 patients with AF were referred to the Department of Cardiology, Linköping University Hospital, Sweden and were eligible for participation in the study. Of those, 192 patients were included in the study. Any exclusions from the study were primarily due to logistical reasons, since we were only able to include four patients per week (Figure 11). Baseline characteristics are shown in Table 6.

Figure 11. Study inclusion flow chart in the SMURF study

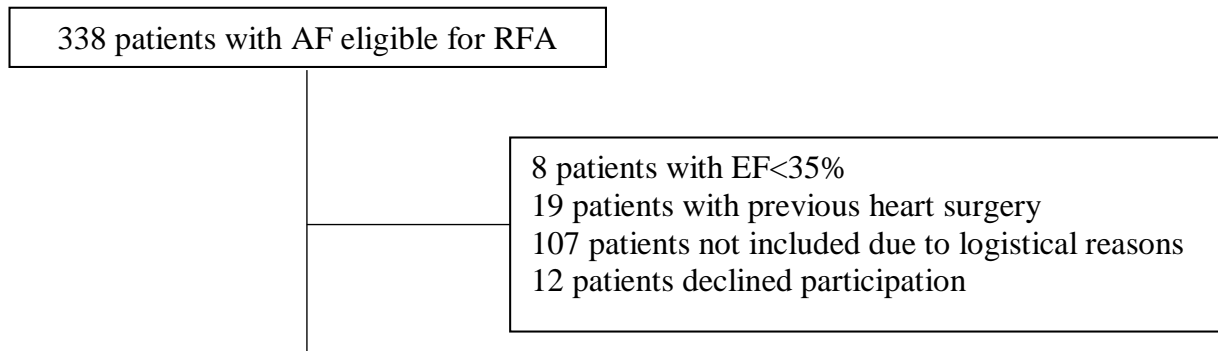

192 patients included in the study

Note: Exclusion for logistical reasons was due to the fact that a maximum of four patients per week could be included. AF: atrial fibrillation; EF: ejection fraction; RFA: radiofrequency catheter ablation 
Table 6. Baseline characteristics in the SMURF study

\begin{tabular}{|c|c|}
\hline Variables & \\
\hline \multicolumn{2}{|l|}{ Characteristics and concomitant diseases } \\
\hline Age & $60.5 \pm 10.2$ \\
\hline Female gender & $56(29 \%)$ \\
\hline Sagittal abdominal diameter $(\mathrm{cm})$ & $24.6 \pm 4.4$ \\
\hline $\operatorname{BMI}\left(\mathrm{kg} / \mathrm{m}^{2}\right)$ & $28.0 \pm 4.2$ \\
\hline Paroxysmal AF & $71(37 \%)$ \\
\hline Longest AF episode $\geq 1 \mathrm{~h}$ & $148(77 \%)$ \\
\hline$>10 \mathrm{AF}$ episodes last month & $78(41 \%)$ \\
\hline Current smokers & $5(3 \%)$ \\
\hline Previous smokers & $93(48 \%)$ \\
\hline Hypertension & $82(43 \%)$ \\
\hline Diabetes mellitus & $16(8 \%)$ \\
\hline Vascular disease & $13(7 \%)$ \\
\hline Heart failure & $18(9 \%)$ \\
\hline CKD $\left(\right.$ GFR $\left.<60 \mathrm{~mL} / \mathrm{min} / 1.73 \mathrm{~m}^{2}\right)$ & $40(21 \%)$ \\
\hline Stroke/TIA & $19(10 \%)$ \\
\hline $\mathrm{CHA}_{2} \mathrm{DS}_{2} \mathrm{VASc}$ & $2(0-3)$ \\
\hline Self-reported alcohol consumption (units/week) & $4(1-9)$ \\
\hline \multicolumn{2}{|l|}{ Anxiety } \\
\hline possible anxiety & $35(18 \%)$ \\
\hline probable anxiety & $20(10 \%)$ \\
\hline \multicolumn{2}{|l|}{ Depression } \\
\hline possible depression & $18(9 \%)$ \\
\hline probable depression & $15(8 \%)$ \\
\hline \multicolumn{2}{|l|}{ Medication } \\
\hline Beta-blockers & $139(72 \%)$ \\
\hline ACEi/ARB & $77(40 \%)$ \\
\hline Statins & $56(29 \%)$ \\
\hline $\mathrm{AAD}$ & $105(55 \%)$ \\
\hline Amiodarone & $42(22 \%)$ \\
\hline Flecainide & $35(18 \%)$ \\
\hline Dronedarone & $23(12 \%)$ \\
\hline \multicolumn{2}{|l|}{ Physical status and laboratory test results } \\
\hline Systolic blood pressure (mmHg) & $146 \pm 20$ \\
\hline Diastolic blood pressure (mmHg) & $90 \pm 11$ \\
\hline AST $(\mu \mathrm{kat} / \mathrm{L})$ & $0.46(0.39-0.52)$ \\
\hline ALT $(\mu$ kat $/ L)$ & $0.46(0.36-0.59)$ \\
\hline GT $(\mu \mathrm{kat} / \mathrm{L})$ & $0.46(0.34-0.74)$ \\
\hline Total cholesterol (mmol/L) & $5.0 \pm 1.2$ \\
\hline $\mathrm{LDL}(\mathrm{mmol} / \mathrm{L})$ & $3.2 \pm 1.0$ \\
\hline $\mathrm{HDL}(\mathrm{mmol} / \mathrm{L})$ & $1.2 \pm 0.34$ \\
\hline hsCRP>3 mg/l & $44(23 \%)$ \\
\hline $\mathrm{TG}(\mathrm{mmol} / \mathrm{L})$ & $1.2 \pm 0.60$ \\
\hline
\end{tabular}


Hair ethyl glucuronide concentration (pg/mg)

$\mathrm{o}(\mathrm{o}-8)$

NT-proBNP (pg/ml)

170 (72-500)

MR-proANP (pmol/l)

135 (92-195)

MR-proADM

$0.68 \pm 0.18$

Procedural variables

$\mathrm{AF}$ at the ablation lab

$51(27 \%)$

Procedural time (min)

$188 \pm 50$

Fluoroscopy time (min)

$21(16-28)$

Number of patients requiring additional ablation

$17(9 \%)$

lines in the LA

Number of patients with an RA isthmus line

Primary successful procedure

$172(90 \%)$

Complications*

AF recurrence within 12 months ${ }^{\dagger}$

$119(62 \%)$

Re-ablation within 12 months

$58(30 \%)$

Echocardiographic measurements and car-

diac pressures

EF (\%)

$56.7 \pm 8.9$

$\operatorname{Max} \mathrm{LAV}(\mathrm{ml})$

$56(46-70)$

Max LAVI $\left(\mathrm{ml} / \mathrm{m}^{2}\right)$

$26.6(22.3-32.5)$

Min LAV (ml)

$30(23-42)$

Min LAVI $\left(\mathrm{ml} / \mathrm{m}^{2}\right)$

$15.0(10.7-20.3)$

RVSP (mmHg)

$30(26-34)$

$\operatorname{RVDP}(\mathrm{mmHg})$

$11(9-15)$

Note: Continuous normally distributed data are presented as means \pm SD and non-normally distributed data as medians with $25^{\text {th }}$ to $75^{\text {th }}$ percentiles within brackets. Categorical data are presented as counts with percent values within brackets.

AAD: anti-arrhythmic drugs; ACEi: angiotensin converting enzyme inhibitor; AF: atrial fibrillation; ARB: angiotensin receptor blocker; ALT: alanine aminotransferase; AST: aspartate aminotransferase; BMI: body mass index $\mathrm{CHA}_{2} \mathrm{DS}_{2} \mathrm{VASc}_{\text {: }}$ congestive heart failure, hypertension, age $\geq 75$, diabetes, stroke/TIA, vascular disease, age 65-74 years, sex category (i.e. female gender); CKD: chronic kidney disease; EF: ejection fraction; GT: glutamyl transferase; h: hour; HDL: high density lipoprotein; hsCRP: highsensitive C-reactive protein; GFR: glomerular filtration rate; LA: left atrium; LAV: left atrial volume; LAVI: left atrial volume index; LDL: low density lipoprotein; MR-proADM: mid-regional portion of pro-adrenomedullin; MR-proANP: mid-regional fragment of the N-terminal precursor of atrial natriuretic peptide; NT-proBNP: N-terminal pro B-type natriuretic peptide; RA: Right atrium; RVDP: right ventricular diastolic pressure; RVSP: right ventricular systolic pressure; SD: standard deviation; TG: triglycerides; TIA: transient ischaemic attack.

*Reported complications were: two cardiac tamponade requiring pericardiocentesis, one pericardial effusion without the need of pericardial drainage, three pseudo aneurysms, one larger than normal hematoma of the groin

$\dagger$ AF recurrence was defined as occurrence of AF or atrial flutter documented with ECG, or re-ablation, within one year from ablation. 


\section{Papers II and IV}

Missing PROMs summary scores varied between 1-19\% for SF-36, 2-20\% for ASTA and 4-18\% for HADS, and were due to not returning the questionnaire or due to missing answers removing the possibility of calculating a summary score.

\section{The Predictors of Arrhythmia-related Symptoms and Health-related Quality of Life}

\section{Arrhythmia-related Symptoms}

Anxiety, low-grade inflammation and LA dilatation significantly predicted arrhythmia-related symptoms at baseline (Table 7).

Female gender and $>10 \mathrm{AF}$ episodes in the last month before RFA were significant positive predictors, while diabetes and AF recurrence were significant negative predictors of improvement in ASTA symptom scale score between baseline and one-year FU (Table 8 and Figure 12).

\section{Health-related Quality of Life}

Anxiety, depression, low-grade inflammation, age, heart failure, MRproADM and AF episode duration significantly predicted arrhythmiarelated HRQoL at baseline, as assessed with the ASTA questionnaire (Table 7). Significant factors predicting PCS at baseline were obesity, RV diastolic pressure, $>10 \mathrm{AF}$ episodes in the last month before treatment, $\mathrm{CHA}_{2} \mathrm{DS}_{2}$-VASc score $\geq 2$, low-grade inflammation and depression (Table 7), while the factors that significantly predicted MCS at baseline were anxiety, depression and longest AF episode duration $\geq 1 \mathrm{~h}$ (Table 7).

More than $10 \mathrm{AF}$ episodes in the last month before treatment and heart failure were significant positive predictors, while diabetes, LAV and $\mathrm{AF}$ recurrence were significant negative predictors of improvement in ASTA HRQoL scale score between baseline and 12 months FU (Table 8 and Figure 12). 
Table 7. Predictors of arrhythmia-related symptoms and health-related quality of life, assessed with ASTA and SF-36, prior to radiofrequency catheter ablation of atrial fibrillation.

\begin{tabular}{|c|c|c|c|c|c|}
\hline Scales & Predictors & $\begin{array}{l}\text { Standardised } \\
\text { beta }\end{array}$ & $\begin{array}{l}\text { Predictor's } \\
p \text {-value }\end{array}$ & $\begin{array}{l}\text { Model's } \\
\mathbf{R}^{2}\end{array}$ & $\begin{array}{l}\text { Model's } \\
p \text {-value }\end{array}$ \\
\hline \multirow{6}{*}{$\begin{array}{l}\text { ASTA symp- } \\
\text { tom scale } \\
\text { score }\end{array}$} & & & & 0.313 & $<0.001$ \\
\hline & Anxiety & & & & \\
\hline & probable anxiety & 0.5 & $<0.001$ & & \\
\hline & possible anxiety & 0.233 & 0.001 & & \\
\hline & $\begin{array}{l}\text { low-grade in- } \\
\text { flammation }\end{array}$ & 0.211 & 0.002 & & \\
\hline & LA dilatation ${ }^{\dagger}$ & 0.141 & 0.033 & & \\
\hline \multirow{12}{*}{$\begin{array}{l}\text { ASTA HRQoL } \\
\text { scale score }\end{array}$} & & & & 0.513 & $<0.001$ \\
\hline & Depression & & & & \\
\hline & probable depression & 0.406 & $<0.001$ & & \\
\hline & possible depression & 0.127 & 0.076 & & \\
\hline & Anxiety & & & & \\
\hline & probable anxiety & 0.343 & $<0.001$ & & \\
\hline & possible anxiety & 0.288 & $<0.001$ & & \\
\hline & Age & 0.227 & 0.001 & & \\
\hline & MR-proADM & -0.218 & 0.004 & & \\
\hline & Heart failure & 0.156 & 0.011 & & \\
\hline & $\begin{array}{l}\text { Low-grade in- } \\
\text { flammation* }\end{array}$ & 0.15 & 0.012 & & \\
\hline & $\begin{array}{l}\text { AF episode dura- } \\
\text { tion } \geq 1 \mathrm{~h}\end{array}$ & 0.131 & 0.026 & & \\
\hline \multirow[t]{9}{*}{ PCS } & & & & 0.359 & $<0.001$ \\
\hline & Obesity $^{\S}$ & -0.301 & $<0.001$ & & \\
\hline & RVDP & 0.244 & 0.001 & & \\
\hline & $\begin{array}{l}>10 \text { AF epi- } \\
\text { sodes } / \text { month }\end{array}$ & -0.233 & 0.001 & & \\
\hline & $\mathrm{CHA}_{2} \mathrm{DS}_{2}-\mathrm{VASc} \geq 2$ & -0.223 & 0.001 & & \\
\hline & $\begin{array}{l}\text { Low-grade in- } \\
\text { flammation* }\end{array}$ & -0.204 & 0.002 & & \\
\hline & Depression & & & & \\
\hline & probable depression & -0.135 & 0.039 & & \\
\hline & possible depression & -0.04 & $0.55^{8}$ & & \\
\hline \multirow[t]{7}{*}{ MCS } & & & & 0.568 & $<0.001$ \\
\hline & Anxiety & & & & \\
\hline & probable anxiety & -0.437 & $<0.001$ & & \\
\hline & possible anxiety & -0.23 & $<0.001$ & & \\
\hline & Depression & & & & \\
\hline & probable depression & -0.256 & $\begin{array}{l}<0.001 \\
<0.001\end{array}$ & & \\
\hline & $\begin{array}{l}\text { AF episode dura- } \\
\text { tion } \geq 1 h\end{array}$ & -0.158 & 0.003 & & \\
\hline
\end{tabular}
Note 1: Multiple linear regression analysis was performed in order to determine possible predictors of variation in patients' symp-
toms and HRQoL. The models were fit by an enter method where all variables were entered into the original model and then variables with p-values over 0.05 were removed.

Note 2: Anxiety and depression were assessed with the HADS questionnaire

Note 3: The ASTA symptom scale score was used as a dependent variable in order to express symptom variation. The diseasespecific ASTA HRQoL and the generic SF-36 component summaries (PCS and MCS) were used in order to express the variation in HRQoL.

Note 4: All reported p-values are two-sided and a p-value $<0.05$ was considered statistically significant.

AF: atrial fibrillation; ASTA: Arrhythmia-Specific questionnaire in Tachycardia and Arrhythmia; $\mathrm{CHA}_{2} \mathrm{DS}_{2}-\mathrm{VASc}_{\mathrm{S}}$ congestive heart failure, hypertension, age $\geq 75$, diabetes, stroke/TIA, vascular disease, sex category (i.e. female gender); EF: ejection fraction; HADS: Hospital Anxiety and Depression Scale; h: hour; LA: left atrium; LAV; left atrial volume; MCS: mental component summary; MR-proADM: mid-regional portion of pro-adrenomedullin; PCS: physical component summary; RVDP: right ventricular diastolic pressure; SF-36: 36-Item Short Form Health Survey.

* Low-grade inflammation was defined as high sensitive C-reactive protein $>3 \mathrm{mg} / 1$

$\dagger$ LA dilatation was defined as LAV $>35 \mathrm{ml} / \mathrm{m}^{2}$

HF was defined as ejection fraction $<45 \%$

§obesity was defined as Body Mass Index $>30 \mathrm{~kg} / \mathrm{m}^{2}$ 


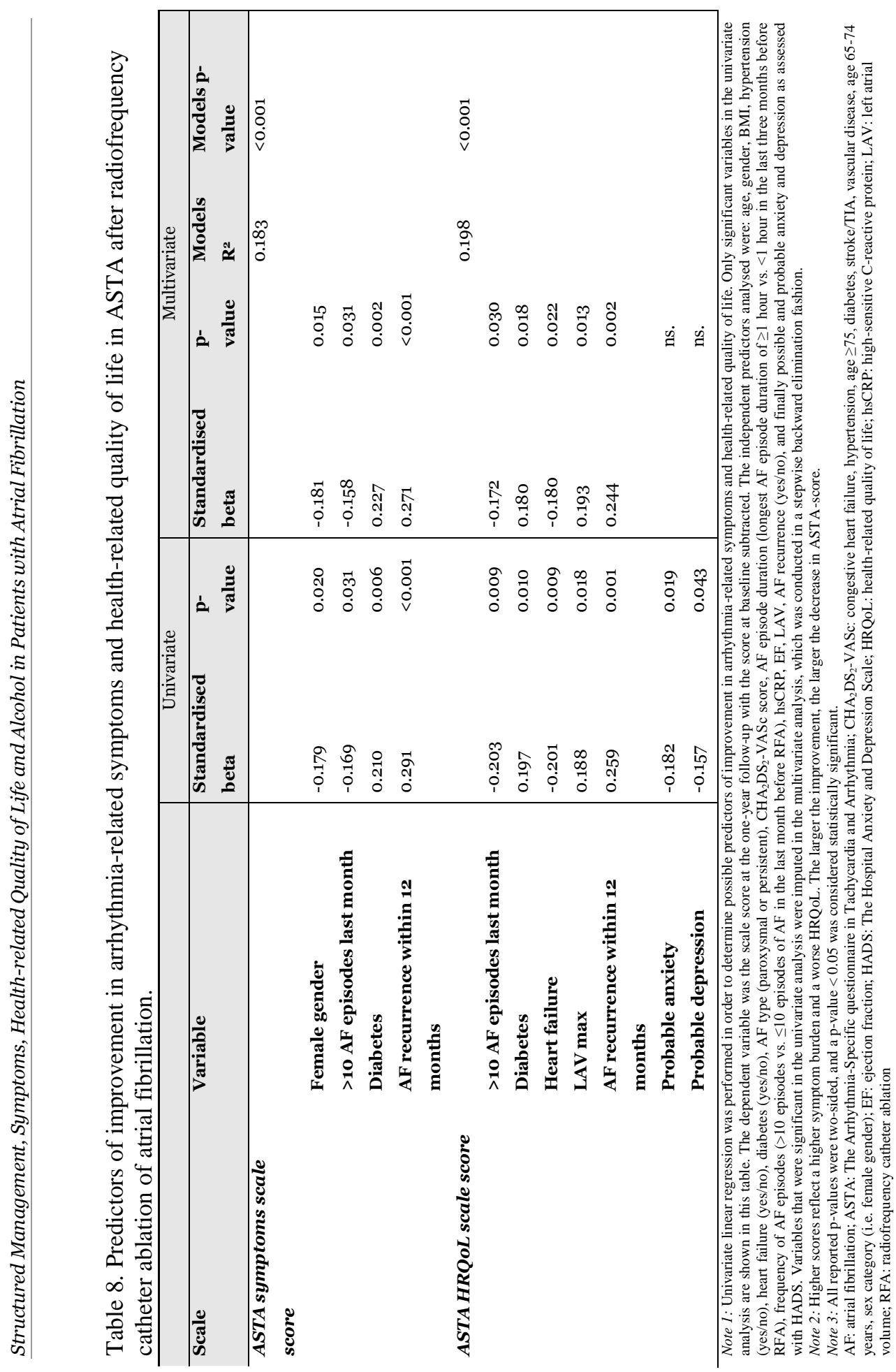

in 


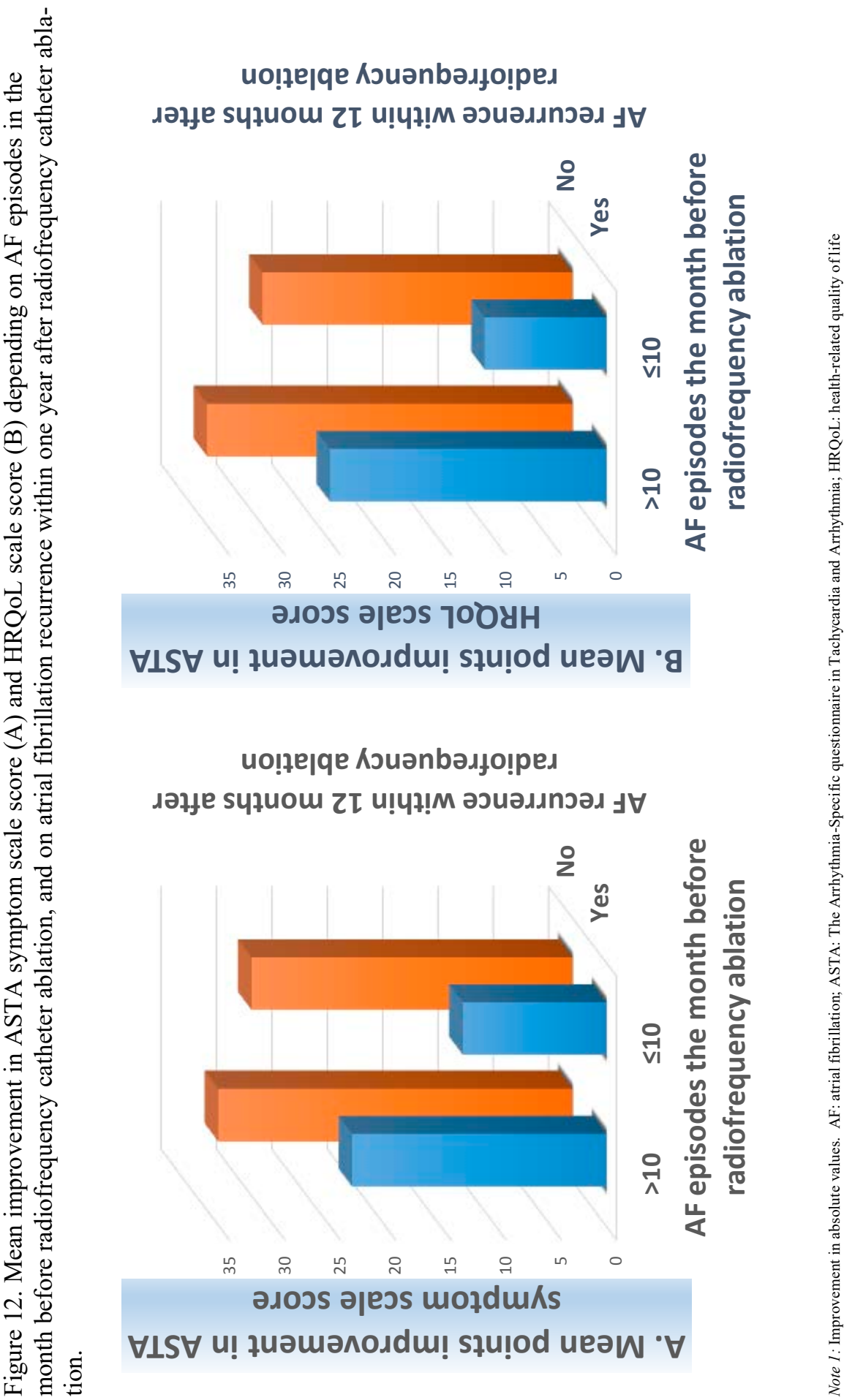




\section{The Effect of Radiofrequency Catheter Ablation on Patient-reported Outcome Measures}

\section{Arrhythmia-related Symptoms}

At baseline, in those patients with ASTA questionnaires available, 135 (71\%) had experienced their latest AF episode within the last month prior to RFA. During an AF episode, 126 (66\%) patients reported the heart beating fast, $151(79 \%)$ reported irregular heartbeat, 90 (47\%) reported harder heart beats than usual and 105 (55\%) had felt one or more missed heart beats. The most commonly reported symptoms were breathlessness during activity and tiredness, while the least frequently reported symptom was chest pain (Figure 13).

After one year, in those patients that completed the ASTA questionnaire, 83 (47\%) were asymptomatic and the number that had experienced their latest AF episode within the last month had decreased significantly to $74(42 \%, p$ < 0.001$)$. Each item in the ASTA symptom scale improved significantly over time (Figure 13), and there was a significant improvement in the ASTA scale score with large ES (Table 9).

\section{Health-related Quality of Life}

The most commonly reported affected arrhythmia-specific HRQoL domains, as assessed with ASTA, were impaired physical activity, deteriorated life situation, avoiding planning things one would have liked to do, and feeling unable to work, study or carry out daily activities (Figure 14). All individual items in the ASTA HRQoL part, as well as the ASTA HRQoL scale score, improved significantly over time, the latter with large ES (Table 9, Figure 15).

The subscales in general HRQoL with the lowest scores at baseline, as assessed with SF-36, were RP and VT (Table 9). Each subscale in SF-36 improved significantly over time, as did the MCS and PCS, with small ES (Table 9, Figure 15).

\section{Anxiety and Depression}

The baseline HADS scores indicated normal levels of anxiety and depression (Table 9). Still, 55 (29\%) and 33 (17\%) patients had possible or probable anxiety and depression, respectively (Table 6). Both anxiety and depression scores improved significantly over time with trivial or small ES (Table 9). 


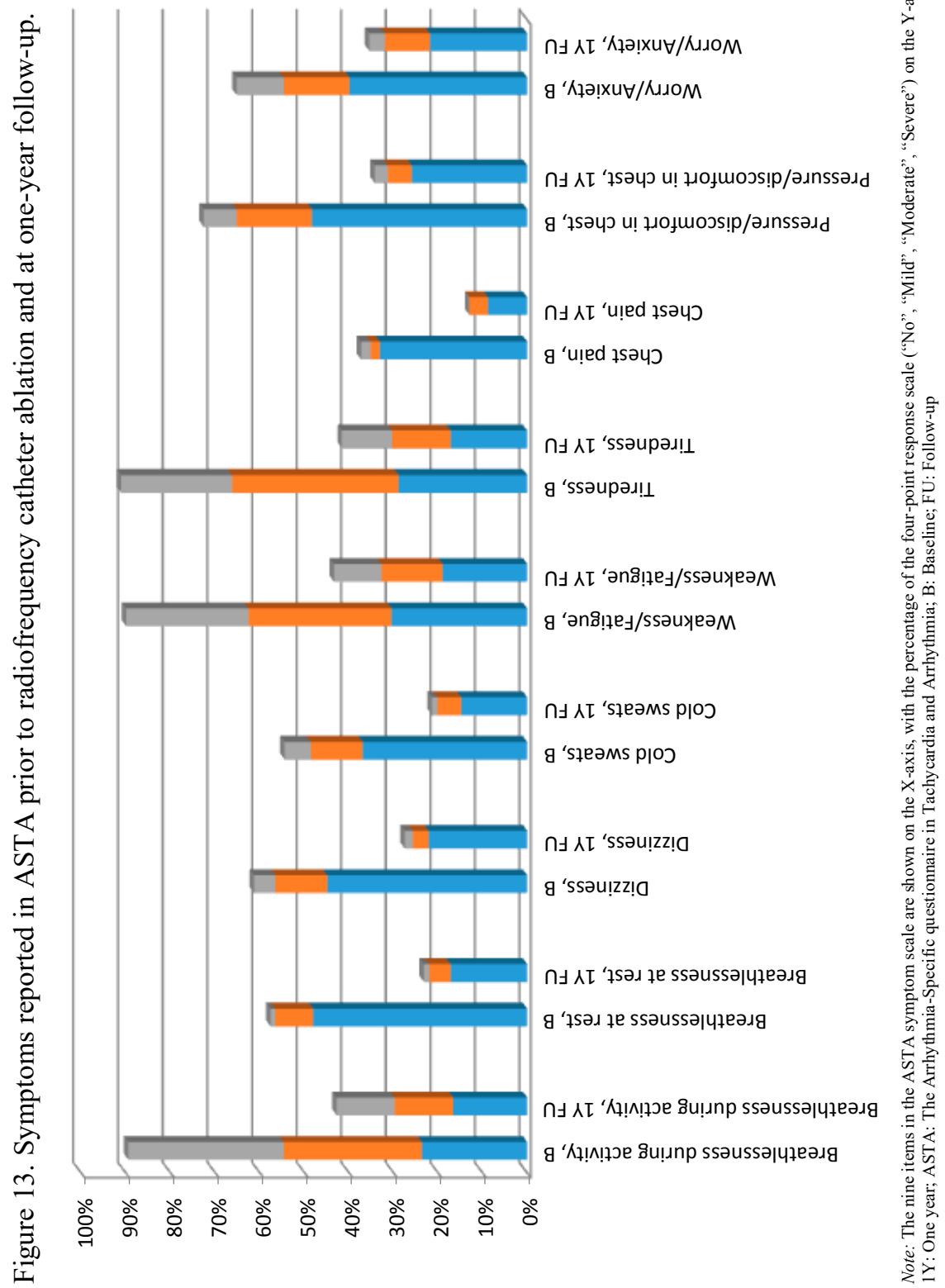



with Atrial Fibrillation

Table 9. ASTA, SF-36, and HADS questionnaire summary scores at baseline, four-month and one-year follow-up.

\begin{tabular}{|c|c|c|c|c|c|c|c|}
\hline \multirow{2}{*}{ ASTA } & \multirow[t]{2}{*}{ B } & \multirow[t]{2}{*}{ 4M FU } & \multirow[t]{2}{*}{ 1Y FU } & \multirow[t]{2}{*}{$\begin{array}{c}\text { ES from } \\
\text { B to 1Y } \\
\text { FU }\end{array}$} & \multirow{2}{*}{$\begin{array}{c}\begin{array}{c}\text { Fried- } \\
\text { man's } \\
\text { test }\end{array} \\
\text { p-value }\end{array}$} & \multicolumn{2}{|c|}{$\begin{array}{c}\text { Pairwise } \\
\text { comparisons }\end{array}$} \\
\hline & & & & & & Time & p-value \\
\hline \multirow{2}{*}{$\begin{array}{l}\text { Symptom } \\
\text { scale score }\end{array}$} & \multirow{2}{*}{$\begin{array}{c}37 \\
(26-50)\end{array}$} & \multirow{2}{*}{$\begin{array}{c}11 \\
(0-33)\end{array}$} & \multirow{2}{*}{$\begin{array}{c}4 \\
(0-30)\end{array}$} & \multirow{2}{*}{-1.20} & \multirow{2}{*}{$<0.001$} & B-4M & $<0.001$ \\
\hline & & & & & & B-1Y & $<0.001$ \\
\hline \multirow{3}{*}{$\begin{array}{l}\text { HRQoL } \\
\text { scale score }\end{array}$} & \multirow{3}{*}{$\begin{array}{c}36 \\
(21-49)\end{array}$} & \multirow{3}{*}{$\begin{array}{c}10 \\
(0-31)\end{array}$} & \multirow{3}{*}{$\begin{array}{c}0 \\
(0-28)\end{array}$} & \multirow[t]{3}{*}{-1.00} & \multirow[t]{3}{*}{$<0.001$} & B-4M & $<0.001$ \\
\hline & & & & & & B-1Y & $<0.001$ \\
\hline & & & & & & $4 \mathrm{M}-1 \mathrm{Y}$ & 0.117 \\
\hline \multicolumn{8}{|l|}{ SF-36 } \\
\hline \multirow[t]{3}{*}{$P F$} & \multirow{3}{*}{$\begin{array}{c}75 \\
(55-90)\end{array}$} & \multirow{3}{*}{$\begin{array}{c}85 \\
(65-95)\end{array}$} & & 0.43 & $<0.001$ & B-4M & $<0.001$ \\
\hline & & & $(70-95)$ & & & B-1Y & $<0.001$ \\
\hline & & & & & & $4 \mathrm{M}-1 \mathrm{Y}$ & 0.103 \\
\hline$R P$ & 50 & 75 & 100 & 0.43 & $<0.001$ & B-4M & 0.013 \\
\hline & $(0-100)$ & $\left(25^{-100}\right)$ & $(25-100)$ & & & B-1Y & $<0.001$ \\
\hline & & & & & & $4 \mathrm{M}-1 \mathrm{Y}$ & 0.069 \\
\hline$B P$ & 74 & 74 & 80 & 0.16 & 0.018 & B-4M & 0.248 \\
\hline & $(41-100)$ & $(51-100)$ & $\left(5^{2-100}\right)$ & & & B-1Y & 0.040 \\
\hline & & & & & & $4 \mathrm{M}-1 \mathrm{Y}$ & 0.204 \\
\hline$G H$ & 60 & 67 & & 0.22 & 0.020 & B-4M & 0.108 \\
\hline & $(45-77)$ & $(47-82)$ & $(47-82)$ & & & B-1Y & 0.001 \\
\hline & & & & & & $4 \mathrm{M}-1 \mathrm{Y}$ & 0.119 \\
\hline$V T$ & 50 & 65 & 60 & 0.40 & $<0.001$ & B-4M & $<0.001$ \\
\hline & $(30-70)$ & $\left(45^{-80}\right)$ & $(40-85)$ & & & B-1Y & $<0.001$ \\
\hline & & & & & & $4 \mathrm{M}-1 \mathrm{Y}$ & 0.574 \\
\hline$S F$ & 75 & 100 & 100 & 0.20 & 0.021 & B-4M & 0.005 \\
\hline & $(63-100)$ & $(75-100)$ & $(63-100)$ & & & B-1Y & 0.008 \\
\hline & & & & & & $4 \mathrm{M}-1 \mathrm{Y}$ & 0.273 \\
\hline$R E$ & 100 & 100 & 100 & 0.31 & 0.028 & B-4M & 0.005 \\
\hline & $(33-100)$ & $(67-100)$ & $(67-100)$ & & & B-1Y & 0.001 \\
\hline & & & & & & $4 \mathrm{M}-1 \mathrm{Y}$ & 0.636 \\
\hline$M H$ & 76 & 84 & 84 & 0.25 & $<0.001$ & B-4M & $<0.001$ \\
\hline & $(60-88)$ & $(76-92)$ & $(68-92)$ & & & B-1Y & $<0.001$ \\
\hline & & & & & & $4 \mathrm{M}-1 \mathrm{Y}$ & 0.332 \\
\hline PCS & 41 & & 48 & 0.39 & $<0.001$ & B-4M & 0.006 \\
\hline & $(34-50)$ & $(37-52)$ & $(39-54)$ & & & B-1Y & $<0.001$ \\
\hline & & & & & & $4 \mathrm{M}-1 \mathrm{Y}$ & 0.006 \\
\hline$M C S$ & 48 & & 53 & 0.28 & 0.006 & B-4M & 0.001 \\
\hline & $(37-55)$ & $(44-57)$ & $(43-56)$ & & & B-1Y & 0.002 \\
\hline & & & & & & $4 \mathrm{M}-1 \mathrm{Y}$ & 0.640 \\
\hline HADS & & & & & & & \\
\hline Anxiety & $5(2-8)$ & $3(1-6)$ & $3(1-7)$ & 0.24 & $<0.001$ & B-4M & 0.001 \\
\hline scale & & & & & & B-1Y & $<0.001$ \\
\hline Depres- & $3(1-6)$ & $2(1-5)$ & $2(1-6)$ & 0.18 & $<0.001$ & B-4M & $\begin{array}{l}0 . / 43 \\
0.002\end{array}$ \\
\hline sion scale & & & & & & B-1Y & 0.001 \\
\hline & & & & & & $4 \mathrm{M}-1 \mathrm{Y}$ & 0.819 \\
\hline
\end{tabular}

Note 1: Summary scores are presented as medians $\left(25^{\text {th }}-75^{\text {th }}\right.$ percentiles $)$.

Note 2: ASTA and SF-36 scores range from 0 to 100 and HADS from 0-21. In SF-36, a higher score reflects better health status while the opposite is the case in ASTA and HADS.

Note 3: Analysis of the change throughout the three measurement points was performed with Friedman's test. In order to analyse between which time points there was a significant change, Wilcoxon's signed rank test was used. A p-value $<0.05$ was considered statistically significant.

Note 4: ES was calculated by dividing the mean difference between baseline and one-year follow-up by the SD at baseline. A result $<0.20$ denotes trivial, 0.20-0.49 small, 0.50-0.79 moderate and $>0.80$ large ES.

1Y: One year; 4M: Four months; ASTA: The Arrhythmia-Specific questionnaire in Tachycardia and Arrhythmia; B: Baseline; BP: bodily pain; ES: Effect size; FU: Follow-up; GH: general health; HADS: Hospital anxiety and depression scale; HRQoL: Healthrelated quality of life; MCS: Mental component summary; MH: mental health; PCS: Physical component summary; PF: physica functioning; RE: role-emotional; RP: role-physical; SF: social functioning; SF-36: Short form 36; VT: vitality 


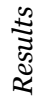

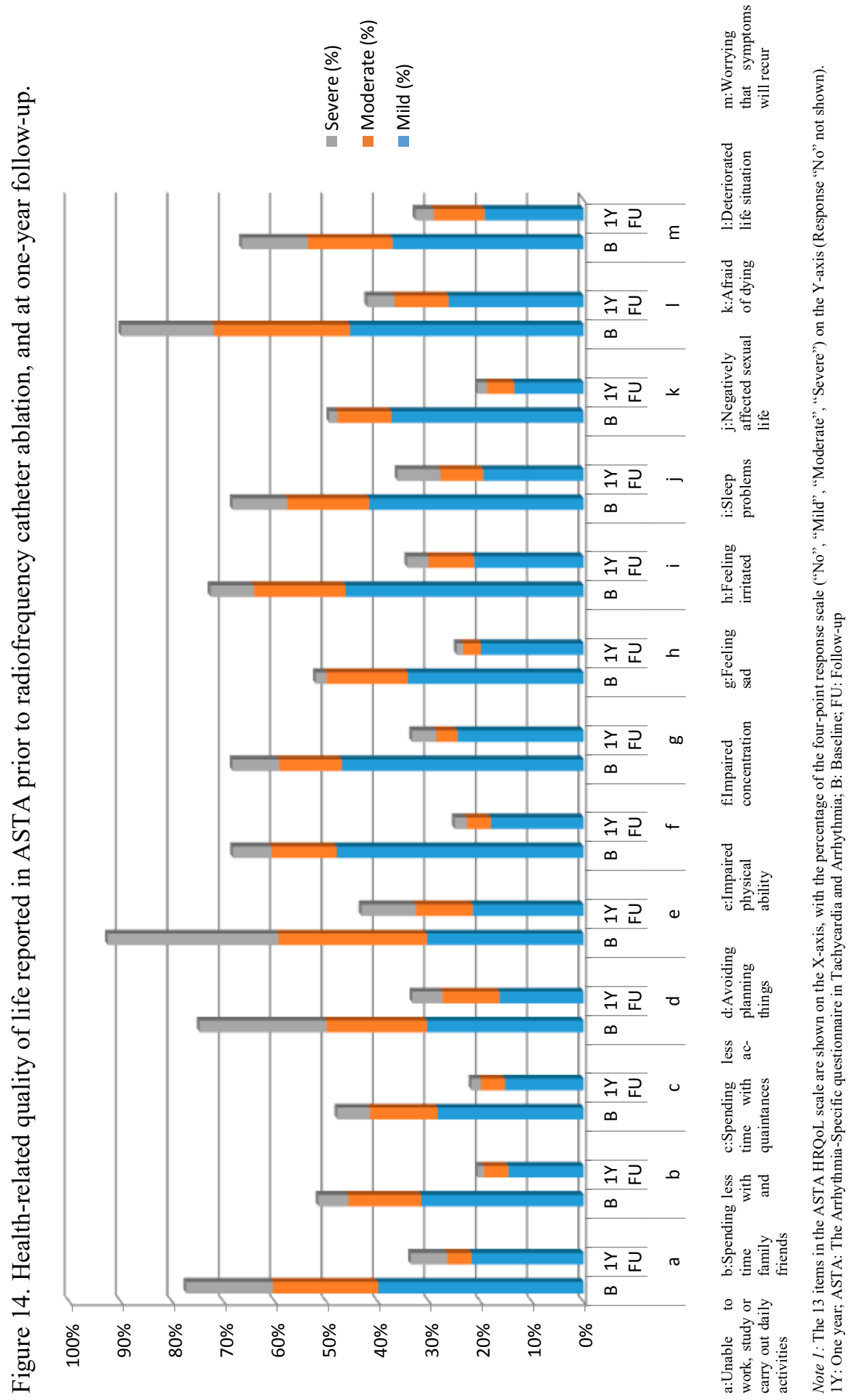




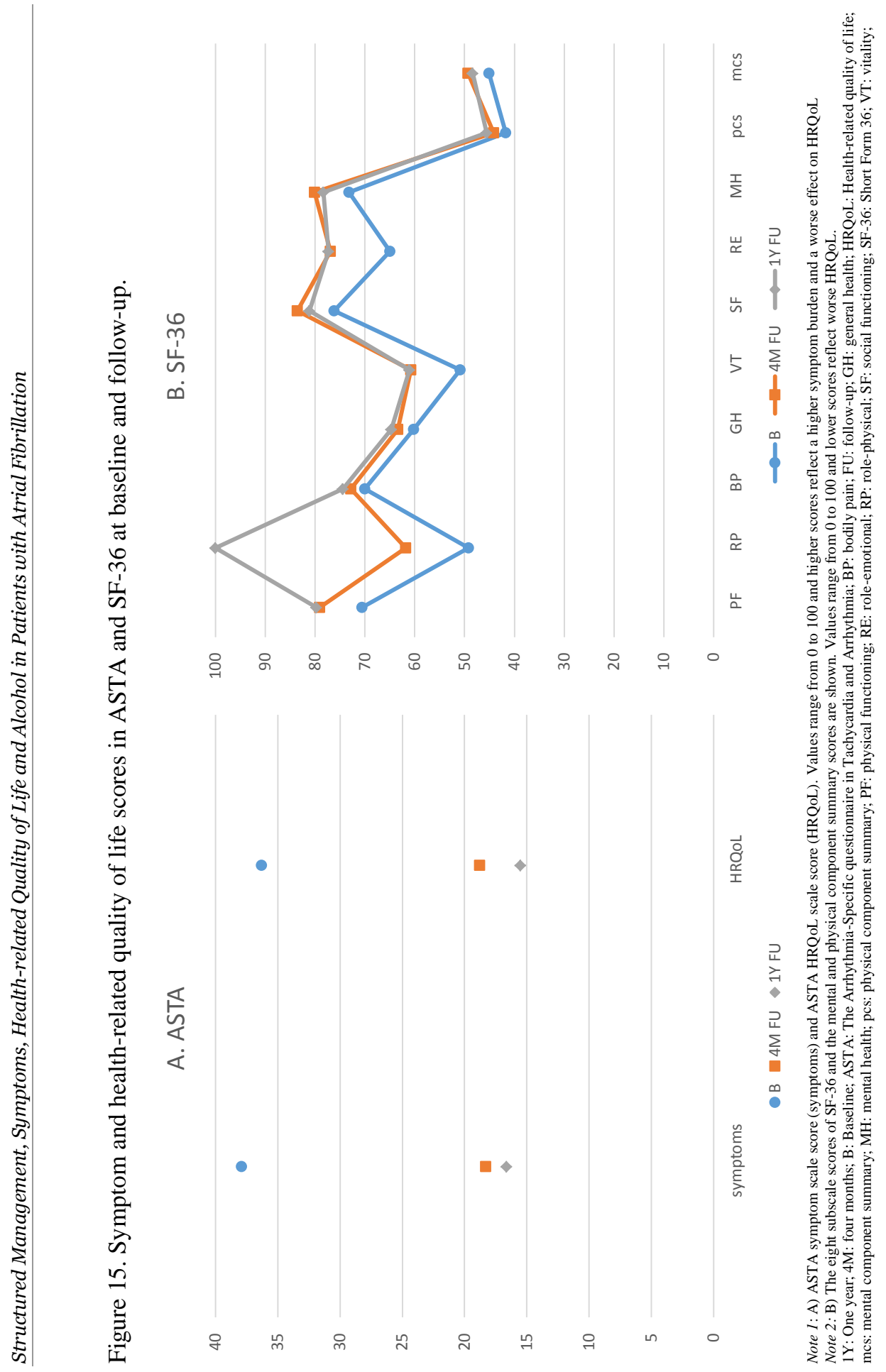




\section{Paper III and the Association of Alcohol Con- sumption with Symptoms and Health-related Quality of Life}

\section{Alcohol Consumption}

Information on self-reported alcohol consumption was available for 181 (94\%) patients and hEtG was analysable in 156 (81\%) patients. Of those with non-analysable hEtG, one was a woman whose sample analysis failed for technical reasons, while the other 35 patients were men whose hair was too short to take a sample (Table 10). The group with non-analysable hEtG had lower HDL and $\mathrm{CHA}_{2} \mathrm{DS}_{2}$-VASc scores (Table 10), which was probably gender-related since adjustment for gender showed that analysable hEtG was not correlated to HDL $(\mathrm{p}=0.438$, model: $\mathrm{R} 2=0.208, \mathrm{~F}=$ 24.759, $\mathrm{p}<0.001)$, nor to $\mathrm{CHA}_{2} \mathrm{DS}_{2}$-VASc score $(\mathrm{p}=0.749$, model: $\mathrm{R} 2=$ $0.179, \mathrm{~F}=20.658, \mathrm{p}<0.001)$, but gender was $(\mathrm{p}<0.001$ for both HDL and $\mathrm{CHA}_{2} \mathrm{DS}_{2}$-VASc scores). Men were younger, had a larger sagittal abdominal diameter, higher alanine aminotransferase (ALT), aspartate aminotransferase (AST), glutamyl transferase (GT), and triglycerides (TG), as well as lower HDL, and $\mathrm{CHA}_{2} \mathrm{DS}_{2}$-VASc scores than women (Table 10). Analyses regarding the predictive role of gender and sagittal abdominal diameter on HDL showed that sagittal abdominal diameter (inversely related, $\mathrm{p}<0.001)$ and gender $(\mathrm{p}<0.001)$, but not the use of statins ( $\mathrm{p}=0.349$ ), were related to HDL (model R2 $=0.266, \mathrm{~F}=22.243$, $\mathrm{p}$ $<0.001)$. There was a statistically significant correlation between selfreported alcohol consumption and $\mathrm{hEtG}(\mathrm{r}=0.63, \mathrm{p}<0.001)$.

\section{Associations between Alcohol Consumption, Cardi- ac Biomarkers, Left Atrial Size, Re-ablation, Symp- toms and Health-related Quality of Life}

\section{Ethyl Glucuronide in Hair}

Of those patients with analysable hEtG, 88 (56\%) had a value of o pg/mg, and nine $(6 \%)$ patients had a value strongly indicating chronic excessive alcohol consumption, i.e. $\geq 30 / \mathrm{mg}$. Forty-three (28\%) patients had values indicative of repeated alcohol consumption, providing evidence to refute a claim of abstinence, i.e. $\geq 7 \mathrm{pg} / \mathrm{mg}$, while the remaining 113 (72\%) had values below this level.

Patients with $\mathrm{hEtG} \geq 7 \mathrm{pg} / \mathrm{mg}$ were more likely to be previous smokers, and had larger sagittal abdominal diameter and higher GT levels compared to the group with hEtG $<7 \mathrm{pg} / \mathrm{mg}$ (Table 10). NT-proBNP, ad- 
justed MRpro-ANP, maximum and minimum LAVI were significantly higher in men with hEtG $\geq 7 \mathrm{pg} / \mathrm{mg}$ as compared to men with hEtG $<7$ $\mathrm{pg} / \mathrm{mg}$, while there were no such findings for women (Table 11 and Figure 16).

Re-ablation was performed in 58 (30\%) patients. The frequency of reablation in patients with $\mathrm{hEtG} \geq 7 \mathrm{pg} / \mathrm{mg}$ vs. $<7 \mathrm{pg} / \mathrm{mg}$ was 14 (42\%) vs. $16(24 \%, \mathrm{p}=0.051)$ in men, and $3(30 \%)$ vs. $13(29 \%, \mathrm{p}=0.944)$ in women. Adjusted analysis showed a significant correlation between hEtG and re-ablation in men (OR 3.5; 95\% confidence interval (CI) 1.3-9.6; p = 0.017) but not in women (OR 0.60; 95\% CI 0.1-3.1; p = 0.541).

There were no significant differences in ASTA symptom and HRQoL scale scores between men with $\mathrm{hEtG} \geq 7 \mathrm{pg} / \mathrm{mg}$ vs. $<7 \mathrm{pg} / \mathrm{mg}$, either at baseline, or at the one-year FU (Table 12). In men, both groups improved significantly between baseline and FU in both scale scores (Table 12).

While there were no significant differences at baseline in ASTA symptom scale score between women with $\mathrm{hEtG} \geq 7 \mathrm{pg} / \mathrm{mg}$ vs. $<7 \mathrm{pg} / \mathrm{mg}$, ASTA HRQoL scale score was significantly better in women with hEtG $\geq 7 \mathrm{pg} / \mathrm{mg}$ vs. $<7 \mathrm{pg} / \mathrm{mg}$ (Table 12). Women with hEtG $<7 \mathrm{pg} / \mathrm{mg}$ improved significantly between baseline and the one-year FU in both scores while women with hEtG $\geq 7 \mathrm{pg} / \mathrm{mg}$ improved in ASTA symptom scale score but not ASTA HRQoL scale score (Table 12). Neither score differed significantly between women with $\mathrm{hEtG} \geq 7 \mathrm{pg} / \mathrm{mg}$ vs. $<7 \mathrm{pg} / \mathrm{mg}$, at FU.

\section{Self-reported Alcohol Consumption}

Median self-reported alcohol consumption was four (1-9) units/week, with 22 (12\%) patients reporting a high consumption. Men reported a higher intake than women (Table 10).

Patients with self-reported high alcohol consumption were more likely to be previous smokers but no other significant differences were observed in baseline characteristics, cardiac biomarkers, echocardiographic measurements (Table 10 and Table 13) or in the frequency of re-ablation (crude analysis, high vs. low consumption, men: 7 (47\%) vs. 32 (29\%), p = o.161; women: 2 (29\%) vs. 14 ( $29 \%), p=0.974$; adjusted analysis, men: OR 2.7; 95\% CI o.8-8.9, p = 0.09; women: OR 1.3; 95\% CI 0.2-10.0, $\mathrm{p}=$ 0.77).

There were no significant differences at baseline in either ASTA score in either gender (Table 14). Although all groups improved significantly between baseline and FU, the improvement was less pronounced in men with high consumption, who scored significantly worse in both scores at FU compared to men with low consumption (Table 14). 


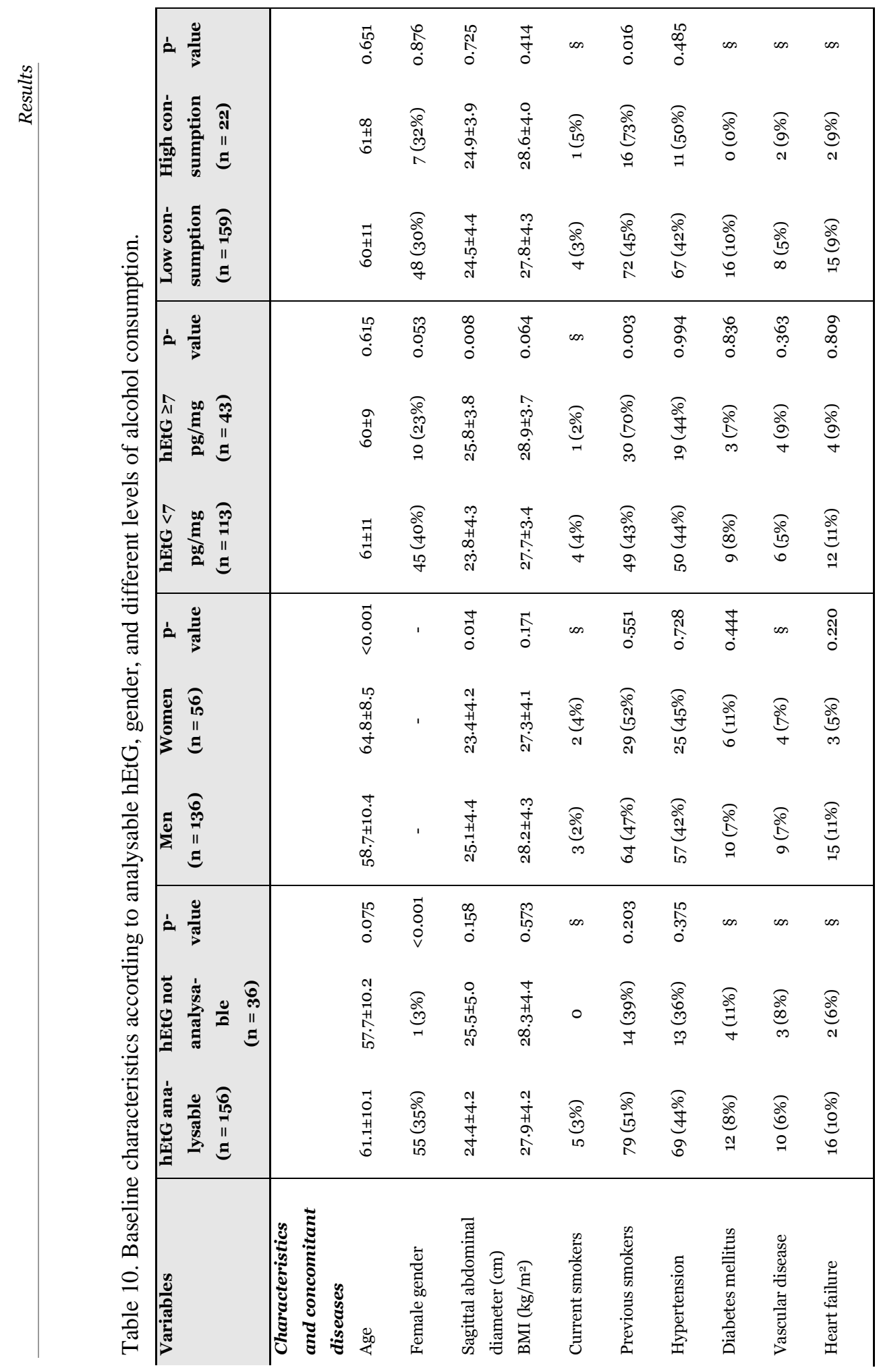




\begin{tabular}{|c|c|c|c|c|c|c|c|c|c|c|c|c|c|c|}
\hline $\cos$ & స్ & $\begin{array}{l}\hat{a} \\
\text { ஸे }\end{array}$ & $\begin{array}{l}\infty \\
\stackrel{\infty}{0} \\
0\end{array}$ & $\stackrel{\overrightarrow{+}}{\stackrel{+}{0}}$ & & 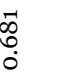 & $\begin{array}{l}\stackrel{R}{0} \\
\stackrel{0}{0} \\
0\end{array}$ & . & 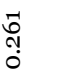 & $\begin{array}{l}\text { m. } \\
\stackrel{0}{0}\end{array}$ & $\begin{array}{l}\infty \\
\stackrel{1}{+} \\
0 \\
0\end{array}$ & $\begin{array}{l}\stackrel{0}{\infty} \\
\stackrel{+}{+} \\
0\end{array}$ & \multicolumn{2}{|l|}{\begin{tabular}{l}
\multirow{2}{0}{} \\
to \\
0
\end{tabular}} \\
\hline 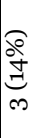 & $\underset{\forall}{\stackrel{d}{\infty}}$ & $\underbrace{\overparen{P}}_{N}$ & $\begin{array}{l}\text { N } \\
\text { H } \\
\text { N }\end{array}$ & $\begin{array}{l}7 \\
\text { 落 }\end{array}$ & & 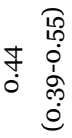 & ఫ̛̣ & $\begin{array}{l}\text { â } \\
0 \\
\dot{1} \\
+ \\
0 \\
0 \\
0\end{array}$ & 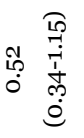 & 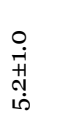 & 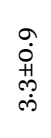 & $\begin{array}{l}m \\
\stackrel{0}{0} \\
\text { m } \\
\text { m }\end{array}$ & $\begin{array}{l}0 \\
\dot{0} \\
\ddot{H} \\
\dddot{m} \\
\text { - }\end{array}$ & \\
\hline 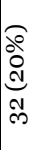 & 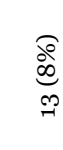 & $\underbrace{\text { ç }}_{\text {है }}$ & $\begin{array}{l}\infty \\
\text { H } \\
\stackrel{N}{N} \\
\end{array}$ & $\frac{N}{\frac{N}{N}}$ & & 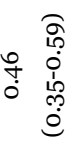 & $\stackrel{0}{+}$ & $\begin{array}{l}\text { â } \\
1 ? \\
0 \\
1 \\
10 \\
0 \\
0 \\
0\end{array}$ & 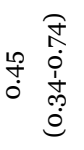 & 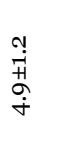 & $\begin{array}{l}\text { r. } \\
\text { in } \\
\text { ñ }\end{array}$ & 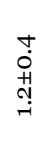 & 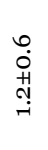 & \\
\hline 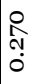 & $\begin{array}{l}0 \\
\stackrel{m}{0} \\
\dot{0}\end{array}$ & $\begin{array}{l}\text { जै } \\
\text { to } \\
0\end{array}$ & $\begin{array}{l}\infty \\
\infty \\
\stackrel{0}{0} \\
\dot{0}\end{array}$ & 字 & & 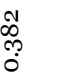 & $\begin{array}{l}\stackrel{0}{0} \\
\text { ọ }\end{array}$ & & $\begin{array}{l}\ddot{\vdots} \\
\stackrel{0}{0} \\
\dot{\dot{v}}\end{array}$ & $\begin{array}{l}\stackrel{L}{\Upsilon} \\
\stackrel{0}{0}\end{array}$ & $\underset{8}{\stackrel{\infty}{f}}$ & $\begin{array}{l}0 \\
i n \\
L \\
0 \\
0\end{array}$ & $\begin{array}{l}\overrightarrow{7} \\
0\end{array}$ & \\
\hline 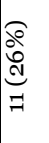 & $\underset{\sigma}{\stackrel{ఠ}{0}}$ & $\underbrace{\Phi}_{-1}$ & $\begin{array}{l}\text { I } \\
\text { H } \\
\text { O } \\
\text { T }\end{array}$ & $\begin{array}{l}\text { } \\
\text { a }\end{array}$ & & 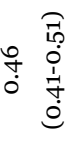 & $\stackrel{5}{\circ}$ & $\begin{array}{l}\text { î } \\
\stackrel{0}{0} \\
1 \\
\hat{1} \\
0 \\
0\end{array}$ & 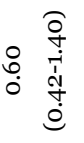 & $\begin{array}{l}\vec{j} \\
\overrightarrow{\dot{H}} \\
\stackrel{+}{\dot{\sigma}}\end{array}$ & $\begin{array}{l}\dot{+} \\
\dot{+} \\
\dot{H} \\
\dot{m}\end{array}$ & $\begin{array}{l}\stackrel{+}{0} \\
\stackrel{+}{+} \\
\stackrel{+}{+}\end{array}$ & 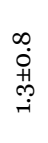 & \\
\hline 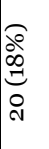 & $\begin{array}{l}\text { } \\
\stackrel{0}{\circ} \\
0\end{array}$ & $\underbrace{\overparen{P}}_{N}$ & $\begin{array}{l}\text { I } \\
\text { H } \\
\text { J } \\
\text { T. }\end{array}$ & $\begin{array}{l}\text { ज̃ } \\
\text { 명 }\end{array}$ & & 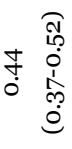 & ্ְ? & 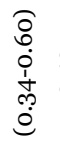 & 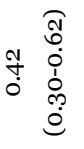 & 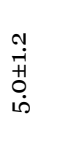 & 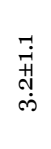 & 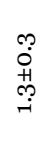 & $\begin{array}{l}\text { L } \\
0 \\
+1 \\
ت 1\end{array}$ & \\
\hline 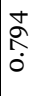 & \begin{tabular}{l}
$\infty$ \\
\multirow{\Upsilon}{*}{} \\
0
\end{tabular} & $\begin{array}{l}\overrightarrow{0} \\
\dot{0} \\
\dot{\theta}\end{array}$ & $\begin{array}{l}\text { त̃ } \\
ٍ \\
0\end{array}$ & 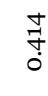 & & $\begin{array}{l}\text { Na } \\
\vdots \\
0\end{array}$ & $\begin{array}{l}\vec{\delta} \\
\dot{0} \\
\dot{v}\end{array}$ & & $\begin{array}{l}\text { ปे } \\
\vdots \\
0 \\
0\end{array}$ & $\begin{array}{l}\infty \\
\infty \\
\text { ஸे } \\
\stackrel{0}{0}\end{array}$ & $\begin{array}{l}\infty \\
\stackrel{0}{0} \\
\dot{0}\end{array}$ & $\begin{array}{l}\tilde{O} \\
\dot{0} \\
\dot{v}\end{array}$ & $\begin{array}{l}\stackrel{0}{0} \\
\stackrel{0}{0}\end{array}$ & \\
\hline 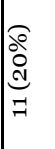 & 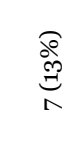 & 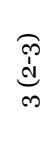 & $\begin{array}{l}\text { Ñ } \\
\text { Hै } \\
\text { 导 }\end{array}$ & $\begin{array}{l}7 \\
\text { 莕 } \\
\infty\end{array}$ & & 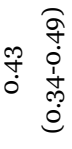 & ๙ิ & $\begin{array}{l}\text { है } \\
0 \\
0 \\
0 \\
0 \\
0 \\
0\end{array}$ & 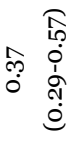 & 节 & $\begin{array}{l}\overrightarrow{7} \\
\text { H } \\
\text { N } \\
\text { in }\end{array}$ & 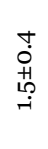 & $\begin{array}{l}10 \\
0 \\
+1 \\
0 \\
\text { H }\end{array}$ & \\
\hline $\begin{array}{l}\text { बे } \\
\text { à } \\
\text { à }\end{array}$ & 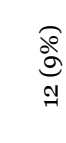 & 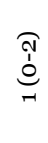 & 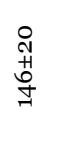 & $\begin{array}{l}\text { 草 } \\
\sigma\end{array}$ & & 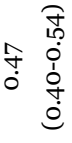 & $\stackrel{\leftrightarrow}{\dot{0}}$ & $\begin{array}{l}\text { ఠ] } \\
0 \\
\dot{0} \\
\infty \\
0 \\
0 \\
0\end{array}$ & 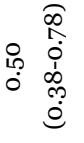 & $\begin{array}{l}\vec{j} \\
\dot{H} \\
\stackrel{+}{\dot{\theta}}\end{array}$ & $\begin{array}{l}0 \\
\text { i. } \\
\text { in } \\
\text { in }\end{array}$ & 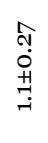 & $\begin{array}{l}\text { } \\
\dot{0} \\
\text { m } \\
\text { r }\end{array}$ & \\
\hline \begin{tabular}{l} 
La \\
\multirow{1}{\alpha}{} \\
0
\end{tabular} & 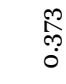 & \begin{tabular}{l}
$\infty$ \\
\multirow{0}{0}{} \\
$\dot{0}$
\end{tabular} & 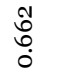 & $\begin{array}{l}\text { J } \\
\infty \\
0\end{array}$ & & 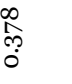 & $\begin{array}{l}\mathscr{L} \\
\stackrel{0}{0} \\
\stackrel{0}{0}\end{array}$ & & ְै & 今ે & $\begin{array}{l}\text { ơ } \\
0 \\
0\end{array}$ & $\begin{array}{l}0 \\
\vdots \\
0\end{array}$ & $\begin{array}{l}\overrightarrow{0} \\
\dot{0}\end{array}$ & \\
\hline 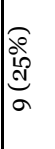 & $\underbrace{\mathbb{d}}_{10}$ & $\underbrace{\widehat{T}}_{-1}$ & \begin{tabular}{l}
$\vec{N}$ \\
H \\
\multirow{J}{*}{}
\end{tabular} & $\begin{array}{l}7 \\
\text { +1 } \\
8\end{array}$ & 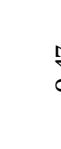 & 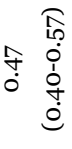 & $\stackrel{\mathscr{P}}{0}$ & $\begin{array}{l}\text { ⿵人 } \\
10 \\
0 \\
0 \\
0 \\
0 \\
0 \\
0\end{array}$ & 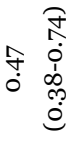 & 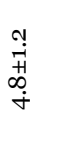 & $\begin{array}{l}\vec{H} \\
\text { H } \\
\dot{H}\end{array}$ & $\begin{array}{l}\infty \\
\stackrel{0}{0} \\
+ \\
ت \\
+\end{array}$ & $\begin{array}{l}0 \\
\dot{0} \\
+ \\
⿱ 艹 \\
-\end{array}$ & \\
\hline $\begin{array}{l}\text { बे } \\
\text { के } \\
\text { ले }\end{array}$ & $\underset{\Xi}{\stackrel{0}{0}}$ & $\underbrace{\overparen{D}}_{N}$ & $\begin{array}{l}\text { Oे } \\
\text { H } \\
\text { O } \\
\text { O }\end{array}$ & $\begin{array}{l}7 \\
+1 \\
8\end{array}$ & 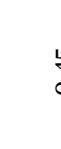 & 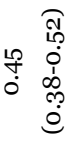 & $\stackrel{0}{+}$ & $\begin{array}{l}\text { Oे } \\
\dot{0} \\
\dot{1} \\
1 \\
0 \\
0 \\
0\end{array}$ & 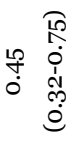 & 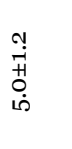 & $\begin{array}{l}0 \\
\text { H. } \\
\text { N } \\
\text { ஸे }\end{array}$ & 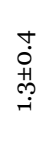 & $\begin{array}{l}0 \\
0 \\
\stackrel{+}{+} \\
\stackrel{\leftrightarrow}{+}\end{array}$ & \\
\hline 照 & 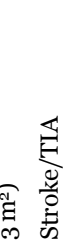 & 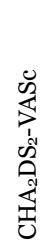 & 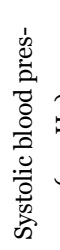 & 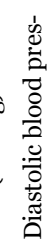 & 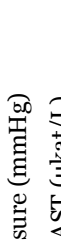 & 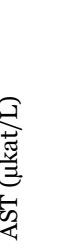 & 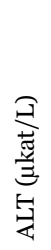 & 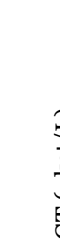 & & 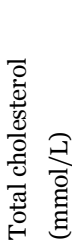 & 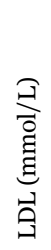 & 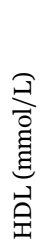 & 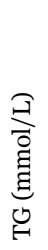 & 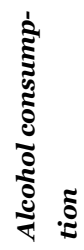 \\
\hline
\end{tabular}




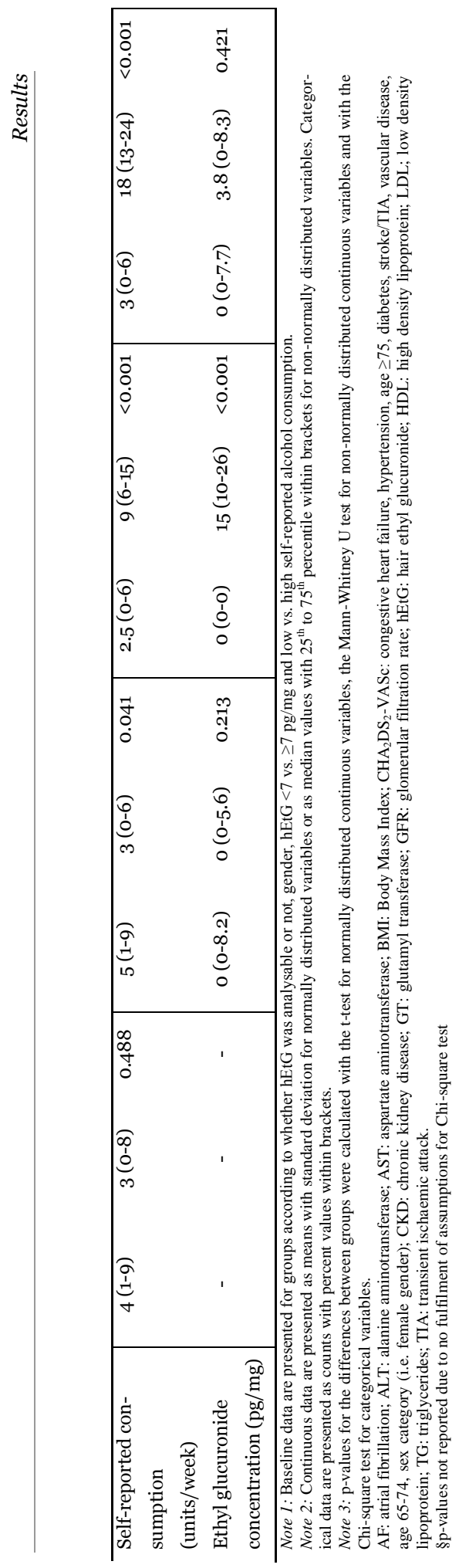




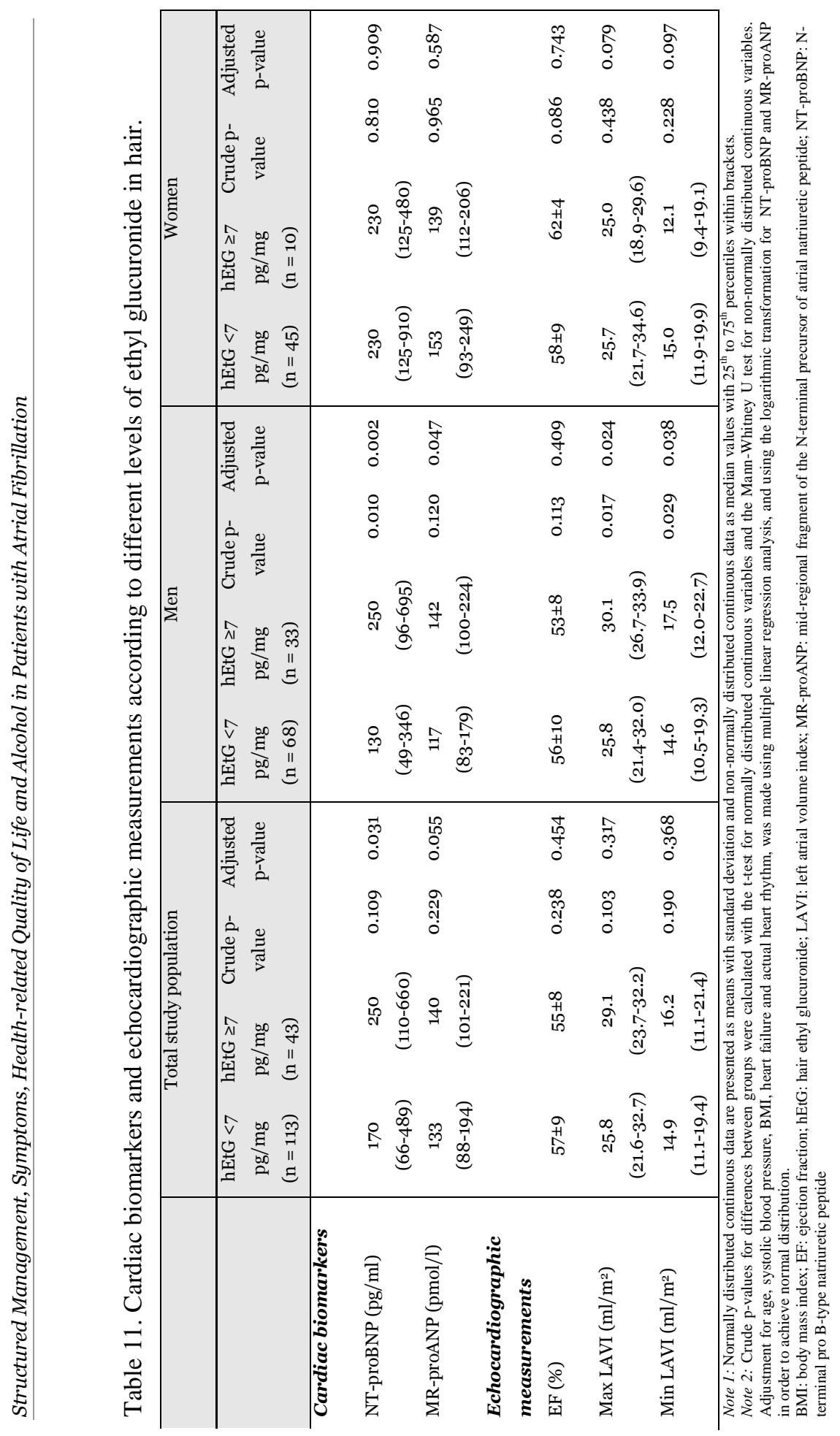




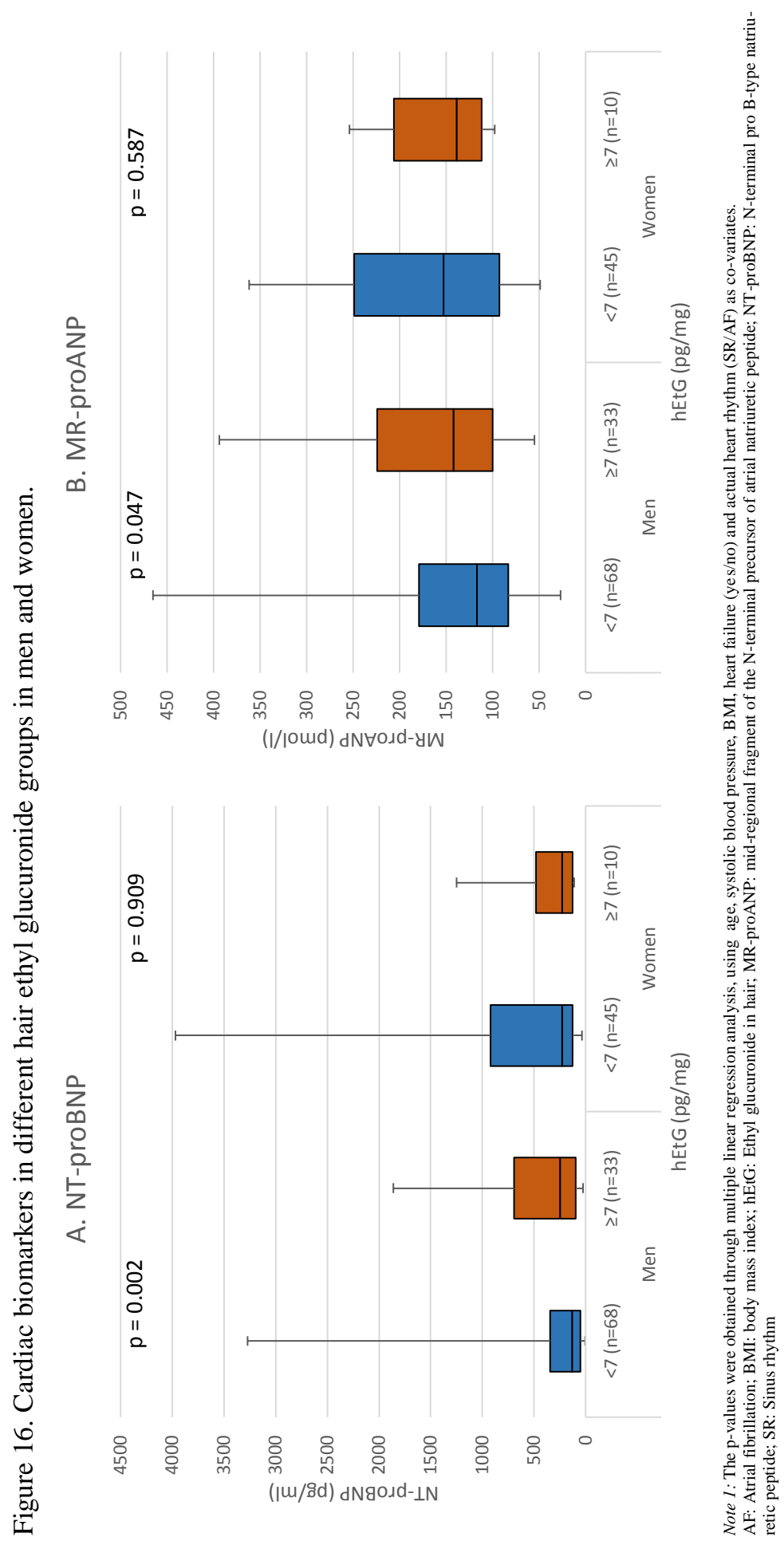




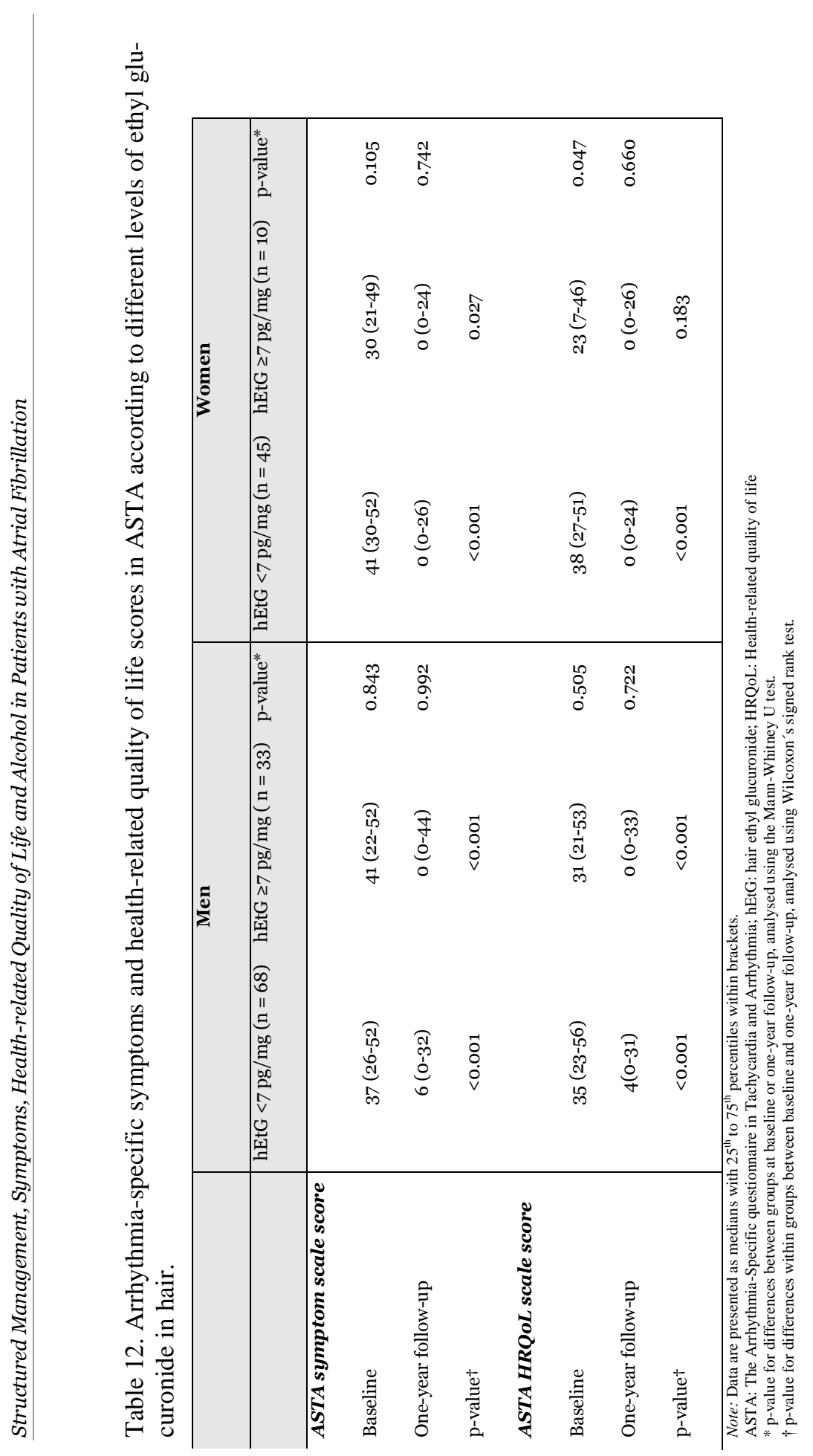


\begin{tabular}{l}
\multirow{3}{*}{} \\
2 \\
2
\end{tabular}

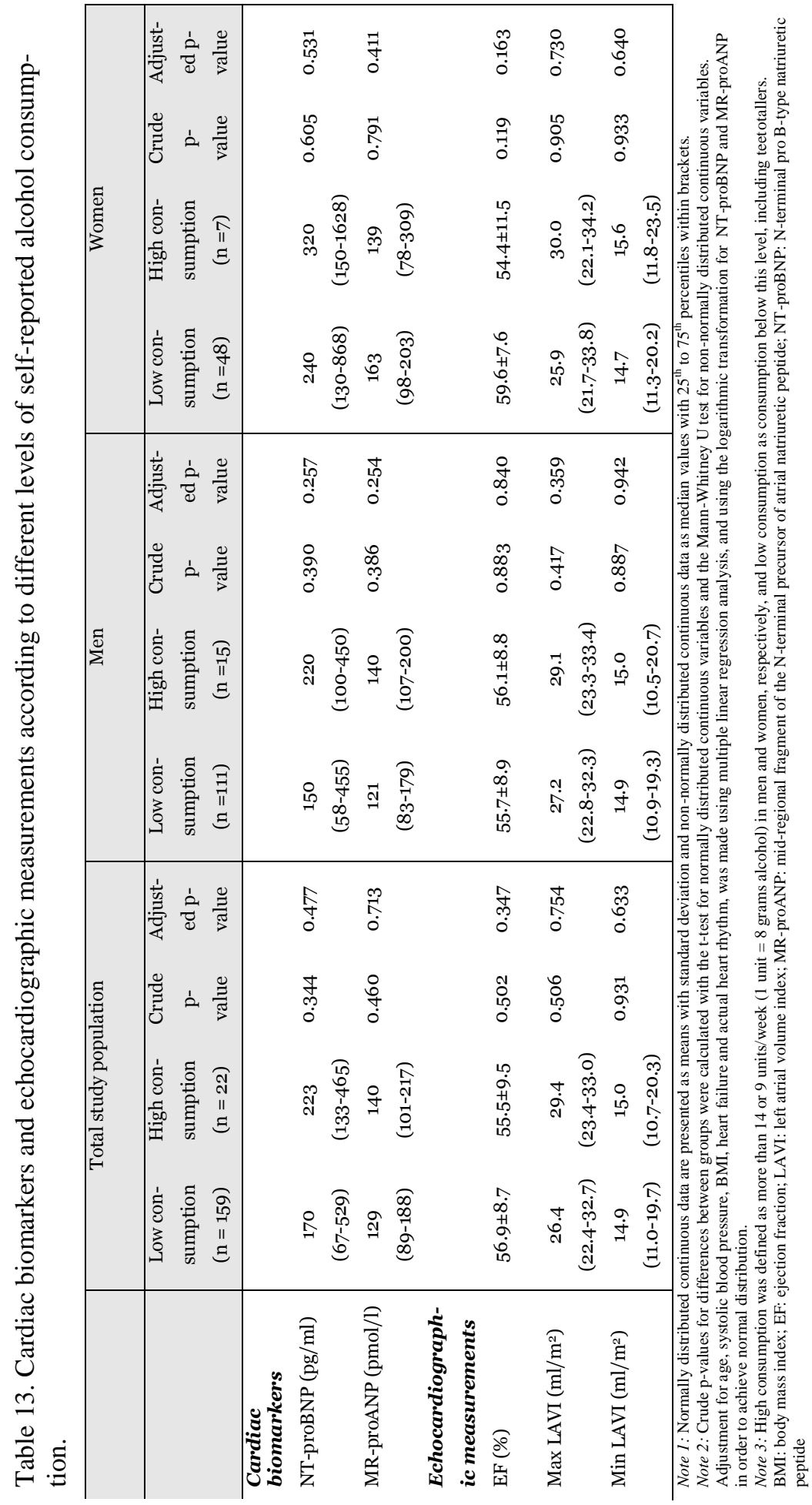




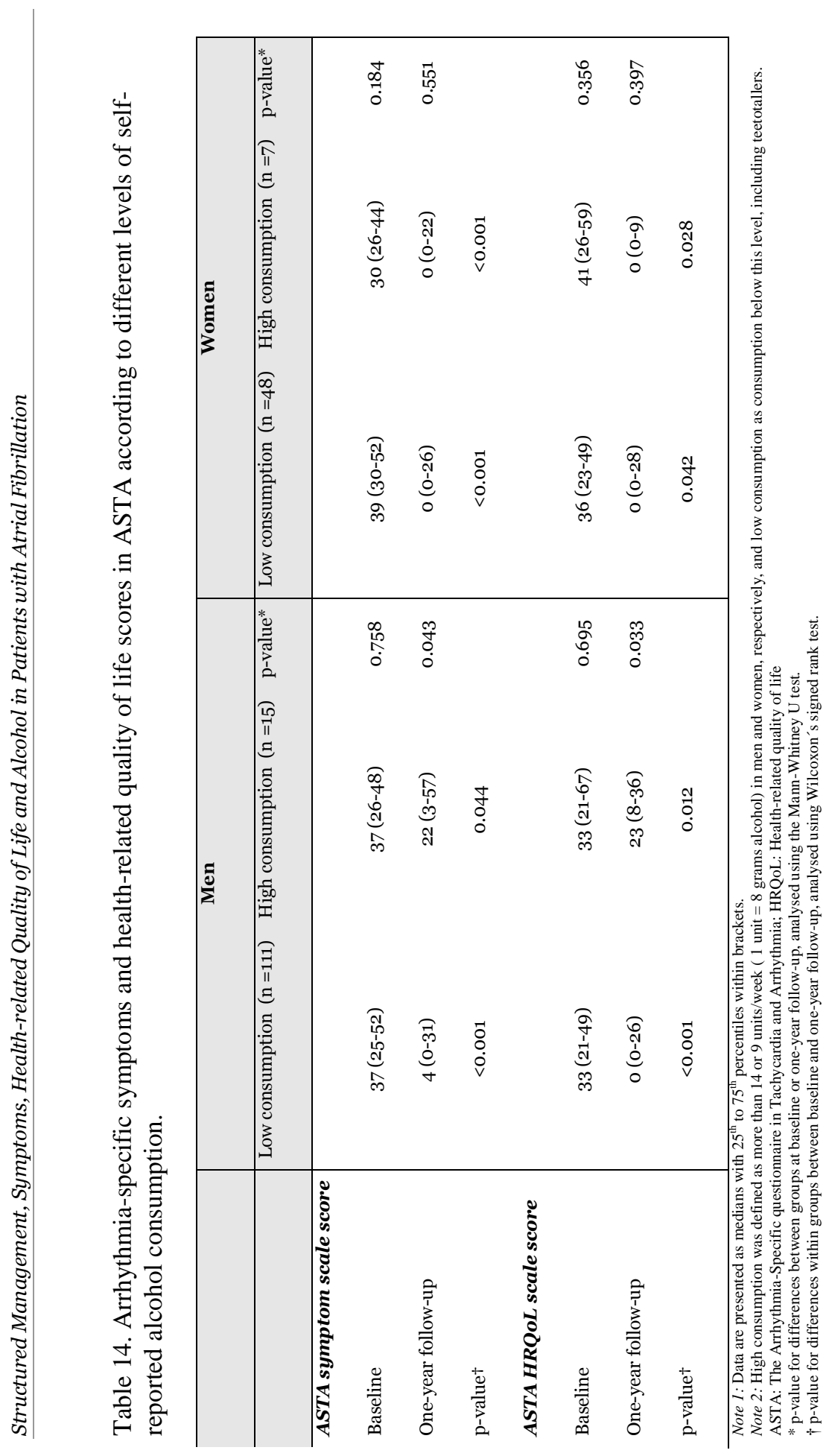




\section{DISCUSSION}

The main findings of this thesis were that 1) structured care given through an AF outpatient clinic was superior to usual care in improving guideline adherence, arrhythmia-specific symptoms, and HRQoL, 2) anxiety and depression, as well as low-grade inflammation had a central role in both arrhythmia-related symptoms and HRQoL in patients with AF prior to RFA, 3) the most important predictors of improvement in both arrhythmia-specific symptoms and HRQoL one year after RFA were frequent AF attacks in the month before RFA, freedom from AF recurrence after RFA, and the absence of diabetes, while female gender was an additional predictor for symptom improvement and the presence of heart failure and the absence of an enlarged LA were additional predictors for HRQoL improvement, 4) men with an alcohol consumption corresponding to hEtG $\geq 7 \mathrm{pg} / \mathrm{mg}$ had elevated cardiac biomarkers, larger LAV, and a higher rate of re-ablations than men with $\mathrm{hEtG}<7 \mathrm{pg} / \mathrm{mg}$, while no such findings were present in women.

\section{The SMaC-PAF Study - Paper I}

\section{The Effect of Structured Management of Patients with Atrial Fibrillation on Guideline Adherence}

Appropriate treatment with OAC was better in the control group at FU than the results from older studies 47 and consistent with new and promising reports ${ }^{105}$. However, the structured care resulted in a greater improvement in adequate use of OAC as well as in overall adherence to guidelines. The results are consistent with the study conducted by Hendriks et al., who showed not only a significant improvement in guideline adherence, but also a significant reduction in cardiovascular mortality and hospitalisation with structured care of AF patients53. Guideline adherence concerning AF management and especially antithrombotic treatment, is improving worldwide ${ }^{105}$, but these studies show the importance of structured care in order to improve guideline adherence to the fullest. 


\section{The Effect of Structured Management of Patients with Atrial Fibrillation on Patient-reported Out- come Measures}

Another similarity between the SMaC-PAF study and the study by Hendriks et al., is the results concerning PROMs. In both studies, the control group scored lower at baseline in symptom burden and HRQoL compared to the intervention group, the scores of the generic SF-36 questionnaire improved and anxiety reduced in both groups, with no significant difference between the groups at FU99. However, in the SMaC-PAF study, the SF-36 scores in the intervention group reached the scores of the agematched norm population to a greater extent than the control group. Moreover, in the SMaC-PAF study, a disease-specific questionnaire was used, demonstrating differences in arrhythmia-specific symptoms and HRQoL after one year, in favour of the intervention group, emphasising the importance of disease-specific questionnaires in addition to generic questionnaires, as discussed further below.

\section{The SMURF study - Papers II-IV}

\section{Papers II and IV}

\section{The Predictors of Symptoms and Health-related Quality of Life}

Anxiety was an important predictor of arrhythmia-specific symptoms and HRQoL at baseline, but did not influence improvement of symptoms and HRQoL after RFA. Previous studies have shown that anxiety is strongly correlated with AF symptoms ${ }^{69,106}$, and that a depressed mood and worry can increase perceptions of AF symptom burden and cause disengagement from daily activities ${ }^{107}$. Still, their relationship can be regarded as a "the egg or the chicken" situation, i.e. are symptoms causing anxiety or is anxiety exaggerating symptoms? Nevertheless, treating the arrhythmia has a positive effect on both symptoms and anxiety, as discussed further below.

Low-grade inflammation was also a significant predictor of arrhythmia-specific symptoms and HRQoL at baseline, consistent with previous studies $^{108,109}$. It is unclear whether low-grade inflammation is the cause or the result of AF. Low-grade inflammation could be a marker of more longstanding and severe AF, or a marker of co-existing comorbidities, both affecting symptoms and HRQoL negatively. 
Another possible indicator of more severe and long-standing AF, is enlargement of the LA. LAV was a negative predictor of arrhythmiaspecific symptoms at baseline and of arrhythmia-specific HRQoL improvement. Large LAV is a known predictor of AF recurrence post RFA ${ }^{110}$, and AF recurrence reduces the likelihood of improvement in HRQoL, especially when using a disease-specific instrument ${ }^{104}$. However, although an arrhythmia-specific instrument was used in this study, both LAV and AF recurrence remained significant negative predictors of HRQoL improvement, indicating that larger LAV per se is negatively associated with HRQoL improvement, and could thus be a sign of more severe and longstanding AF, affecting HRQoL negatively, even after a successful RFA.

The occurrence of frequent attacks of AF before RFA was a predictor of baseline PCS, consistent with the study by van den Berg et al., in which the frequency of AF paroxysms was an important predictor of physical functioning ${ }^{111}$. The occurrence of frequent AF attacks was also a significant predictor of improvement in arrhythmia-specific symptom and HRQoL. In a study by Gaita et al. a higher reduction of arrhythmic burden and a higher freedom from AF recurrence after RFA correlated with a significant improvement in HRQoL ${ }^{112}$. A low arrhythmic burden prior to RFA is likely to be reduced to a lesser extent compared to a high arrhythmic burden, explaining why the occurrence of frequent attacks of $\mathrm{AF}$ was a significant predictor of improvement in symptom burden and HRQoL.

There was an inverse relationship between recurrence of $\mathrm{AF}$ and improvement in symptoms and in HRQoL, which might be regarded as a quite self-evident fact. However, the two factors do not have to be mutually exclusive. In a previous study by Wokhlu et al., substantial improvement in general HRQoL was also noted in patients with AF recurrence after RFA ${ }^{113}$. However, only a minor improvement in arrhythmia-specific symptoms occurred, highlighting the difference between generic and disease-specific instruments. While the former reflects general health, influenced by comorbidities commonly present in patients with $\mathrm{AF}$, the latter reflects health specific to a certain disease. In a study by Björkenheim et al., an arrhythmia-specific questionnaire was more sensitive to changes related to $\mathrm{AF}$ burden than a generic questionnaire, and more accurately reflected the effect of RFA ${ }^{104}$. This indicates the importance of using a disease-specific instrument when evaluating the effects of RFA, and can explain why AF recurrence was one of the strongest inverse predictors of symptom and HRQoL improvement in this study.

The most important predictor of PCS at baseline was obesity. Obesity has been linked to AF development and progression, as well as to low HRQoL, with impaired diastolic function, inflammation and pericardial fat as possible mechanisms ${ }^{114,115}$. However, it is a modifiable risk factor, and AF-related outcomes have been shown to be improved post RFA with 
weight management as a part of an overall aggressive cardiovascular risk factor management programme ${ }^{23}$. Although BMI was not a significant negative predictor of improvement in symptoms and HRQoL, the presence of diabetes was. In contrast to our study, Mohanty et al. reported a higher post ablation improvement in generic HRQoL in patients with the metabolic syndrome ${ }^{4}$. However, only a generic instrument was used in that study, and there was no significant change in patients with AF recurrence ${ }^{4}$. In this study, both diabetes and AF recurrence remained significant predictors in the multivariate regression analysis, indicating that diabetes per se, regardless of whether AF recurred or not, was a negative predictor of improvement in symptoms and HRQoL.

The presence of heart failure was a negative predictor of ASTA HRQoL at baseline, but a positive predictor of its improvement after RFA. In the CASTLE-AF study, in which RFA was compared to medical therapy in AF patients with heart failure, RFA was associated with a significantly lower rate of the composite end point of death or hospitalisation, improved EF and improved six-minute walk test 45 . Although the CASTLEAF study only included patients with an $\mathrm{EF}<35 \%$, which was an exclusion criterion in this study, the diagnosis of heart failure in our study was also associated with improvement after RFA.

Chronic conditions, such as diabetes and heart failure, can affect HRQoL negatively. In this study, they had an opposite effect on HRQoL improvement post RFA. While affection of several organs may be the reason for reduced HRQoL in diabetic patients, cardiac dysfunction is most likely to be the cause of reduced HRQoL in patients with heart failure. Improving cardiac function through restoration of atrial function consequently has a greater effect on HRQoL in heart failure patients than in patients with diabetes.

Finally, female gender was a significant predictor of symptom improvement. A previous study by Forleo et al. pointed in the same direction $^{116}$. Previous studies show that women tend to have higher symptom burden and are referred for RFA later and less often than men, despite equal results after RFA concerning clinical outcomes, such as AF recurrence, treatment success rate, hospitalisation and complications ${ }^{116,117}$. These gender-related inequalities have no obvious explanations.

\section{The Effect of Radiofrequency Catheter Ablation on Patient-reported Outcome Measures}

Breathlessness during activity and tiredness were the most commonly reported symptoms, consistent with the 'Medical Anti-arrhythmic Treatment or Radiofrequency Ablation in Paroxysmal Atrial Fibrillation' (MANTRA-PAF) trial ${ }^{118}$. Each symptom item, as well as the ASTA symp- 
tom scale score, improved after RFA. The large ES implies a large effect of RFA on symptom improvement, which is in line with other studies ${ }^{118-120}$.

There was also a large improvement in the disease-specific ASTA HRQoL score, which is in line with previous studies ${ }^{121}$. General HRQoL improved also, but to a lesser extent, probably due to the above mentioned differences between generic and disease-specific instruments.

Both anxiety and depression improved after RFA, which is in line with previous studies ${ }^{70,71}$. Thrall et al. showed that anxiety and depression, which are known predictors of $\mathrm{HRQOL}^{69}$ and associated with AF recurrence after RFA ${ }^{71}$, affect approximately one third of patients with $\mathrm{AF}^{69}$, as was the case in this study. Several possible mechanisms have been suggested, such as elevated sympathetic tone and correlation with systemic inflammation 70 , but the mechanisms behind this relationship remain unclear.

\section{Paper III and the Association of Alcohol Con- sumption with Symptoms and Health-related Quality of Life}

\section{Associations between Alcohol Consumption, Cardi- ac Biomarkers, Left Atrial Size, Re-ablation, Symp- toms and Health-related Quality of Life}

hEtG $\geq 7 \mathrm{pg} / \mathrm{mg}$ was associated with higher NT-proBNP and MR-proANP concentrations in men, consistent with previous studies which have shown a dose-response related positive correlation between reported alcohol consumption and ANP, and a relationship between excessive alcohol consumption and elevated levels of B-type natriuretic peptide per2-124. $^{124}$ This study showed that even moderate consumption, as indicated by an hEtG-value $\geq 7 \mathrm{pg} / \mathrm{mg}$, was associated with increased levels.

Men with $\mathrm{hEtG} \geq 7 \mathrm{pg} / \mathrm{mg}$ had larger LAV than men with hEtG $<7$ $\mathrm{pg} / \mathrm{mg}$. This is consistent with the study by McManus et al., who showed a $0.16 \mathrm{~mm}$ larger LA dimension with every additional $10 \mathrm{~g}$ of alcohol per day ${ }^{125}$. Similarly, Hung et al. showed that light to moderate intake of alcohol in a dose-dependent manner was related to larger LAV as well as impaired LA strain ${ }^{126}$.

There were three-fold increased odds of having a re-ablation in men with $\mathrm{hEtG} \geq 7 \mathrm{pg} / \mathrm{mg}$ than men with $\mathrm{hEtG}<7 \mathrm{pg} / \mathrm{mg}$, consistent with the study by Takigawa et al. and Qiao et al., who showed a strong association between alcohol consumption and unfavourable ablation outcomes ${ }^{127,128}$. Contrary to those studies, this study also used an objective marker of alcohol consumption in addition to self-reported alcohol intake. 
Baseline HRQoL scores were better in women with $\mathrm{hEtG} \geq 7 \mathrm{pg} / \mathrm{mg}$ compared to women with hEtG $<7 \mathrm{pg} / \mathrm{mg}$. This might be explained by the fact that the relationship between alcohol consumption and HRQoL has been described as a $\mathrm{J}$ - or U-curve, in which light to moderate drinkers tend to have the best HRQoL, while both abstinence and heavy consumption is associated with poor HRQoL ${ }^{129-131}$. The reason there was no significant difference in men, might be due to the fact that men have a higher alcohol consumption than women ${ }^{130}$, possibly diminishing the effect of light to moderate drinkers' HRQoL on the result.

After RFA, HRQoL improved in both genders and irrespective of alcohol consumption, except for women with $\mathrm{hEtG} \geq 7 \mathrm{pg} / \mathrm{mg}$, probably due to the low number in that group, rendering the analysis underpowered. In men with self-reported high alcohol consumption, improvement was clearly not as great as in the low consumption group, leading to a statistically significant difference between the high and low alcohol consumption groups in men at the one-year FU. Men with high alcohol consumption might thus benefit from RFA, but probably not as much as those with low consumption, in terms of symptom and HRQoL improvement.

The pathophysiology behind the negative effects of alcohol on the heart is complex and several possible mechanisms for the increased risk of AF have been suggested ${ }^{127,132}$. Before a left ventricular systolic dysfunction is evident, subclinical alterations in myocardial contractility may occur $^{126}$. Studies have shown a possibly dose-response relationship between alcohol consumption and atrial remodelling ${ }^{127}$, and that even moderate intake of alcohol is associated with the risk of $\mathrm{AF}^{80}$. In that context, it is interesting that the relatively low cut-off level of $7 \mathrm{pg} / \mathrm{mg}$ used in this study was sufficient to observe a difference in cardiac biomarkers, LA size and in the rate of re-ablations. Studies have also shown that impaired systolic LA mechanics can predict success in maintaining SR after cardioversion and RFA ${ }^{133,134}$, potentially explaining the more frequent re-ablations in men with $\mathrm{hEtG} \geq 7 \mathrm{pg} / \mathrm{mg}$ that we found. 


\section{Methodological Considerations and Limitations}

\section{The SMaC-PAF Study}

The most important limitation of the SMaC-PAF study is its nonrandomised design with different centres recruiting patients to either the intervention group, or the control group, but not both. This is probably an important reason for the observed differences between the groups at baseline. Due to the nature of the intervention, in which many care-givers and patient flows were involved, it was considered that the risk of unplanned crossovers would have been significant if both patient groups had been enrolled at the same site. To avoid this, recruitment at different sites was preferred, increasing the risk of selection bias. An alternative could have been a cluster randomised study.

Interestingly, despite its randomised design baseline differences in favour for the intervention group were also observed in the study by Hendriks et al., which is the largest study in this area99. Both studies also suffered from a considerable number of non-responders. The design of the study with the intention to do as little as possible to the control group in order to resemble usual care as much as possible, probably also led to lower motivation for filling in and returning the questionnaires.

Furthermore, in the intervention group, the questionnaires were handed out and brought back to the first visit at the outpatient AF clinic. The knowledge that one was being taken care of in a structured way could thus have influenced HRQoL, and may not have reflected the original HRQoL prior to inclusion. The patients in the control group on the other hand, often filled out the questionnaires while still at the hospital. These factors might also have been a reason for baseline differences.

The initial intention of the SMaC-PAF study was to include patients only at two centres. However, due to a slow inclusion rate at the control centre, two more centres were added and the time for enrolment was extended. Still, the intended recruitment goal of 200 patients in each group was not met, rendering the study underpowered to a certain extent.

\section{The SMURF Study}

Some of the limitations of the SMURF study were that it was a single centre observational cohort study of moderate size without any control group, and that it was constituted of a heterogenic group of patients including people with both paroxysmal and persistent AF, SR or AF upon admission, normal or reduced EF etc.

The major reason for not being included in the study despite eligibility was a logistical reason. It was only possible to include four patients per 
week, due to the fact that an included patient was expected to be considerably more time-consuming. Blood samples and pressure measurements were handled by extra personnel, who were not available throughout the week. However, a separate analysis, which has previously been published ${ }^{135}$, showed that there were no baseline differences between the participants included in our study and those not included due to logistical difficulties or because they declined participation. This makes selection bias less likely.

There was a numeral gender imbalance in the study, which has been observed in other studies ${ }^{136}$, and as discussed above, might be due to the fact that women seem to be referred more seldom and later than men $^{116,117}$. The low number of women could have rendered the analyses concerning alcohol underpowered in the female group.

Assessing AF recurrence post RFA with an implantable loop recorder could have been an alternative to examination of medical records, the local RFA register and 24-hour Holter monitoring. However, this would mean a greater cost, and especially a greater inconvenience for the patient, and thus was considered ethically not motivated. Thus, the number of patients with $\mathrm{AF}$ recurrence was probably underestimated.

In line with previous studies, in which social drinkers often have unmeasurable hEtG results ${ }^{137,138}$, some patients in this study who reported that they drank, had o pg/mg in hEtG. There might be different reasons for this. Although hEtG has been proved to perform excellently in the cutoff level of $30 \mathrm{pg} / \mathrm{mg}$, the performance in the lower ranges is less accurate $^{90}$. hEtG can also be influenced by cosmetic hair treatments and thermal hair straightening tools, leading to false negative results ${ }^{92}$. This may not be known by the researcher and is only rarely reported ${ }^{137}$, which was also the case in this study. Furthermore, hEtG cannot be analysed in men without hair, or with hair that is very short, which is the explanation for the gender differences between the groups with analysable and nonanalysable hEtG. Moreover, drinking pattern (such as seldom binge drinking vs. continuous moderate intake) can influence $\mathrm{hEtG}^{90}$. In this study, self-reported alcohol consumption was assessed with only a single question concerning weekly alcohol intake. A more thorough alcohol questionnaire and other blood tests in addition to hEtG, could have added valuable information. 


\section{CONCLUSIONS}

The SMaC-PAF study showed that structured care of AF led to an improvement in guideline adherence, mainly driven by an improvement in OAC prescription. Although the degree of anxiety and the scoring concerning HRQoL were improved in both patient groups at FU, the arrhythmia-specific symptoms were less frequently experienced, and the $\mathrm{SF}-36$ scores were more similar to the norm population, in the intervention group compared to the control group.

The SMURF study showed that the most important predictors of arrhythmia-related symptoms and HRQoL at baseline in patients with AF eligible for RFA were anxiety, depression and low-grade inflammation, and that the most significant predictor of general physical status was obesity. The most important predictors of improvement in arrhythmiaspecific symptoms and $\mathrm{HRQoL}$ at the one-year $\mathrm{FU}$ were frequent $\mathrm{AF}$ attacks before RFA, freedom from AF recurrence after RFA, absence of diabetes, and additionally, female gender for symptom improvement and the presence of heart failure and the absence of an enlarged LA for HRQoL improvement.

In contrast to previous studies relying on self-reported alcohol consumption, the SMURF study is, to the best of my knowledge, the first study using an objective marker of long-term alcohol consumption in patients undergoing RFA. hEtG $\geq 7 \mathrm{pg} / \mathrm{mg}$ was associated with higher cardiac biomarker concentrations, larger LAV and a higher rate of re-ablations in men, while no such differences were found in women. This implies that men with an alcohol consumption corresponding to an hEtG-value $\geq 7$ $\mathrm{pg} / \mathrm{mg}$, have a higher risk for LA remodelling, which could potentially worsen the AF situation. 
Structured Management, Symptoms, Health-related Quality of Life and Alcohol in Patients with Atrial Fibrillation 


\section{FUTURE PERSPECTIVES}

All the previous studies on structured care of patients with AF have either been conducted in, or recruited patients from, tertiary care centres. However, most patients are treated and followed up at primary health care centres. Future studies should investigate the outcomes of implementation of a structured management programme for patients with AF in primary care.

Although this thesis has increased our knowledge about the predictors of symptoms and HRQoL before and after RFA, the results have to be confirmed in future studies. Furthermore, the wide variety of symptoms in patients with AF is still a puzzle that is far from being solved. Further studies, investigating the associations of symptoms and HRQoL with more sensitive markers of AF impairment and remodelling, such as magnetic resonance findings and atrial strain, are needed to gain further insights into the reasons for the great variety of symptoms in patients with AF.

The indication for RFA is symptom-driven. Still, trials have most often used AF recurrence as the primary endpoint instead of symptom and HRQoL improvement. Although this thesis has shown that AF recurrence is an important issue when it comes to symptom and HRQoL improvement post RFA, future studies on RFA should to a greater extent use symptoms and HRQoL as endpoints, preferably using a combination of general and disease-specific PROMs. Clinicians following up the patients after RFA should also to a greater extent use PROMs as tools to assess symptoms and HRQoL in order to improve patient-centred care.

The role of light to moderate alcohol consumption in $\mathrm{AF}$ is an interesting subject that needs further clarification. To my knowledge, the SMURF study is the first study using an objective marker of long-term alcohol consumption in patients conducting RFA. The findings of the study have to be confirmed in further studies, suggestively using a more comprehensive alcohol questionnaire such as the AUDIT questionnaire, combined with more than one objective measure of alcohol consumption, such as hEtG and PEths. 
Structured Management, Symptoms, Health-related Quality of Life and Alcohol in Patients with Atrial Fibrillation 


\section{ACKNOWLEDGEMENTS}

Several years of work on this thesis are now coming to an end. This would not have been possible without the help of several people, to whom I wish to express my sincere gratitude. Especially, I would like to thank:

All the patients who participated in the SMaC-PAF and the SMURF studies.

Associate professor Håkan Walfridsson, my main supervisor. Thank you for inviting me to take part in the SMURF study. I would also like to thank you for believing in me and helping me throughout the entire process, no matter what. Thank you for your endurance. I do not know how many times I was ready to give up, but your unending positive energy and your continuous positive and constructive feedback kept me going. You helped push me to reach the goal that I felt was so far away and unattainable for so many years. Thank you!

Research nurse Ulla Walfridsson, my co-supervisor. Thank you for the great and important ASTA questionnaire. Thank you for your cooperation, help and discussion about symptoms and HRQoL in general, and concerning AF patients in particular. Most importantly, I would like to thank you for being the person that you are, seeing the human in me, understanding the ups and downs, and together with Håkan for keeping me going in order to let me reach my goal.

Associate professor Jan-Erik Karlsson, my co-supervisor. Thank you for introducing me to the great world of research. Together, we have spent several hours, days, years on planning, conducting and evaluating the SMaC-PAF study. I would like to thank you for all the help and support throughout that process.

Emmanouil Charitakis, my co-supervisor, and my main co-author. Thank you for letting me take part in the SMURF study, and thank you for your most valuable input in the articles, and not least in the statistical analyses. Your support throughout the doctoral studies is much appreciated. 
Professor Fredrik Nyström, my co-supervisor. Thank you for making the paper about alcohol possible. I would also like to thank you for taking part in my doctoral studies as co-supervisor, since your advice, support and input throughout the doctoral studies have been very valuable.

Professor Robert Kronstrand, co-author and responsible for handling and analysing the hair samples. Thank you for sharing your knowledge on hEtG.

Nurses Emma Hag, Pia Wibring and secretary Gun Ljungqvist, thank you for your tremendous effort and work with the SMaC-PAF study.

Mats Fredriksson, Lars Valter and Birgit Ljungquist, statisticians - for your help with the statistical analyses.

FUTURUM - the Academy for Health and Care, Region Jönköping County and Eva-Lena Enell, head of the department of Internal Medicine, County Hospital Ryhov, Jönköping, for granting me the research time that enabled the completion of this thesis.

Thank you my dear colleagues Jörg Lauermann, Tomasz Zwierzchlewski, Werner Puskar and former colleague Berne Åsberg, for teaching me everything you know about percutaneous coronary interventions, and for coping with the heavier workload at the cath lab during my absence doing research.

My colleague Patric Karlström, for fruitful discussions concerning research and for your valuable input on this thesis.

Thanks to all my other colleagues and great staff at the Department of Internal Medicine in general and the staff at the Cardiology section in particular, for the wonderful atmosphere you are creating and for taking part and recruiting patients to the SMaC-PAF study.

Thanks to all the staff at the departments of Cardiology and Physiology at Linköping University Hospital, participating in the SMURF study. 
To the staff at the departments of Internal Medicine and Cardiology at the hospitals in Kalmar, Eksjö and Norrköping, participating in the SMaC-PAF study.

My uncle and friend Hikmet Baymano, who unfortunately is not with us any longer. You were always so smart, kind and helpful, no matter what. In my heart you will always stay.

My brothers, Nadan Barmano and Mano Barmano, for always being there when needed. I know that I can always count on you, and you can always count on me. Love you!

To my parents, my father Simon Barmano and my mother Semiran Barmano. You are my true role models. Thank you for your unconditional love and support. There are no words that can express my love and gratitude towards you.

And most of all, to my family: my life companion, my anchor in life, my true friend, my beautiful wife Alena Barmano, without whom I could not have completed this work, and to my dear children Tibelio, Leonora and Ilona, for giving me so much joy and happiness and always reminding me what is important in life. I love you so much!

The SMaC-PAF study was supported by FUTURUM - the Academy of Health and Care, Region Jönköping County and FORSS - the Medical Research Council of Southeast Sweden. The SMURF study was supported by grants from ALF grants (County Council of Östergötland), the Carldavid Jönsson Research Foundation, the Heart Foundation, Linköping University and by unrestricted grants from Biosense Webster, Johnson \& Johnson. 
Structured Management, Symptoms, Health-related Quality of Life and Alcohol in Patients with Atrial Fibrillation 


\section{REFERENCES}

1. Scurlock J, Andersen BR. Diagnoses in Assyrian and Babylonian medicine: ancient sources, translations, and modern medical analyses. Urbana: University of Illinois Press; 2005.

2. Lip GY, Beevers DG. ABC of atrial fibrillation. History, epidemiology, and importance of atrial fibrillation. $B M J 1995 ; \mathbf{3 1 1}(7016)$ : 1361-3.

3. Curran J. The Yellow Emperor's Classic of Internal Medicine. BMJ: British Medical Journal 2008; 336(7647): 777.

4. Mohanty S, Mohanty P, Di Biase L, et al. Impact of metabolic syndrome on procedural outcomes in patients with atrial fibrillation undergoing catheter ablation. $J$ Am Coll Cardiol 2012; 59(14): 1295-301.

5. Prystowsky EN. The history of atrial fibrillation: the last 100 years. Journal of cardiovascular electrophysiology 2008; 19(6): 575-82.

6. Friberg L, Bergfeldt L. Atrial fibrillation prevalence revisited. Journal of internal medicine 2013; 274(5): 461-8.

7. Chugh SS, Havmoeller R, Narayanan K, et al. Worldwide epidemiology of atrial fibrillation: a Global Burden of Disease 2010 Study. Circulation 2014; 129(8): 837-47.

8. Kirchhof P, Benussi S, Kotecha D, et al. 2016 ESC Guidelines for the management of atrial fibrillation developed in collaboration with EACTS. Eur Heart $J$ 2016; 37(38): 2893-962.

9. Go AS, Hylek EM, Phillips KA, et al. Prevalence of diagnosed atrial fibrillation in adults: national implications for rhythm management and stroke prevention: the AnTicoagulation and Risk Factors in Atrial Fibrillation (ATRIA) Study. JAMA 2001; 285(18): 2370-5.

10. Ferrari R, Bertini M, Blomstrom-Lundqvist C, et al. An update on atrial fibrillation in 2014: From pathophysiology to treatment. Int $J$ Cardiol 2016; 203: 22-9.

11. January CT, Wann LS, Alpert JS, et al. 2014 AHA/ACC/HRS guideline for the management of patients with atrial fibrillation: a report of the American College of Cardiology/American Heart Association Task Force on Practice Guidelines and the Heart Rhythm Society. $J$ Am Coll Cardiol 2014; 64(21): e1-76.

12. Iwasaki YK, Nishida $K$, Kato $T$, Nattel S. Atrial fibrillation pathophysiology: implications for management. Circulation 2011; 124(20): 2264-74.

13. Haissaguerre M, Jais P, Shah DC, et al. Spontaneous initiation of atrial fibrillation by ectopic beats originating in the pulmonary veins. The New England journal of medicine 1998; 339(10): 659-66.

14. Savelieva I, Camm AJ. Clinical relevance of silent atrial fibrillation: prevalence, prognosis, quality of life, and management. Journal of 
interventional cardiac electrophysiology: an international journal of arrhythmias and pacing 2000; 4(2): 369-82.

15. Sposato LA, Cipriano LE, Saposnik G, Ruiz Vargas E, Riccio PM, Hachinski V. Diagnosis of atrial fibrillation after stroke and transient ischaemic attack: a systematic review and meta-analysis. Lancet Neurol 2015; 14(4): 377-87.

16. Svennberg E, Engdahl J, Al-Khalili F, Friberg L, Frykman V, Rosenqvist M. Mass Screening for Untreated Atrial Fibrillation: The STROKESTOP Study. Circulation 2015; 131(25): 2176-84.

17. Engdahl J, Holmen A, Rosenqvist M, Stromberg U. A prospective 5year follow-up after population-based systematic screening for atrial fibrillation. Europace: European pacing, arrhythmias, and cardiac electrophysiology: journal of the working groups on cardiac pacing, arrhythmias, and cardiac cellular electrophysiology of the European Society of Cardiology 2018; 2o(FI_3): f306-f11.

18. Aronsson M, Svennberg E, Rosenqvist M, et al. Cost-effectiveness of mass screening for untreated atrial fibrillation using intermittent ECG recording. Europace: European pacing, arrhythmias, and cardiac electrophysiology: journal of the working groups on cardiac pacing, arrhythmias, and cardiac cellular electrophysiology of the European Society of Cardiology 2015; 17(7): 1023-9.

19. Stewart S, Hart CL, Hole DJ, McMurray JJ. A population-based study of the long-term risks associated with atrial fibrillation: 20-year follow-up of the Renfrew/Paisley study. Am J Med 2002; 113(5): 359-64.

20. Calkins H, Hindricks G, Cappato R, et al. 2017 HRS/EHRA/ECAS/APHRS/SOLAECE expert consensus statement on catheter and surgical ablation of atrial fibrillation: Executive summary. $J$ Arrhythm 2017; 33(5): 369-409.

21. Benjamin EJ, Chen PS, Bild DE, et al. Prevention of atrial fibrillation: report from a national heart, lung, and blood institute workshop. Circulation 2009; 119(4): 606-18.

22. Gallagher C, Hendriks JM, Mahajan R, et al. Lifestyle management to prevent and treat atrial fibrillation. Expert Rev Cardiovasc Ther 2016; 14(7): 799-809.

23. Pathak RK, Middeldorp ME, Lau DH, et al. Aggressive risk factor reduction study for atrial fibrillation and implications for the outcome of ablation: the ARREST-AF cohort study. $J$ Am Coll Cardiol 2014; 64(21): 2222-31.

24. Wolf PA, Abbott RD, Kannel WB. Atrial fibrillation: a major contributor to stroke in the elderly. The Framingham Study. Arch Intern Med 1987; 147(9): 1561-4.

25. Lamassa M, Di Carlo A, Pracucci G, et al. Characteristics, outcome, and care of stroke associated with atrial fibrillation in Europe: data from a multicenter multinational hospital-based registry (The European Community Stroke Project). Stroke 2001; 32(2): 392-8.

26. Flaker GC, Belew K, Beckman K, et al. Asymptomatic atrial fibrillation: demographic features and prognostic information from the 
Atrial Fibrillation Follow-up Investigation of Rhythm Management (AFFIRM) study. Am Heart $J$ 2005; 149(4): 657-63.

27. Lip GY, Boos CJ. Antithrombotic treatment in atrial fibrillation. Heart 2006; 92(2): 155-61.

28. Nieuwlaat R, Dinh T, Olsson SB, et al. Should we abandon the common practice of withholding oral anticoagulation in paroxysmal atrial fibrillation? Eur Heart $J$ 2008; 29(7): 915-22.

29. Lip GY, Frison L, Halperin JL, Lane DA. Identifying patients at high risk for stroke despite anticoagulation: a comparison of contemporary stroke risk stratification schemes in an anticoagulated atrial fibrillation cohort. Stroke 2010; 41(12): 2731-8.

30. Van Gelder IC, Groenveld HF, Crijns HJ, et al. Lenient versus strict rate control in patients with atrial fibrillation. The New England journal of medicine 2010; 362(15): 1363-73.

31. Kirchhof P, Auricchio A, Bax J, et al. Outcome parameters for trials in atrial fibrillation: recommendations from a consensus conference organized by the German Atrial Fibrillation Competence NETwork and the European Heart Rhythm Association. Europace: European pacing, arrhythmias, and cardiac electrophysiology: journal of the working groups on cardiac pacing, arrhythmias, and cardiac cellular electrophysiology of the European Society of Cardiology 2007; 9(11): 1006-23.

32. Calkins H, Reynolds MR, Spector $\mathrm{P}$, et al. Treatment of atrial fibrillation with antiarrhythmic drugs or radiofrequency ablation: two systematic literature reviews and meta-analyses. Circ Arrhythm Electrophysiol 2009; 2(4): 349-61.

33. Freemantle N, Lafuente-Lafuente C, Mitchell S, Eckert L, Reynolds M. Mixed treatment comparison of dronedarone, amiodarone, sotalol, flecainide, and propafenone, for the management of atrial fibrillation. Europace: European pacing, arrhythmias, and cardiac electrophysiology: journal of the working groups on cardiac pacing, arrhythmias, and cardiac cellular electrophysiology of the European Society of Cardiology 2011; 13(3): 329-45.

34. Essebag V, Wylie JV, Josephson ME. Effectiveness of catheter ablation of atrial fibrillation. Eur Heart $J$ 2006; 27(2): 130-1.

35. Wazni OM, Marrouche NF, Martin DO, et al. Radiofrequency ablation vs antiarrhythmic drugs as first-line treatment of symptomatic atrial fibrillation: a randomized trial. JAMA 2005; 293(21): 2634-40.

36. Pappone C, Augello G, Sala S, et al. A randomized trial of circumferential pulmonary vein ablation versus antiarrhythmic drug therapy in paroxysmal atrial fibrillation: the APAF Study. $J$ Am Coll Cardiol 2006; 48(11): 2340-7.

37. Jais P, Cauchemez B, Macle L, et al. Catheter ablation versus antiarrhythmic drugs for atrial fibrillation: the A4 study. Circulation 2008; 118(24): 2498-505.

38. Blomstrom-Lundqvist C, Gizurarson S, Schwieler J, et al. Effect of Catheter Ablation vs Antiarrhythmic Medication on Quality of Life in 
Patients With Atrial Fibrillation: The CAPTAF Randomized Clinical Trial. JAMA 2019; 321(11): 1059-68.

39. Mark DB, Anstrom KJ, Sheng S, et al. Effect of Catheter Ablation vs Medical Therapy on Quality of Life Among Patients With Atrial Fibrillation: The CABANA Randomized Clinical Trial. JAMA 2019 (Epub ahead of print).

40. Hagens VE, Crijns HJ, Van Veldhuisen DJ, et al. Rate control versus rhythm control for patients with persistent atrial fibrillation with mild to moderate heart failure: results from the RAte Control versus Electrical cardioversion (RACE) study. Am Heart $J$ 2005; 149(6): 1106-11.

41. Hohnloser SH, Kuck KH, Lilienthal J. Rhythm or rate control in atrial fibrillation--Pharmacological Intervention in Atrial Fibrillation (PIAF): a randomised trial. Lancet 2000; 356(9244): 1789-94.

42. Opolski G, Torbicki A, Kosior DA, et al. Rate control vs rhythm control in patients with nonvalvular persistent atrial fibrillation: the results of the Polish How to Treat Chronic Atrial Fibrillation (HOT CAFE) Study. Chest 2004; 126(2): 476-86.

43. Wyse DG, Waldo AL, DiMarco JP, et al. A comparison of rate control and rhythm control in patients with atrial fibrillation. The New England journal of medicine 2002; 347(23): 1825-33.

44. Carlsson J, Miketic S, Windeler J, et al. Randomized trial of ratecontrol versus rhythm-control in persistent atrial fibrillation: the Strategies of Treatment of Atrial Fibrillation (STAF) study. $J$ Am Coll Cardiol 2003; 41(10): 1690-6.

45. Marrouche NF, Brachmann J, Andresen D, et al. Catheter Ablation for Atrial Fibrillation with Heart Failure. The New England journal of medicine 2018; 378(5): 417-27.

46. Packer DL, Mark DB, Robb RA, et al. Effect of Catheter Ablation vs Antiarrhythmic Drug Therapy on Mortality, Stroke, Bleeding, and Cardiac Arrest Among Patients With Atrial Fibrillation: The CABANA Randomized Clinical Trial. JAMA 2019 (Epub ahead of print).

47. Frykman V, Beerman B, Ryden L, Rosenqvist M, Medical Products A, Swedish Society of C. Management of atrial fibrillation: discrepancy between guideline recommendations and actual practice exposes patients to risk for complications. Eur Heart $J$ 2001; 22(20): 1954-9.

48. Glader EL, Stegmayr B, Norrving B, et al. Large variations in the use of oral anticoagulants in stroke patients with atrial fibrillation: a Swedish national perspective. Journal of internal medicine 2004; 255(1): 22-32.

49. Friberg L, Hammar N, Ringh M, Pettersson H, Rosenqvist M. Stroke prophylaxis in atrial fibrillation: who gets it and who does not? Report from the Stockholm Cohort-study on Atrial Fibrillation (SCAF-study). Eur Heart J 2006; 27(16): 1954-64.

50. Nieuwlaat R, Capucci A, Lip GY, et al. Antithrombotic treatment in real-life atrial fibrillation patients: a report from the Euro Heart Survey on Atrial Fibrillation. Eur Heart $J$ 2006; 27(24): 3018-26.

51. Deplanque D, Leys D, Parnetti L, et al. Stroke prevention and atrial fibrillation: reasons leading to an inappropriate management. Main 
results of the SAFE II study. British journal of clinical pharmacology 2004; 57(6): 798-806.

52. Laguna P, Martn A, del Arco C, Gargantilla P. Risk factors for stroke and thromboprophylaxis in atrial fibrillation: what happens in daily clinical practice? The GEFAUR-1 study. Annals of emergency medicine 2004; 44(1): 3-11.

53. Hendriks JM, de Wit R, Crijns HJ, et al. Nurse-led care vs. usual care for patients with atrial fibrillation: results of a randomized trial of integrated chronic care vs. routine clinical care in ambulatory patients with atrial fibrillation. Eur Heart $J$ 2012; 33(21): 2692-9.

54. Stewart S, Ball J, Horowitz JD, et al. Standard versus atrial fibrillation-specific management strategy (SAFETY) to reduce recurrent admission and prolong survival: pragmatic, multicentre, randomised controlled trial. Lancet 2015; 385(9970): 775-84.

55. Tran HN, Tafreshi J, Hernandez EA, Pai SM, Torres VI, Pai RG. A multidisciplinary atrial fibrillation clinic. Curr Cardiol Rev 2013; 9(1): $55-62$.

56. Conti A, Canuti E, Mariannini Y, et al. Clinical management of atrial fibrillation: early interventions, observation, and structured follow-up reduce hospitalizations. Am J Emerg Med 2012; 30(9): 1962-9.

57. Carter L, Gardner M, Magee K, et al. An Integrated Management Approach to Atrial Fibrillation. J Am Heart Assoc 2016; 5(1): e002950. 58. Cleeland CS. Symptom burden: multiple symptoms and their impact as patient-reported outcomes. J Natl Cancer Inst Monogr 2007; (37): 1621.

59. Reynolds MR, Ellis E, Zimetbaum P. Quality of life in atrial fibrillation: measurement tools and impact of interventions. Journal of cardiovascular electrophysiology 2008; 19(7): 762-8.

6o. Thrall G, Lane D, Carroll D, Lip GY. Quality of life in patients with atrial fibrillation: a systematic review. Am J Med 2006; 119(5): 448 e1-19. 61. Testa MA, Simonson DC. Assessment of quality-of-life outcomes. The New England journal of medicine 1996; 334(13): 835-40.

62. Fayers PM, Machin D. Quality of life: the assessment, analysis, and interpretation of patient-reported outcomes. Chichester: Wiley; 2007.

63. WHO definition of Quality of Life.

https://www.who.int/healthinfo/survey/whoqol-qualityoflife/en/ (accessed 20 March 2019).

64. Farquhar M. Definitions of quality of life: a taxonomy. $J$ Adv Nurs 1995; 22(3): 502-8.

65. Dagres N, Nieuwlaat R, Vardas PE, et al. Gender-related differences in presentation, treatment, and outcome of patients with atrial fibrillation in Europe: a report from the Euro Heart Survey on Atrial Fibrillation. $J$ Am Coll Cardiol 2007; 49(5): 572-7.

66. Paquette M, Roy D, Talajic M, et al. Role of gender and personality on quality-of-life impairment in intermittent atrial fibrillation. The American journal of cardiology 2000; 86(7): 764-8. 
67. Reynolds MR, Lavelle T, Essebag V, Cohen DJ, Zimetbaum P. Influence of age, sex, and atrial fibrillation recurrence on quality of life outcomes in a population of patients with new-onset atrial fibrillation: the Fibrillation Registry Assessing Costs, Therapies, Adverse events and Lifestyle (FRACTAL) study. Am Heart $J$ 2006; 152(6): 1097-103.

68. Dorian P, Jung W, Newman D, et al. The impairment of healthrelated quality of life in patients with intermittent atrial fibrillation: implications for the assessment of investigational therapy. $J$ Am Coll Cardiol 2000; 36(4): 1303-9.

69. Thrall G, Lip GY, Carroll D, Lane D. Depression, anxiety, and quality of life in patients with atrial fibrillation. Chest 2007; 132(4): 1259-64.

70. Efremidis M, Letsas KP, Lioni L, et al. Association of quality of life, anxiety, and depression with left atrial ablation outcomes. Pacing and clinical electrophysiology: PACE 2014; 37(6): 703-11.

71. Yu S, Zhao Q, Wu P, et al. Effect of anxiety and depression on the recurrence of paroxysmal atrial fibrillation after circumferential pulmonary vein ablation. Journal of cardiovascular electrophysiology 2012; 23 Suppl 1: S17-23.

72. Rehm J, Mathers C, Popova S, Thavorncharoensap M, Teerawattananon Y, Patra J. Global burden of disease and injury and economic cost attributable to alcohol use and alcohol-use disorders. Lancet 2009; 373(9682): 2223-33.

73. Marfella R, Cacciapuoti F, Siniscalchi M, et al. Effect of moderate red wine intake on cardiac prognosis after recent acute myocardial infarction of subjects with Type 2 diabetes mellitus. Diabet Med 2006; 23(9): 97481.

74. Gronbaek M. The positive and negative health effects of alcohol- and the public health implications. Journal of internal medicine 2009; 265(4): 407-20.

75. Tonelo D, Providencia R, Goncalves L. Holiday heart syndrome revisited after 34 years. Arq Bras Cardiol 2013; 101(2): 183-9.

76. Roerecke M, Rehm J. The cardioprotective association of average alcohol consumption and ischaemic heart disease: a systematic review and meta-analysis. Addiction 2012; 107(7): 1246-60.

77. Piano MR. Alcoholic cardiomyopathy: incidence, clinical characteristics, and pathophysiology. Chest 2002; 121(5): 1638-50.

78. Djousse L, Levy D, Benjamin EJ, et al. Long-term alcohol consumption and the risk of atrial fibrillation in the Framingham Study. The American journal of cardiology 2004; 93(6): 710-3.

79. Gallagher C, Hendriks JML, Elliott AD, et al. Alcohol and incident atrial fibrillation - A systematic review and meta-analysis. Int $J$ Cardiol 2017; 246: 46-52.

8o. Larsson SC, Drca N, Wolk A. Alcohol consumption and risk of atrial fibrillation: a prospective study and dose-response meta-analysis. $J A m$ Coll Cardiol 2014; 64(3): 281-9.

81. Kodama S, Saito K, Tanaka S, et al. Alcohol consumption and risk of atrial fibrillation: a meta-analysis. J Am Coll Cardiol 2011; 57(4): 427-36. 
82. Kalinowski A, Humphreys K. Governmental standard drink definitions and low-risk alcohol consumption guidelines in 37 countries. Addiction 2016; 111(7): 1293-8.

83. Risc consumption in Sweden. https://www.can.se/Fakta/Fragoroch-Svar/Alkohol/ (accessed 18 March 2019).

84. Torrente MP, Freeman WM, Vrana KE. Protein biomarkers of alcohol abuse. Expert Rev Proteomics 2012; 9(4): 425-36.

85. Bertol E, Vaiano F, Boscolo-Berto R, et al. Alcohol, caffeine, and nicotine consumption in adolescents: hair analysis versus self-report. The American journal of drug and alcohol abuse 2017; 43(3): 341-9.

86. Jastrzebska I, Zwolak A, Szczyrek M, Wawryniuk A, SkrzydloRadomanska B, Daniluk J. Biomarkers of alcohol misuse: recent advances and future prospects. Prz Gastroenterol 2016; 11(2): 78-89.

87. Kummer N, Lambert WE, Samyn N, Stove CP. Alternative sampling strategies for the assessment of alcohol intake of living persons. Clin Biochem 2016; 49(13-14): 1078-91.

88. Society of Hair Testing guidelines for drug testing in hair. https://www.soht.org/statements/9-nicht-kategorisiert/85-statement$\underline{2011}$ (accessed 2018, October 2).

89. Crunelle CL, Yegles M, Nuijs A, et al. Hair ethyl glucuronide levels as a marker for alcohol use and abuse: a review of the current state of the art. Drug Alcohol Depend 2014; 134: 1-11.

90. Kronstrand R, Brinkhagen L, Nystrom FH. Ethyl glucuronide in human hair after daily consumption of 16 or $32 \mathrm{~g}$ of ethanol for 3 months. Forensic science international 2012; 215(1-3): 51-5.

91. Boscolo-Berto R, Favretto D, Cecchetto G, et al. Sensitivity and specificity of EtG in hair as a marker of chronic excessive drinking: pooled analysis of raw data and meta-analysis of diagnostic accuracy studies. Ther Drug Monit 2014; 36(5): 560-75.

92. 2016 Consensus for the Use of Alcohol Markers in Hair for Assessment of both Abstinence and Chronic Excessive Alcohol Consumption. 2016.

https://www.soht.org/images/pdf/Revision\%202016 Alcoholmarkers.pd f (accessed 2018, October 3).

93. Rickham PP. Human Experimentation. Code of Ethics of the World Medical Association. Declaration of Helsinki. British medical journal 1964; 2(5402): 177.

94. Ware JE, Snow KK, Kosinski M, Gandek B, Institute NEMCHH. SF36 health survey: manual and interpretation guide: The Health Institute, New England Medical Center; 1993.

95. Taft C, Karlsson J, Sullivan M. Do SF-36 summary component scores accurately summarize subscale scores? Quality of life research: an international journal of quality of life aspects of treatment, care and rehabilitation 2001; 10(5): 395-404.

96. Dolan P. Modeling valuations for EuroQol health states. Medical care 1997; 35(11): 1095-108. 
97. Zigmond AS, Snaith RP. The hospital anxiety and depression scale. Acta psychiatrica Scandinavica 1983; 67(6): 361-70.

98. Bjelland I, Dahl AA, Haug TT, Neckelmann D. The validity of the Hospital Anxiety and Depression Scale. An updated literature review. Journal of psychosomatic research 2002; 52(2): 69-77.

99. Hendriks JM, Vrijhoef HJ, Crijns HJ, Brunner-La Rocca HP. The effect of a nurse-led integrated chronic care approach on quality of life in patients with atrial fibrillation. Europace: European pacing, arrhythmias, and cardiac electrophysiology: journal of the working groups on cardiac pacing, arrhythmias, and cardiac cellular electrophysiology of the European Society of Cardiology 2014; 16(4): 491-9.

100. Walfridsson U, Stromberg A, Arestedt K. Development and validation of an arrhythmia-specific scale in tachycardia and arrhythmia with focus on health-related quality of life. The Journal of cardiovascular nursing 2015; 30(2): 98-108.

101. Walfridsson U, Arestedt K, Stromberg A. Development and validation of a new Arrhythmia-Specific questionnaire in Tachycardia and Arrhythmia (ASTA) with focus on symptom burden. Health and quality of life outcomes 2012; 10: 44.

102. Walter L, Noorlind Brage H. Östgötens hälsa 2006. Linköping: Folkhälsovetenskapligt centrum i Östergötland; 2006.

103. Wozakowska-Kaplon B. Effect of sinus rhythm restoration on plasma brain natriuretic peptide in patients with atrial fibrillation. The American journal of cardiology 2004; 93(12): 1555-8.

104. Bjorkenheim A, Brandes A, Magnuson A, Chemnitz A, Edvardsson N, Poci D. Patient-Reported Outcomes in Relation to Continuously Monitored Rhythm Before and During 2 Years After Atrial Fibrillation Ablation Using a Disease-Specific and a Generic Instrument. Journal of the American Heart Association 2018; 7(5): e008362.

105. Lip GY, Laroche C, Popescu MI, et al. Improved outcomes with European Society of Cardiology guideline-adherent antithrombotic treatment in high-risk patients with atrial fibrillation: a report from the EORP-AF General Pilot Registry. Europace: European pacing, arrhythmias, and cardiac electrophysiology: journal of the working groups on cardiac pacing, arrhythmias, and cardiac cellular electrophysiology of the European Society of Cardiology 2015; 17(12): 1777-86.

106. Thompson TS, Barksdale DJ, Sears SF, Mounsey JP, Pursell I, Gehi AK. The effect of anxiety and depression on symptoms attributed to atrial fibrillation. Pacing and clinical electrophysiology: PACE 2014; 37(4): 439-46.

107. Akintade BF, Chapa D, Friedmann E, Thomas SA. The influence of depression and anxiety symptoms on health-related quality of life in patients with atrial fibrillation and atrial flutter. The Journal of cardiovascular nursing 2015; 30(1): 66-73. 
108. Garvin P, Nilsson E, Ernerudh J, Kristenson M. The joint subclinical elevation of CRP and IL-6 is associated with lower health-related quality of life in comparison with no elevation or elevation of only one of the biomarkers. Quality of life research: an international journal of quality of life aspects of treatment, care and rehabilitation 2016; 25(1): 213-21. 109. Son YJ, Song EK. The impact of type D personality and highsensitivity C-reactive protein on health-related quality of life in patients with atrial fibrillation. European journal of cardiovascular nursing: journal of the Working Group on Cardiovascular Nursing of the European Society of Cardiology 2012; 11(3): 304-12.

110. Njoku A, Kannabhiran M, Arora R, et al. Left atrial volume predicts atrial fibrillation recurrence after radiofrequency ablation: a metaanalysis. Europace: European pacing, arrhythmias, and cardiac electrophysiology: journal of the working groups on cardiac pacing, arrhythmias, and cardiac cellular electrophysiology of the European Society of Cardiology 2018; 20(1): 33-42.

111. van den Berg MP, Hassink RJ, Tuinenburg AE, et al. Quality of life in patients with paroxysmal atrial fibrillation and its predictors: importance of the autonomic nervous system. Eur Heart $J$ 2001; 22(3): 247-53.

112. Gaita F, Scaglione M, Battaglia A, et al. Very long-term outcome following transcatheter ablation of atrial fibrillation. Are results maintained after 10 years of follow up? Europace: European pacing, arrhythmias, and cardiac electrophysiology: journal of the working groups on cardiac pacing, arrhythmias, and cardiac cellular electrophysiology of the European Society of Cardiology 2018; 2o(3): 443-50.

113. Wokhlu A, Monahan KH, Hodge DO, et al. Long-term quality of life after ablation of atrial fibrillation the impact of recurrence, symptom relief, and placebo effect. $J$ Am Coll Cardiol 2010; 55(21): 2308-16.

114. Nalliah CJ, Sanders P, Kottkamp H, Kalman JM. The role of obesity in atrial fibrillation. Eur Heart $J$ 2016; 37(20): 1565-72.

115. Ul-Haq Z, Mackay DF, Fenwick E, Pell JP. Impact of metabolic comorbidity on the association between body mass index and healthrelated quality of life: a Scotland-wide cross-sectional study of 5,608 participants. BMC public health 2012; 12: 143.

116. Forleo GB, Tondo C, De Luca L, et al. Gender-related differences in catheter ablation of atrial fibrillation. Europace: European pacing, arrhythmias, and cardiac electrophysiology: journal of the working groups on cardiac pacing, arrhythmias, and cardiac cellular electrophysiology of the European Society of Cardiology 2007; 9(8): 613-20.

117. Michelena HI, Powell BD, Brady PA, Friedman PA, Ezekowitz MD. Gender in atrial fibrillation: Ten years later. Gend Med 2010; 7(3): 20617.

118. Walfridsson H, Walfridsson U, Nielsen JC, et al. Radiofrequency ablation as initial therapy in paroxysmal atrial fibrillation: results on health-related quality of life and symptom burden. The MANTRA-PAF 
trial. Europace: European pacing, arrhythmias, and cardiac electrophysiology: journal of the working groups on cardiac pacing, arrhythmias, and cardiac cellular electrophysiology of the European Society of Cardiology 2015; 17(2): 215-21.

119. Weerasooriya R, Jais P, Hocini M, et al. Effect of catheter ablation on quality of life of patients with paroxysmal atrial fibrillation. Heart rhythm: the official journal of the Heart Rhythm Society 2005; 2(6): 619-23.

120. Erdogan A, Carlsson J, Neumann T, et al. Quality-of-life in patients with paroxysmal atrial fibrillation after catheter ablation: results of longterm follow-up. Pacing and clinical electrophysiology: PACE 2003; 26(3): 678-84.

121. Gonzalez J, Macle L, Deyell MW, et al. Effect Of Catheter Ablation On Quality Of Life In Atrial Fibrillation. J Atr Fibrillation 2014; 6(6): 1063 .

122. Leon DA, Shkolnikov VM, Borinskaya S, et al. Hazardous alcohol consumption is associated with increased levels of B-type natriuretic peptide: evidence from two population-based studies. Eur $J$ Epidemiol 2013; 28(5): 393-404.

123. Hofer P, Syeda B, Bergler-Klein J, et al. Amino-terminal pro-B-type brain natriuretic peptide: screening for cardiovascular disease in the setting of alcoholism. Alcohol Alcohol 2011; 46(3): 247-52.

124. Djousse L, Hunt SC, Eckfeldt JH, Arnett DK, Province MA, Ellison RC. Alcohol consumption and plasma atrial natriuretic peptide (from the HyperGEN study). The American journal of cardiology 2006; 98(5): 628-32.

125. McManus DD, Yin X, Gladstone R, et al. Alcohol Consumption, Left Atrial Diameter, and Atrial Fibrillation. J Am Heart Assoc 2016; 5(9): e004060.

126. Hung CL, Goncalves A, Lai YJ, et al. Light to Moderate Habitual Alcohol Consumption Is Associated with Subclinical Ventricular and Left Atrial Mechanical Dysfunction in an Asymptomatic Population: DoseResponse and Propensity Analysis. J Am Soc Echocardiogr 2016; 29(11): 1043-51 e4.

127. Qiao Y, Shi R, Hou B, et al. Impact of Alcohol Consumption on Substrate Remodeling and Ablation Outcome of Paroxysmal Atrial Fibrillation. Journal of the American Heart Association 2015; 4(11): eo02349.

128. Takigawa M, Takahashi A, Kuwahara T, et al. Impact of Alcohol Consumption on the Outcome of Catheter Ablation in Patients With Paroxysmal Atrial Fibrillation. Journal of the American Heart Association 2016; 5(12): eo04149.

129. Mathiesen EF, Nome S, Eisemann M, Richter J. Drinking patterns, psychological distress and quality of life in a Norwegian general population-based sample. Quality of life research: an international journal of quality of life aspects of treatment, care and rehabilitation 2012; 21(9): 1527-36. 
130. Polen MR, Green CA, Perrin NA, Anderson BM, Weisner CM. Drinking patterns, gender and health I: Attitudes and health practices. Addiction Research \& Theory 2010; 18(2): 122-42.

131. Kim K, Kim JS. The association between alcohol consumption patterns and health-related quality of life in a nationally representative sample of South Korean adults. PLoS One 2015; 10(3): e0119245.

132. Balbao CE, de Paola AA, Fenelon G. Effects of alcohol on atrial fibrillation: myths and truths. Therapeutic advances in cardiovascular disease 2009; 3(1): 53-63.

133. Schneider C, Malisius R, Krause K, et al. Strain rate imaging for functional quantification of the left atrium: atrial deformation predicts the maintenance of sinus rhythm after catheter ablation of atrial fibrillation. Eur Heart $J$ 2008; 29(11): 1397-409.

134. Wang T, Wang M, Fung JW, et al. Atrial strain rate echocardiography can predict success or failure of cardioversion for atrial fibrillation: a combined transthoracic tissue Doppler and transoesophageal imaging study. Int J Cardiol 2007; 114(2): 202-9.

135. Charitakis E, Walfridsson H, Alehagen U. Short-Term Influence of Radiofrequency Ablation on NT-proBNP, MR-proANP, Copeptin, and MR-proADM in Patients With Atrial Fibrillation: Data From the Observational SMURF Study. Journal of the American Heart Association 2016; 5(9): eo03557.

136. Kaiser DW, Fan J, Schmitt S, et al. Gender Differences in Clinical Outcomes after Catheter Ablation of Atrial Fibrillation. JACC Clin Electrophysiol 2016; 2(6): 703-10.

137. Boscolo-Berto R, Viel G, Montisci M, Terranova C, Favretto D, Ferrara SD. Ethyl glucuronide concentration in hair for detecting heavy drinking and/or abstinence: a meta-analysis. Int $J$ Legal Med 2013; 127(3): 611-9.

138. Lees R, Kingston R, Williams TM, Henderson G, Lingford-Hughes A, Hickman M. Comparison of ethyl glucuronide in hair with self-reported alcohol consumption. Alcohol and alcoholism 2012; 47(3): 267-72. 


\section{Papers}

The papers associated with this thesis have been removed for copyright reasons. For more details about these see:

http://urn.kb.se/resolve?urn=urn:nbn:se:liu:diva-156364 


\section{FACULTY OF MEDICINE AND HEALTH SCIENCES}

Linköping University Medical Dissertation No. 1673, 2019

Department of Medical and Health Sciences

Linköping University

SE-581 83 Linköping, Sweden

www.liu.se 